\title{
Economic Targeting of Agricultural Beneficial Management Practices to Address Phosphorus Runoff in Manitoba
}

\author{
A Thesis \\ Submitted to the College of Graduate Studies and Research \\ in partial fulfillment of the requirements \\ for the Degree of Master of Science
}

Department of Agricultural and Resource Economics University of Saskatchewan

Saskatoon, Saskatchewan, Canada

By

Kaitlin E. Kelly

(C) Copyright Kaitlin E. Kelly, September 2016. All Rights Reserved 


\section{Permission to Use}

In presenting this thesis in partial fulfilment of the requirements for a graduate degree from the University of Saskatchewan, I agree that the Libraries of this University may make it freely available for inspection. I further agree that permission for copying of this thesis in any manner, in whole or in part, for scholarly purposes may be granted by the professor or professors who supervised my thesis work or, in their absence, by the Head of the Department or the Dean of the College in which my thesis work was done. It is understood that any copying or publication or use of this thesis or parts thereof for financial gain shall not be allowed without my written permission. It is also understood that due recognition shall be given to me and to the University of Saskatchewan in any scholarly use which may be made of any material in this thesis.

Requests for permission to copy or to make other use of material in this thesis in whole or part should be addressed to:

Head of the Department of Agricultural and Resource Economics

College of Agriculture and Bioresources

University of Saskatchewan

Saskatoon, Saskatchewan S7N 5A8 


\section{Abstract}

Non-point nutrient pollution from agricultural sources is known to have detrimental effects on water quality and aquatic ecosystem health within agricultural landscapes and is considered to be a significant negative externality associated with intensive agricultural production (Tilman et al. 2002; Pretty 2003; Lankoski and Ollikainen 2003). The detrimental effects of nutrient pollution, specifically phosphorus, are visible in Lake Winnipeg, Manitoba where excess phosphorus inputs contribute to eutrophication. The majority of excess phosphorus flowing into Lake Winnipeg is thought to come from upstream agricultural sources, such as synthetic fertilizer and livestock manure which enter surface waterways through over-field runoff.

The Government of Manitoba, in partnership with Agriculture and Agri-Food Canada, subsidizes agricultural producers to adopt beneficial management practices (BMPs) aimed at preventing excess phosphorus from entering surface waterways through over-field runoff. BMPs are currently administered under a uniform subsidy structure where each producer is offered the same cost-share subsidy for each BMP on a first-come, first-serve basis within a fixed budget. However, previous literature suggests that uniform subsidies are inefficient in terms of minimizing the costs and maximizing the environmental benefits provided by agri-environmental subsidies, especially when environmental improvement is dependent on heterogeneous landscape characteristics (Boxall et al. 2008; Lankoski and Ollikainen 2003). Rather, differentiated or targeted policy instruments are often the most efficient tools to increase the production of public environmental benefits on private agricultural lands through subsidization (Khana et al. 2003).

The purpose of this research was to determine the relative performance of targeted nutrient management BMP subsidies compared to current uniform BMP subsidies using a case study of water retention pond BMPs to reduce phosphorus runoff in the La Salle sub-watershed of Manitoba. Benefit-cost targeting was shown to be the most cost effective way to allocate water retention pond subsidies in the La Salle sub-watershed so as to maximize the amount of phosphorus removed from surface runoff under the limited BMP subsidy budget. Using benefitcost targeting to distribute water retention pond subsidies instead of the current uniform subsidy structure provided an efficiency gain equal to an additional 641 kilograms to 2,503 kilograms (depending on the discount rate used) of phosphorus removed from the La Salle sub-watershed. 


\section{Acknowledgements}

I would like to acknowledge and thank Jason Vanrobaeys, Patsy Michiels, and Marcos Cordeiro of Agriculture and Agri-Food Canada for the very important hydrological modelling and GIS mapping contributions they provided. This research would not have been possible without their contributions. I would like to acknowledge Agriculture and Agri-Food Canada for providing my research funding.

I would like to thank my co-supervisors Dr. Ken Belcher and Dr. Mohammad Khakbazan for their advice, guidance, and unwavering support. I would like to thank Dr. Belcher for his guidance and support throughout the last six years as both my undergraduate and graduate advisor. Thank you to Dr. Khakbazan for providing me the opportunity to work with Agriculture and Agri-Food Canada to conduct my thesis research and for his support in developing my thesis project. I would also like to thank my committee members Dr. Hayley Hesseln and Dr. Angela Bedard-Haughn for their insight, guidance, and support. Thank you to all my committee members for their commitment and willingness to provide comments and revisions quickly to help me complete my thesis on time.

I would like to acknowledge and thank Bradly Weir of the Saskatchewan Forest Service for his patience, support, and guidance with the GIS mapping component of my thesis.

Lastly, I would like to thank my family and loved ones for their unending support and encouragement. 


\section{Table of Contents}

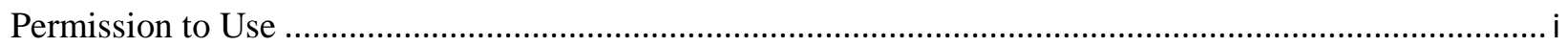

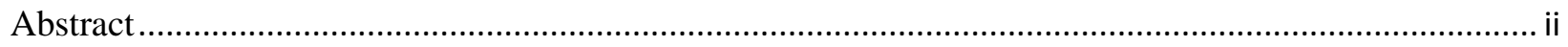

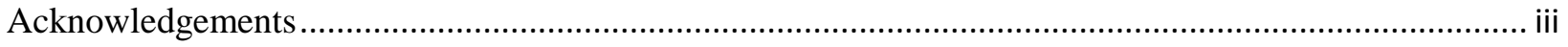

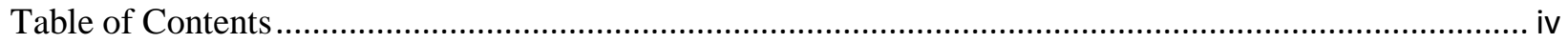

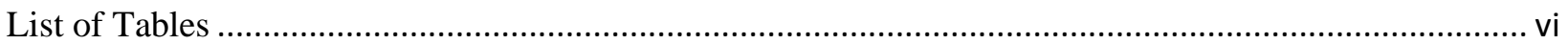

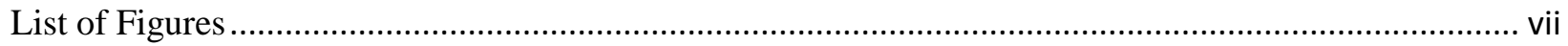

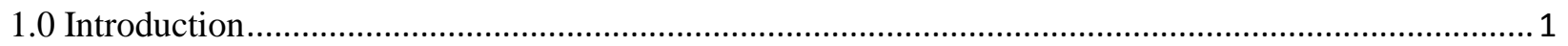

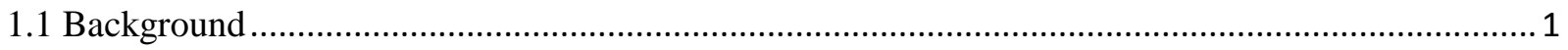

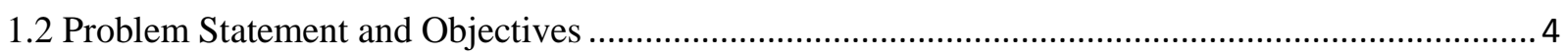

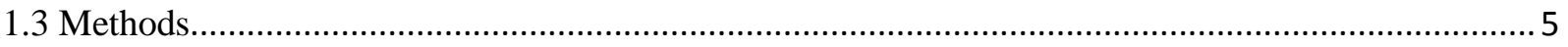

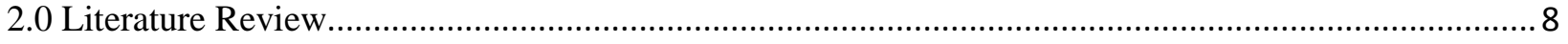

2.1 Agri-Environmental Externalities and the Need for Public Intervention......................................... 8

2.2 Nutrient Runoff as a Negative Externality of Agricultural Production ......................................... 10

2.3 Nutrient Runoff and Water Quality in Manitoba ........................................................................ 11

2.4 Growing Forward 2 and the Administration of BMPs in Manitoba............................................ 15

2.5 Economic and Spatial Targeting of Agri-Environmental Policy .................................................. 16

2.6 Uniform versus Targeted Policy Instruments in Previous Literature.............................................. 20

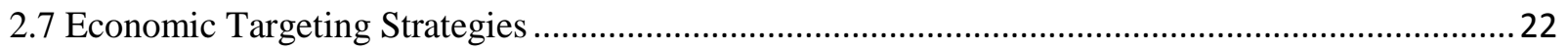

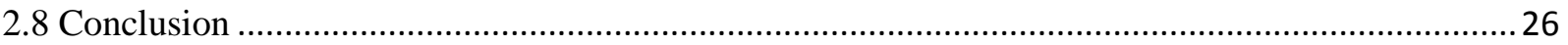

3.0 Economic Targeting of Agricultural Beneficial Management Practices to Address Phosphorus Runoff

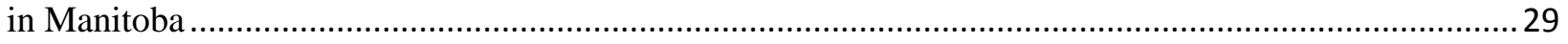

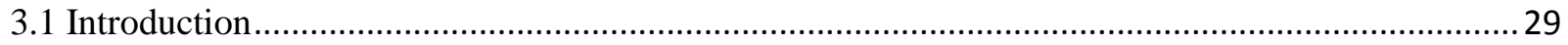

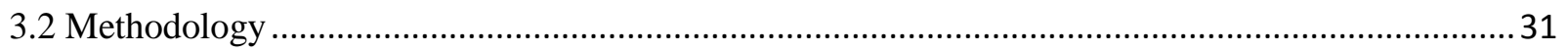

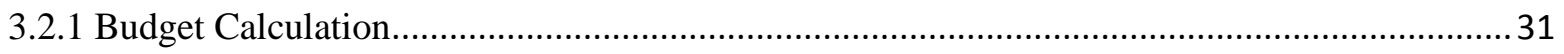

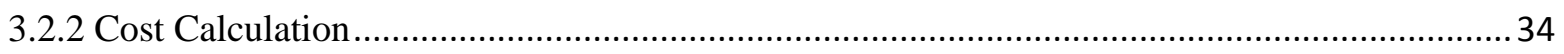

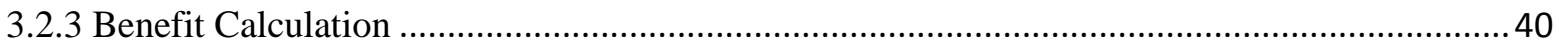

3.2.4 Net Present Value Calculation .................................................................................... 41

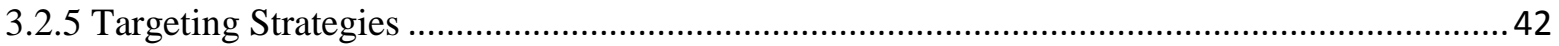

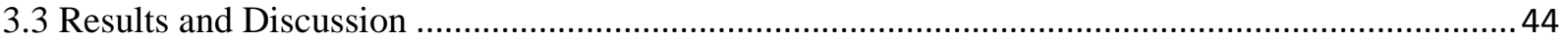

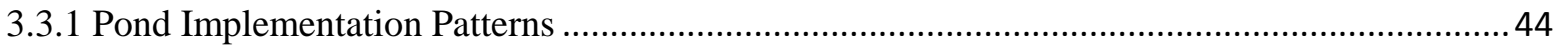

3.3.2 Targeting Strategy Cost Effectiveness ...................................................................................... 46 


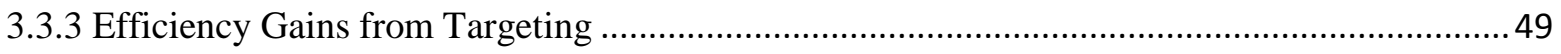

3.3.4 Alternative Objectives: Maximizing Participation or Land Enrollment ...................................50

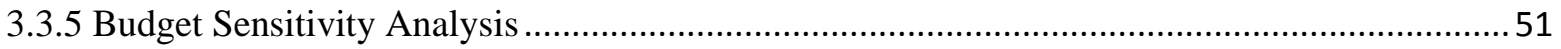

3.3.6 Calculating the Optimal Level of Expenditure on Water Retention Ponds ..............................53

3.3.7 Common Characteristics among Ponds with a High Benefit-Cost Ratio.................................56

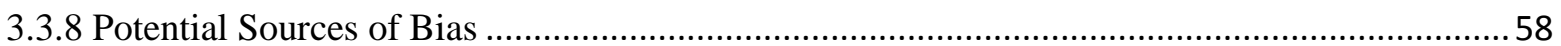

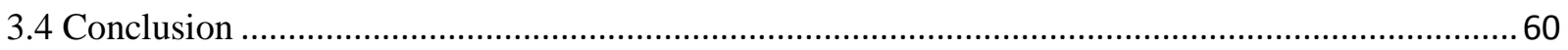

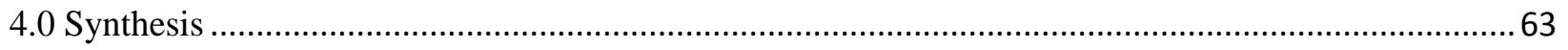

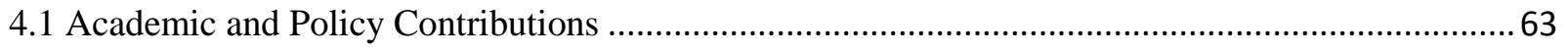

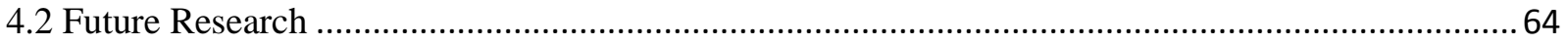

4.2.1 Estimating Demand for Phosphorus Removal in the La Salle Sub-watershed ..........................64

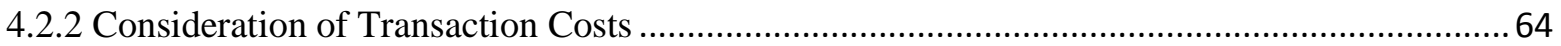

4.2.3 Determining Price Feedback Slippage Effects of Benefit-Cost Targeting..............................65

4.2.4 Determining Characteristics that Affect the Benefit-Cost Ratio.............................................66

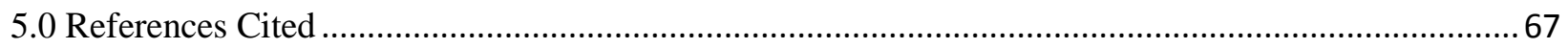

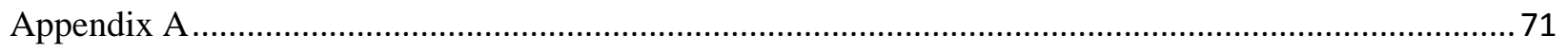

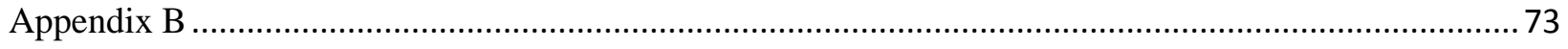

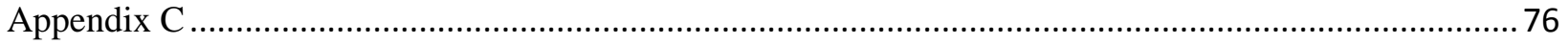

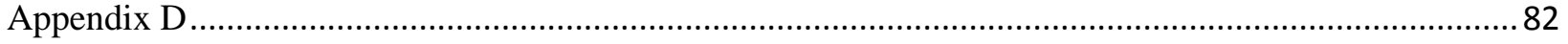

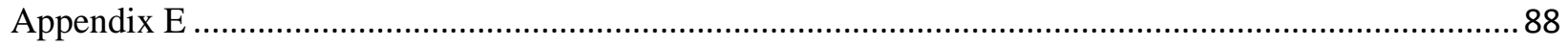

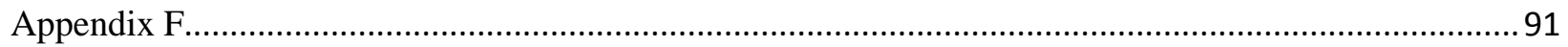

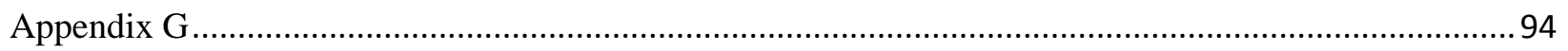

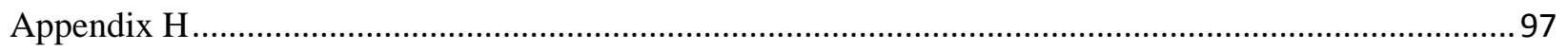

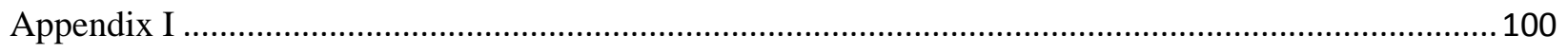




\section{List of Tables}

Table 3.1: Surface water management program expenditures for the La Salle River Watershed within the

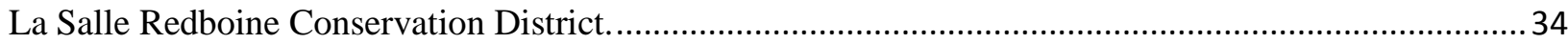

Table 3.2: Cropping system, representative crop, and simplified four-year crop rotation in the La Salle sub-watershed.

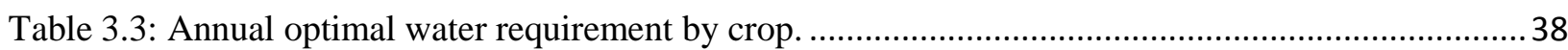




\section{List of Figures}

Figure 1.1: La Salle River Watershed within the La Salle Redboine Conservation District ........................ 6

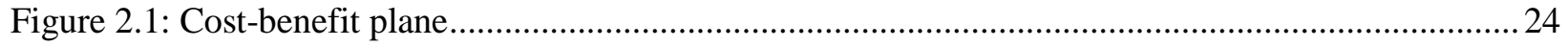

Figure 3.1: Annual precipitation in the La Salle sub-watershed during the study period compared to the annual optimal water requirement of each representative crop. 39

Figure 3.2: Pond implementation pattern under benefit targeting, cost targeting, and benefit-cost targeting

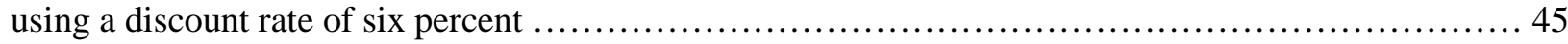

Figure 3.3: Quantity of TP runoff reduced in the La Salle sub-watershed during the study period under different targeting strategies and budget constraints using a discount rate of six percent 47

Figure 3.4: Average cost of TP removal in the La Salle sub-watershed during the study period under different targeting strategies and budget constraints using a discount rate of six percent

Figure 3.5: Flooded area compared to number of ponds in the La Salle sub-watershed during the study period under different targeting strategies and budget constraints using a discount rate of six percent .... 51 Figure 3.6: Marginal cost and marginal benefit of TP removal in the La Salle sub-watershed during the study period under cost targeting with a discount rate of six percent

Figure 3.7: Quantity of TP reduced compared to level of expenditure in the La Salle sub-watershed during the study period under different targeting strategies using a discount rate of six percent 55 Figure 3.8: Distribution of ponds in the La Salle sub-watershed according to benefit-cost ratio assuming a

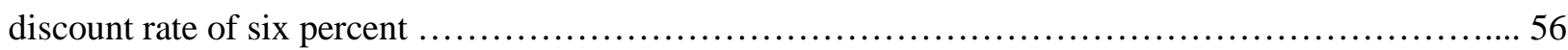




\subsection{Introduction}

\subsection{Background}

Since the 1960s global cereal production has doubled largely as a result of greater fertilizer, water, and pesticide inputs, the introduction of new crop varieties, and other technological innovations during the Green Revolution (Tilman et al. 2002). The agricultural innovations that enabled substantial yield increases during the Green Revolution allowed for a dramatic increase in world food supply, however, some of the intensive agricultural practices introduced at that time are now associated with harmful environmental side-effects. It has been estimated that another doubling of global grain production will be necessary by 2050 to keep up with rapid population growth (Tilman et al. 2002). Thus there is a need to introduce sustainable management practices in agricultural systems now to ensure that future gains in food production do not come at the cost of continued degradation of natural ecosystems (Tilman et al. 2002; Pretty 2003).

An environmental impact of intensive agricultural production that is of particular concern globally, and within Canada, is the leaching of phosphorus (P) fertilizer into aquatic systems.

The rate of $\mathrm{P}$ fertilizer application is expected to triple if current agricultural practices are simply intensified on lands already under production and expanded to lands not yet under production without modification to achieve the required doubling of grain production by 2050 (Tilman et al. 2002). Tilman et al. (2002) estimated that under current agricultural practices 45 percent of applied $\mathrm{P}$ fertilizer is taken up by the crop while the remaining 55 percent is susceptible to transport through over-field runoff. Phosphorus runoff from agricultural fields is a form of nonpoint nutrient pollution, which can lead to large algae blooms in surface water bodies that result in anoxic conditions when the algae begin to die off, damaging the health of the aquatic ecosystem in a process known as eutrophication (Tilman et al. 2002).

Previous studies conducted by Pretty (2003) and Lankoski and Ollikainen (2003) identified nutrient runoff from agricultural fields entering surface water bodies as a significant negative externality associated with agricultural production. Currently, the costs of negative externalities created by agricultural production are largely paid by society, not by the producer. Since the producer does not have to pay for the negative environmental impacts he/she imposes on society, 
there is no monetary incentive to change production practices. The external costs associated with non-point nutrient pollution are imposed on an unaware public and effectively act as a subsidy from society to agricultural producers (Pretty 2003).

Governments have largely chosen to address the negative externalities associated with agricultural production through subsidization (Pretty 2003; Lankoski and Ollikainen 2003). Governments offer subsidies to farmers to deter them from using production practices that create external costs and instead encourage farmers to adopt environmentally beneficial management practices (BMPs). Agricultural BMPs are management practices or technological changes that reduce an environmental bad or increase an environmental good that is jointly produced with an agricultural commodity (AAFC 2012). Most BMPs require significant investment on the part of the producer both for initial implementation and ongoing maintenance. Therefore, BMP adoption often increases private production costs and imposes an opportunity cost on producers by changing business-as-usual practices. It is therefore recognized that subsidies are often required to offset the cost to producers of implementing and maintaining BMPs (AAFC 2012).

Pannell (2008) created a framework for selecting the most appropriate policy mechanism to encourage beneficial land management changes on privately owned land. Pannell's framework is based on the assumption that the choice of the best policy mechanism is dependent on the levels of public and private net benefits provided by the beneficial management practice being promoted. Agricultural BMPs provide public net benefits to society but usually inflict private net costs on adopting producers. Pannell's framework dictates that the appropriate policy tool to be used when faced with public net benefits and private net costs is a positive incentive, such as a subsidy (Pannell 2008).

In Canada the adoption of agricultural BMPs is subsidized through a joint agreement between the federal government and provincial/territorial governments called Growing Forward 2. Growing Forward 2 is a five-year agricultural policy framework which, among other things, prescribes federal and provincial/territorial government investments in cost-sharing subsidies to promote the adoption of strategic BMPs within each province (Province of Manitoba 2015). The suite of BMPs offered under Growing Forward 2 includes nutrient management BMPs that reduce the amount of nutrient pollution from agricultural sources entering surface waterbodies by limiting excess nutrient loss at the time of fertilizer application (precision farming BMPs) or by removing 
excess nutrients from field runoff after fertilizer application (water retention pond, small dam, wetland restoration, or riparian buffer strip BMPs) (AAFC 2012).

Pannell's framework is relevant when analyzing the Growing Forward 2 policy agreement. Growing Forward 2 promotes the adoption of BMPs that provide public net benefits to society while often imposing private net costs on adopting producers. Pannell's framework dictates that the appropriate policy tool, in this case, is a positive incentive (Pannell 2008). However, there are three restrictions on the use of positive incentives to promote land management changes; 1 ) public net benefits of the change must be positive; 2) producers must be unwilling to adopt the change without additional incentives; and 3) public net benefits must outweigh private net costs (Pannell 2008). It is assumed that the nutrient management BMPs recommended by Growing Forward 2 produce positive public net benefits, are not adopted by farmers without an incentive, and provide public net benefits that are greater than the private net costs imposed. Based on these assumptions positive incentives, such as subsidies, appear to be the best policy tool to promote nutrient management BMP adoption under Growing Forward 2 according to Pannell's framework.

Although subsidies are often the most appropriate policy tool to promote the adoption of nutrient management BMPs, the way in which BMP subsidies are allocated may hinder their efficiency. BMPs are currently administered under a uniform subsidy structure where each producer is offered the same cost-share subsidy for each BMP on a first-come, first-serve basis until the allocated budget has been spent. This type of subsidy allocation system, based on policy objectives of ensuring equity and maximizing participation, has been shown to be inefficient in terms of minimizing costs and maximizing environmental benefits under a limited agrienvironmental subsidy budget (Boxall et al. 2008).

Due to the heterogeneity of agricultural landscapes, the marginal cost of implementing a BMP will vary between different parcels of land, as will the marginal environmental benefit provided by applying the BMP (Lankoski and Ollikainen 2003). Therefore, policy efficiency may be improved by using differentiated or targeted policy tools. Lankoski and Ollikainen (2003) recognized that under conditions of heterogeneous land quality, it is socially optimal to use differentiated policy instruments to address agricultural externalities if the level of environmental improvement is dependent on specific land characteristics, as is the case for nutrient management 
BMPs. These differentiated policy instruments are therefore the first-best or most efficient policy solutions (Lankoski and Ollikainen 2003). Khana et al. (2003) also recognized differentiated or targeted policy instruments as the most efficient tools to increase the production of public environmental benefits on private agricultural lands through subsidization.

However, because differentiated policy tools are data-intensive and complicated to administer, policy makers often turn to second-best solutions, such as uniform policy instruments (Lankoski and Ollikainen 2003; Khana et al. 2003). Uniform policy instruments, although less efficient in terms of maximizing environmental benefits provided per dollar spent on agri-environmental subsidies, are easier to administer, involve less intensive data requirements, and may be perceived by farmers as a fairer payment system (Khana et al. 2003). Lankoski and Ollikainen (2003) showed that using uniform instruments in agri-environmental policy often resulted in the overproduction of non-commodity outputs and the underproduction of commodity outputs. In other words, uniform policy instruments may lead to overproduction of environmental goods beyond the socially optimal quantity, diverting an unnecessary amount of resources away from agricultural commodity production (Lankoski and Ollikainen 2003).

Previous research done for Agriculture and Agri-Food Canada (AAFC) has suggested the use of targeting strategies to improve the efficiency of BMP subsidies. A previous study conducted in the South Tobacco Creek watershed of Manitoba by Boxall et al. (2008) tested a targeted approach to BMP funding. This study considered cost targeting of BMP subsidies through revealed producer costs in a reverse auction (Boxall et al. 2008). Boxall et al. (2008) confirmed there are efficiency gains to be made in BMP subsidization in Manitoba if producer and landscape heterogeneity are recognized and used to target subsidies.

\subsection{Problem Statement and Objectives}

The purpose of this research was to determine the relative performance of targeted nutrient management BMP subsidies in Manitoba compared to the current uniform subsidy structure. Specific research objectives were as follows:

- Identify potential nutrient management BMP sites within an agricultural watershed;

- Quantify the nutrient reduction potential of each identified site;

- Quantify the total cost of implementing a nutrient management BMP at each site; 
- Estimate the watershed-scale nutrient reduction potential if nutrient management BMP subsidies are allocated according to different targeting strategies;

- Compare nutrient reduction outcomes under each targeting strategy to determine which is the most efficient strategy in terms of removing the greatest quantity of nutrients under a fixed BMP subsidy budget;

- Compare the nutrient reduction outcome provided by the most efficient targeting strategy to the nutrient reduction outcome under the current uniform subsidy structure to determine the potential efficiency gain;

- Estimate the optimal level of expenditure on nutrient management BMPs at the watershed scale to evaluate whether existing BMP subsidy budgets result in overspending or underspending; and

- Identify common characteristics among potential nutrient management BMP sites with a high benefit-cost ratio to facilitate efficient BMP subsidization in similar watersheds.

\subsection{Methods}

This research was conducted as part of the Red-Assiniboine water quality project undertaken by Agriculture and Agri-Food Canada (AAFC) in Manitoba. The Red-Assiniboine water quality project focused on determining the potential for subsidized nutrient management BMPs to reduce the amount of nutrient runoff from agricultural sources entering the Red and Assiniboine Rivers as they flow through Manitoba before draining into Lake Winnipeg. This study focused specifically on using water retention pond nutrient management BMPs to reduce phosphorus runoff from agricultural fields in the La Salle sub-watershed, part of the Red River drainage basin.

The La Salle River is a tributary of the Red River and the La Salle sub-watershed makes up the northernmost portion of the La Salle River Watershed, located between Winnipeg and Portage La Prairie in central Manitoba (La Salle River Watershed Planning Authority 2010). The La Salle River Watershed is part of the larger La Salle Redboine Conservation District, one of 18 conservation districts in Manitoba (Province of Manitoba 2014). The La Salle River Watershed is shown within the La Salle Redboine Conservation District in Figure 1.1 below. The La Salle River Watershed is intensively cultivated with approximately 80 percent of its land base in agricultural production (Yang et al. 2014). Water quality has declined significantly within the La 
Salle River Watershed since the early 1970s due to naturally high nutrient levels and a slowmoving river system combined with increased phosphorus and nitrogen inputs from agricultural sources (La Salle River Watershed Planning Authority 2010).

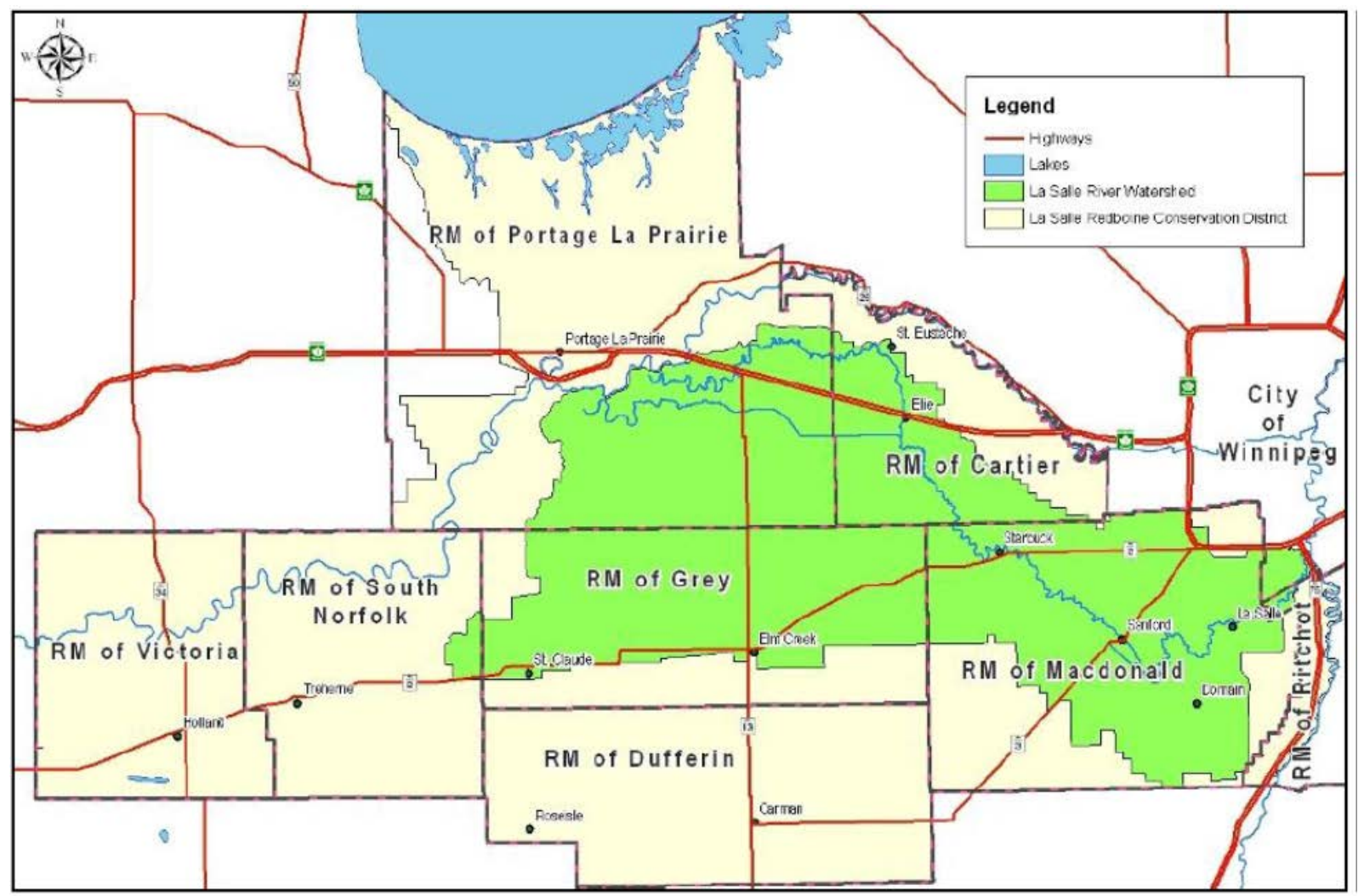

Figure 1.1: La Salle River Watershed within the La Salle Redboine Conservation District (La Salle River Watershed Planning Authority 2010).

Water retention ponds are one type of nutrient management BMP designed to prevent excess phosphorus applied to agricultural fields from entering surrounding surface waterbodies through over-field runoff. Water retention ponds are created within or adjacent to agricultural fields to collect and hold field runoff to facilitate the uptake of excess phosphorus by aquatic plants and sediments before the runoff water is released into nearby waterways.

AAFC researchers mapped potential water retention pond sites within the La Salle sub-watershed and used the Canadian Soil and Water Assessment Tool (CanSWAT) to determine the phosphorus reduction potential of each pond site. Since there is a limited budget for BMP subsidization under Growing Forward 2 as it is applied in Manitoba, not all potential pond sites can receive a subsidy and thus the method by which BMP subsidies are allocated becomes important to ensure that the subsidy program is functioning efficiently. My research modelled 
the pond implementation pattern and resulting phosphorus reduction in the La Salle subwatershed over a 12-year study period using three different targeting strategies to allocate BMP subsidies in order to evaluate the relative performance of each targeting strategy in terms of phosphorus reduction provided under the limited budget. The targeting strategies used in this research were cost targeting, benefit targeting, and benefit-cost targeting. For the purpose of this analysis it was assumed that the outcome of the cost targeting strategy would closely resemble the outcome of the current uniform allocation strategy therefore cost targeting was used as a proxy for the uniform allocation strategy and compared to benefit targeting and benefit-cost targeting. 


\subsection{Literature Review}

\subsection{Agri-Environmental Externalities and the Need for Public Intervention}

Agriculture is considered a multifunctional industry because agricultural lands jointly produce both commodity and non-commodity outputs of which many non-commodity outputs are often externalities, outputs that are not accounted for in market transactions of agricultural goods (Lankoski and Ollikainen 2003). Recently, focus has shifted from the traditional economic value of agricultural food and fiber commodities for human consumption to the multifunctional value of agricultural landscapes and their ability to provide public environmental benefits along with private market goods. It is increasingly recognized that sustainable agricultural landscapes can co-produce non-commodity ecological goods and services along with traditional agricultural commodities (Crossman and Bryan 2009). Ecological goods and services such as nutrient cycling, regulation of atmospheric gases, soil formation, sediment trapping, and wildlife habitat are increasingly recognized as having value to society (Lant et al. 2005). However, the provision of these public ecological goods and services depends on individual management decisions on private agricultural lands (Crossman and Bryan 2009).

Agricultural landscapes usually provide fewer ecological goods and services than the forest, prairie, or wetland ecosystems they replace (Lant et al. 2005; Costanza et al. 1989). The potential to restore or protect ecological goods and services flowing from agricultural landscapes is dependent on the ability to convince farmers to provide public ecological goods and services on private agricultural lands (Lant et al. 2005). Public goods are characterized as being non-rival in consumption, meaning an additional individual using the good does not affect the quality or quantity of the good remaining for others to use, and non-excludable in use, meaning it is impossible or prohibitively expensive to exclude people from using the good (Hansen et al. 2015). The non-excludable nature of public goods prevents them from being traded in private markets, resulting in market failure. Due to the lack of markets for ecological goods and services they are often under-produced in agricultural landscapes in favour of agricultural commodities that can be traded in private markets (Lant et al. 2005; Roberts and Leitch 1997). As Brander et al. (2006) described, the public good nature of most ecological goods and services results in their under-provision due to market failure. 
In private markets, prices serve as signals indicating resource scarcity. Prices are considered to provide a true measure of economic value only if the market is characterized by a large number of buyers and sellers and by private property rights that are enforceable and transferable. Also in a private market, consumers, faced with a budget constraint, must choose between rival goods and services. If these conditions hold, i.e. the market contains a large number of buyers and sellers, private property rights exist that are enforceable and transferable, and consumers facing a limited budget choose between rival goods, then economic theory assumes that prices will direct the allocation of scarce resources to their highest valued use. Market failure, or the absence of efficiently functioning markets that have the characteristics listed above, is the reason behind the under-valuation and under-production of many ecological goods and services (Costanza et al. 1989).

Despite the absence of prices and markets for ecological goods and services, policy makers are increasingly focused on giving value to these non-market goods and services in order to prevent market failure and encourage their provision (Costanza et al. 1989; Khakbazan et al. 2013). According to these authors, ecological goods and services have contributory value, assigned not because they provide direct benefits to humans, but rather because of their indirect role in maintaining ecosystem functions that benefit humans. Costanza et al. (1989) argued that contributory value is an estimate of the value individuals would assign to ecological goods and services if they were fully informed about the ecosystem functions on which society and the economy rely.

Boxall et al. (2008) stated that it is justifiable to use public funds to provide incentives for land use or land management changes in order to increase the joint production of non-market ecological goods and services alongside commodities on private agricultural lands. Bryan and Kandulu (2011) stressed the importance of providing financial compensation for farmers when the requested land use change involves taking land out of commodity production to provide public ecological goods and services. Costanza et al. (1989) wrote that in situations where private incentives lead to outcomes that diverge from the social optimum, as is the case when natural ecosystems that provide large public benefits are converted to agricultural land uses that provide smaller private benefits, public intervention is justified. Lant et al. (2005) agreed and 
showed that subsidies can improve the joint production of agricultural commodities and noncommodity ecological goods and services within agricultural landscapes.

When considering the joint production of farm commodities and ecological goods and services, a production possibilities frontier (PPF) can be defined where farmers must choose between dedicating available resources to the production of farm commodities or to the production of environmental benefits (Lant et al. 2005). For example, a farmer must decide between draining a wetland to grow canola and leaving the wetland untouched to provide water filtration and flood mitigation services. Subsidies paid to farmers for the provision of environmental benefits expand the PPF by offering compensation for taking agricultural land out of production rather than forcing farmers to remain on the same PPF making trade-offs between farm income and the provision of ecological goods and services. By expanding the PPF outward, subsidies allow farmers to produce higher levels of both farm income and ecological goods and services (Lant et al. 2005).

Lant et al. (2005) argued that agri-environmental subsidies should be enhanced by shifting funds from agricultural income support subsidies tied to commodity production or price to subsidies based on the provision of public environmental benefits. This would ensure that public expenditures on agriculture produce a valuable public benefit in the form of enhanced ecological goods and services flowing from agricultural landscapes. Agricultural support payments in return for the provision of public ecological goods and services are also legitimate under trade rules established by the General Agreement on Tariffs and Trade whereas direct production subsidies are considered unacceptable (Lant et al. 2005). By shifting the nature of agricultural subsidies from income transfers tied to commodity production and prices to ecosystem-based subsidies that encourage the provision of public environmental benefits, the conditions under which farmers make decisions would change. This new decision environment would encourage farmers to change land use and land management practices to simultaneously maximize the production of agricultural commodities and the production of ecological goods and services rather than focusing solely on farm income through commodity production (Lant et al. 2005).

\subsection{Nutrient Runoff as a Negative Externality of Agricultural Production}

When natural ecosystems are converted to agricultural land to maximize farm income through commodity production, not only are the positive external environmental benefits flowing from 
that natural ecosystem lost, the ability of the ecosystem to mitigate negative externalities arising from agricultural production is also lost. For example, nutrient runoff from agricultural fields entering surface water bodies is a significant negative externality associated with agricultural production (Pretty 2003; Lankoski and Ollikainen 2003). Wetland plants and sediments provide natural nutrient assimilation services by absorbing excess nutrients from field runoff. When wetlands within agricultural landscapes are drained they are no longer able to provide nutrient assimilation services and mitigate the negative externality of nutrient runoff from agricultural fields. Many previous authors have identified nutrient runoff, a form of non-point source pollution, as a concerning negative externality of agricultural production and a significant threat to water quality (Pretty 2003; Lankoski and Ollikainen 2003; Tilman et al. 2002; Kurkalova 2015; Khakbazan et al. 2013).

Nitrogen (N) and phosphorus (P) in organic and synthetic fertilizers are the main pollutants of concern that affect water quality (Burkart and Jha 2012). Nutrient runoff occurs when more fertilizer is applied than is needed or can be taken up by the crop, resulting in excess nutrients that are carried to and deposited in surface water bodies through field runoff when it rains or during snowmelt (Burkart and Jha 2012). Both nitrogen and phosphorus are naturally present in aquatic systems and are necessary to maintain a healthy aquatic ecosystem, however high concentrations of either can cause serious problems (Bourne et al. 2002). Additional nitrogen inputs into surface water bodies can lead to nitrate levels that exceed the maximum safe drinking water standard (Burkart and Jha 2012; Khakbazan et al. 2013). Additional phosphorus inputs can lead to eutrophication where large algae blooms create anoxic conditions as the algae begin to decay. Eutrophication can result in fish kills, decreased biodiversity, increased downstream water treatment costs, and potentially dangerous levels of toxic cyanobacteria (Burkart and Jha 2012; Khakbazan et al. 2013; La Salle River Watershed Planning Authority 2010; Bourne et al. 2002).

\subsection{Nutrient Runoff and Water Quality in Manitoba}

Nutrient enrichment of surface waters is one of the largest water quality issues facing Manitoba and is especially problematic in Lake Winnipeg (Bourne et al. 2002; Boxall et al. 2008). Excess nutrients entering Lake Winnipeg and its tributaries come from a variety of sources, however upstream non-point nutrient pollution from agricultural sources is considered to be one of the 
major contributors (Boxall et al. 2008; Yang et al. 2014). Covering an area of 24,500 square kilometres, Lake Winnipeg is the sixth largest freshwater lake in Canada and the tenth largest in the world. Surface water drains into Lake Winnipeg from a large drainage basin covering approximately one million square kilometres within four Canadian provinces and four American states. Water quality has consistently declined in Lake Winnipeg since the 1970s due to elevated nutrient levels that contribute to large algae blooms and subsequent eutrophication.

Eutrophication has negatively affected fisheries in the lake as well as recreational users (Yang et al. 2014).

Approximately 15 per cent of the land base in Manitoba is used for agriculture. Most agricultural activity takes place in the southern third of the province and is most intensive in the Assiniboine, Souris, and Red River watersheds. Intensive agriculture is accompanied by high rates of fertilizer application and as a result there is concern over excess nutrients entering surface water bodies in these intensively cultivated watersheds (Bourne et al. 2002). Runoff from snowmelt or rainfall carries dissolved nutrients from agricultural fields into surface water bodies leading to elevated levels of nitrogen and phosphorus and, subsequently, reduced water quality downstream (Khakbazan et al. 2013; Yang et al. 2014). Bourne et al. (2002) warned that the majority of streams and rivers in the Assiniboine River and Red River watersheds showed increasing concentrations of both total nitrogen (TN) and total phosphorus (TP) between 1970 and 1999.

Total dissolved nutrient loads are contributed by two general processes: (1) nutrients arising from within-stream processes and (2) nutrients arising from watershed processes, which include nutrients released from animal manure and from the application of synthetic fertilizers (Bourne et al. 2002). Bourne et al. (2002) compared mean TN and TP loads from watershed processes to mean TN and TP loads from within-stream processes within the Red and Assiniboine Rivers. They found that watershed processes (including runoff of nutrients from animal manure and synthetic fertilizers) contributed the largest amount of TN and TP to both the Red and Assiniboine Rivers. Within the Assiniboine River basin, an average of 71 percent of annual TN and 76 percent of annual TP was contributed by watershed processes between 1994 and 2001 (Bourne et al. 2002). In the Red River basin, an average of 59 percent of annual TN and 73 percent of annual TP was contributed by watershed processes over the same time period (Bourne 
et al. 2002). Therefore, Bourne et al. (2002) concluded that watershed processes were the leading contributors of excess nutrients to the Red and Assiniboine Rivers between 1994 and 2001.

The Red River was the single largest contributor of TN and TP to Lake Winnipeg during the period 1994 to 2001 (Bourne et al. 2002). Of the TN carried by the Red River to Lake Winnipeg each year, an average of 4,176 tons (6.6 percent) comes from within-stream processes in Manitoba while an average of 5,924 tons (9.4 percent) comes from watershed processes in Manitoba (Bourne et al. 2002). Of the TP carried by the Red River to Lake Winnipeg each year, an average of 470 tons (8.1 percent) comes from within-stream processes in Manitoba while an average of 1,260 tons (22 percent) comes from watershed processes in Manitoba (Bourne et al. 2002).

Major tributaries of the Red River within Manitoba include the Assiniboine, Roseau, Seine, La Salle, Rat, Pembina, and Morris Rivers. Of these tributaries, the Assiniboine River was consistently the largest single contributor to TN and TP loads in the Red River between 1994 and 2001 (Bourne et al. 2002). This same research reported that the Assiniboine River contributed between 6.7 percent and 21 percent of the annual TP load in the Red River and between 7.9 percent and 19 percent of the annual TN load in the Red River between 1994 and 2001. The La Salle River contributed between 0.2 percent and 1.5 percent of the annual TN load and between 0.2 percent and 2.0 percent of the annual TP load in the Red River between 1994 and 2001 (Bourne et al. 2002). Average TN load in the La Salle River between 1994 and 2001 was 237 tons/year while average TP load was 52 tons/year (Bourne et al. 2002). From 1974 to 1999, the average annual TN and TP concentrations within the La Salle River increased by 146 percent and 193 percent respectively (La Salle River Watershed Planning Authority 2010).

In response to increasing TN and TP loads in the La Salle River, the La Salle Redboine Conservation District initiated an integrated watershed management plan (IWMP) for the La Salle River Watershed in 2006 (La Salle River Watershed Planning Authority 2010). One of the main goals identified in the La Salle River Watershed IWMP was to protect and improve water quality. The IWMP confirmed that water quality has declined significantly within this watershed since the early 1970s (La Salle River Watershed Planning Authority 2010). Water quality decline in the La Salle River was attributed to increased point and non-point source nutrient 
loading, a slow-moving river, and naturally high nutrient levels. Identified sources of point and non-point nutrient pollutants entering the La Salle River included runoff of commercial fertilizers and livestock manure from agricultural lands, septic leakage, and effluent from wastewater treatment facilities (La Salle River Watershed Planning Authority 2010). Nutrient runoff from excess fertilizer application on agricultural lands is of particular concern in the La Salle River Watershed due to the prevalence of intensive agricultural production and the finding by Bourne et al. (2002) that watershed processes, which include nutrient runoff from agricultural fields, are the major cause of elevated nutrient levels in the Red River drainage basin (which includes the La Salle River).

The La Salle River Watershed IWMP defined a desirable target of TP outflow at 10 percent less than the 2006 level. Yang et al. (2014) used the Soil and Water Assessment Tool (SWAT) to estimate annual TP outflow from the La Salle River Watershed for every year between 1993 and 2007 and compared these estimates with the target TP level. This comparison revealed that annual TP load had consistently exceeded the target TP level during the time period studied. In fact, annual TP outflow from the La Salle River Watershed was greater than the target level 50 percent of the time between 1993 and 2007 (Yang et al. 2014). Yang et al. (2014) concluded there is a need for policy intervention to reduce TP outflows from the La Salle River Watershed. To address the goal of improving water quality in the La Salle River Watershed by limiting TP runoff, the La Salle River Watershed IWMP suggested providing incentive programs and technical assistance to producers to encourage the adoption of beneficial management practices (BMPs) that reduce or eliminate excess TP runoff from agricultural fields (La Salle River Watershed Planning Authority 2010). This approach is consistent with most water quality improvement programs in the United States which address water pollution from non-point agricultural sources through voluntary subsidy programs (Kurkalova 2015).

The negative effects of nutrient runoff on water quality and aquatic ecosystem health can be addressed through precise application of manure or commercial fertilizers on agricultural lands, through land use change to perennial forages or restored wetlands, and through runoff control from livestock yards and agricultural fields (Khakbazan et al. 2013; Yang et al. 2014). Management practices used to control nutrient runoff from livestock yards and agricultural fields include the establishment of water retention ponds, small dams, and riparian buffer strips 
(Khakbazan et al. 2013). Cook and Norman (1996) suggested removing frequently flooded land from intensive agricultural production to create in-field or field-adjacent ponds that assimilate excess nutrients before they enter surrounding surface waterbodies. Adoption of these management practices is often subsidized to acknowledge the opportunity cost to farmers of changing business-as-usual practices or removing land from agricultural production (Boxall et al. 2008; Bryan and Kandulu 2011).

\subsection{Growing Forward 2 and the Administration of BMPs in Manitoba}

In Canada the subsidization of agricultural BMPs is administered as part of the Growing Forward 2 policy framework, a joint agreement between the federal and provincial/territorial governments (Province of Manitoba 2014). Growing Forward 2 encourages the voluntary adoption of BMPs by running education and awareness campaigns, appealing to environmental values and stewardship motives, and subsidizing producers who choose to adopt BMPs (Boxall et al. 2008). The BMP subsidy program in Canada uses a uniform payment structure in which each producer is eligible to receive the same cost-share subsidy for each BMP regardless of the suitability of the producer's land to provide the desired environmental benefit (Boxall et al. 2008).

There are two programs within Growing Forward 2 as it is applied in Manitoba that address BMP subsidies: Growing Assurance- Environment and Growing Assurance- Ecological Goods and Services. The Growing Assurance- Environment program provides financial assistance to individual agricultural producers or agribusinesses for the adoption of BMPs to improve the environmental sustainability of their operation (Province of Manitoba 2015a). The Growing Assurance- Ecological Goods and Services program provides financial assistance to conservation districts (CDs) in Manitoba to implement BMPs in partnership with local producers (Province of Manitoba 2015b). Under this program, BMP projects are undertaken as a partnership between producers and their local CD. Project implementation takes place on private land but project funding and technical support are provided by the CD using BMP subsidy funds obtained through the Growing Assurance- Ecological Goods and Services program (Province of Manitoba 2015b). Funding for BMP projects under the Growing Assurance- Ecological Goods and Services program is through a cost-share structure where the CD will fund 70 percent of project construction costs up to a maximum amount, which is decided by the CD on a case-by-case 
basis. The remaining project costs are paid by the producer (La Salle Redboine Conservation District 2015).

Conservation districts (CDs) in Manitoba are formed as a partnership between the province and local municipalities to protect, restore, and manage land and water resources at the watershed scale (Province of Manitoba 2015c). CDs also act as designated water planning authorities for integrated watershed management plans (IWMPs) to improve watershed health and sustainability (Province of Manitoba 2015c). Each CD offers a unique set of BMP programs to achieve the objectives set out in the IWMP(s) it administers (Province of Manitoba 2014). CDs often lead the effort to reduce non-point nutrient pollution of surface water bodies within their respective watersheds (Province of Manitoba 2014). The study area of the research presented in this thesis is the La Salle sub-watershed, which is in the mandated area of the La Salle Redboine Conservation District. The La Salle Redboine CD funds a surface water management program that focuses specifically on excess nutrient and sediment runoff into surface water bodies. This program seeks to lessen the impact of runoff events by helping farmers implement water retention and erosion control projects (La Salle Redboine Conservation District 2015).

\subsection{Economic and Spatial Targeting of Agri-Environmental Policy}

As discussed above, BMP subsidy programs in Canada primarily use a uniform cost-share payment structure where all farmers are eligible to receive the same cost-share subsidy to adopt a certain BMP, regardless of how much it will cost the individual farmer to implement the BMP or the level of environmental benefit the BMP will provide on the individual farmer's land (Boxall et al. 2008). It has been shown that uniform payment structures are often inefficient and have a high adverse selection bias where lands that provide low quality environmental benefits use up part of a fixed budget that could have been spent on lands that provide high quality environmental benefits (Boxall et al. 2008). In recognition of the heterogeneity within agricultural landscapes, economic and spatial targeting has been identified as a potential tool to improve the efficiency or cost effectiveness of BMP subsidies (AAFC 2012). The notion that agri-environmental payment programs can be made more effective and efficient using spatial and economic targeting to locate the most suitable or relevant geographic areas for policy intervention is growing more common in related literature (Van der Horst 2006; Van der Horst 2007). 
Many agri-environmental payment programs are delivered in accordance with the objective of enrolling more land or recruiting more farmers into the program with little consideration given to the level of environmental benefit provided per dollar spent (Cook and Norman 1996). Considerations of environmental value for money, while acknowledged by policy makers, are not explicitly included in the design or delivery of most agri-environmental payment programs, leading to inefficiency (Cook and Norman 1996). Instead of striving to maximize land enrollment or farmer participation, Babcock et al. (1997) suggested efficiency or cost effectiveness should be the goal of agri-environmental payment programs.

Efficiency is attained through an optimization exercise which seeks to maximize the level of benefit provided under a predetermined budget or minimize the cost of achieving a predetermined level of benefit (Van der Horst 2006). The goal of efficiency is to maximize the benefit-cost ratio of policy implementation (Babcock et al. 1997). The term cost effectiveness is often used instead of the term efficiency in cases where the economic value of environmental benefits has not been estimated and therefore benefits are measured in biophysical units rather than monetary units. Cost effectiveness still measures the ratio of benefits provided per dollar spent, but benefits are measured in biophysical units while costs are measured in monetary units. The term efficiency is used when both benefits and costs are measured in monetary units when compared in a benefit-cost ratio (Babcock et al. 1997).

The literature on agri-environmental policy efficiency or cost effectiveness often includes the "fixed budget" assumption where there is a fixed amount of funding for agri-environmental payment programs aimed at decreasing a negative externality or increasing a positive externality associated with agricultural production. Another assumption, "farmers are profit maximizing actors”, states that farmers are motivated by profit objectives when choosing a management practice and therefore will only adopt a BMP if the payment offered is equal to or exceeds the total cost incurred by the farmer (Kurkalova 2015). Kurkalova (2015) suggested that since policy makers face a fixed budget and profit-maximizing farmers they must prioritize which BMPs should be subsidized at which locations in order to maximize environmental benefits within a fixed program budget. In other words, spatial and economic targeting should be used to determine which BMPs should be subsidized at which locations so that the program is delivered in an efficient/cost effective way (Kurkalova 2015). Cook and Norman (1996) pointed out that 
where agri-environmental policies require large, potentially permanent shifts in land use or land management, targeting allows for higher subsidy rates to be paid to a smaller group of farmers in order to increase the uptake of the program by ensuring farmers are adequately compensated for the full cost of the imposed land use or land management change.

Spatial targeting is used to identify areas with the greatest potential to provide a desired environmental benefit and requires knowledge of the spatial variability of the environmental benefit in question. Spatial variability is often represented using geographic information system (GIS) software to map differing levels of an environmental benefit over a specified area in a “benefit map” (Van der Horst 2007). Van der Horst (2006) suggested that benefit maps should be monetarized to delineate the economic benefits of a given policy at a given location and facilitate the simultaneous use of economic and spatial data to target agri-environmental policy. Similarly, Cook and Norman (1996) proposed expanding the use of GIS to create spatial data sets outlining both the costs and benefits of implementing an agri-environmental payment program within an area. Integrating biophysical and economic data using GIS allows benefitcost ratios to be calculated for various locations within a policy area, allowing policy makers to consider a necessary combination of biophysical and economic data at a spatial scale that is relevant to policy programming (Walpole and Sinden 1997). Crossman and Bryan (2009) agreed that economic and spatial data should be used simultaneously to target cost effective "hotspots" of environmental benefits on the landscape. Ferrero (2004) also advocated for the joint use of spatially variable biophysical and economic data to target agri-environmental policy.

Heterogeneity in BMP implementation costs and the provision of environmental benefits due to differing producer and landscape characteristics within a policy area creates the opportunity for efficiency/effectiveness gains by using spatial and economic targeting to administer BMP subsidies (Baker 2012). Baker (2012) noted that BMP implementation costs and the potential environmental benefits provided by BMPs vary widely across watersheds in Canada; therefore, recommendations to adopt a certain BMP within a watershed must take into consideration location-specific implementation costs and environmental benefits. Boxall et al. (2008) agreed noting that, to achieve environmental objectives in the most cost effective way, programs that encourage BMP adoption must take into consideration producer and landscape heterogeneity, which affect BMP implementation costs and the level of environmental benefits provided. 
Boxall et al. (2008) recognized that producers face different BMP implementation costs and therefore a BMP that is cost effective for one producer is not necessarily cost effective for another. These authors also noted that producers with the lowest cost of adopting a BMP may not always provide the greatest environmental benefits as determined by the location and physical features of their land.

Lankoski and Ollikainen (2003) recognized that under conditions of land heterogeneity, it is socially optimal to use differentiated/targeted policy instruments to address agri-environmental externalities if environmental improvements are dependent on specific land characteristics, as is the case for nutrient runoff reduction BMPs. Lankoski and Ollikainen (2003) described differentiated or targeted programs as the first-best policy instruments to address agrienvironmental externalities under conditions of heterogeneous land quality. Similar to Lankoski and Ollikainen (2003), Burkart and Jha (2012) promoted targeted policy tools to maximize water quality improvement when nutrient runoff reduction was dependent on heterogeneous landscape characteristics. Hansen and Hansen (2014) also promoted the use of spatial and economic targeting in nutrient management payment programs to maximize the water quality improvements provided by limited public funds. Similarly, Hansen et al. (2015) promoted generating spatial estimates of wetland costs and benefits to aid in decision making and found that economic and spatial targeting could provide efficiency gains in wetland conservation due to heterogeneity in wetland restoration costs and in the level of ecological goods and services provided by individual wetlands.

While there is strong evidence that targeting agri-environmental policy provides efficiency gains, multiple authors have recognized that differentiated/targeted policy instruments are more difficult and costly to administer (Lankoski and Ollikainen 2003; Kurkalova 2015; Khana et al. 2003). Kurkalova (2015) noted that there are high transaction costs associated with targeted policy instruments since location-specific costs and benefits of implementing an agrienvironmental program must be calculated across the policy area. Transaction costs include expenditures on information gathering and data analysis, enacting enabling legislation, policy design, policy implementation and administration, labour, and policy enforcement (Khana et al. 2003). Policy makers must ensure that the efficiency gains achieved by using a targeted policy tool are not negated by higher transaction costs (Khana et al. 2003). 
A study by Khana et al. (2003) comparing a targeted payment strategy to a capped rental payment strategy to allocate Conservation Reserve Program (CRP) funds in the United States associated high transaction costs with the targeted payment strategy. These authors determined that transaction costs would be substantially higher under the targeted payment strategy since the implementation of this strategy requires detailed knowledge of the biophysical characteristics of all potential conservation sites in the program area and their ability to provide environmental benefits under the CRP. In fact, Khana et al. (2003) cited research estimating the per farm transaction costs to implement a targeted conservation strategy to be 24 percent higher than the transaction costs associated with implementing a uniform conservation strategy. Additionally, the authors hypothesized that a targeted conservation policy would elicit greater resistance from farmers as it may be viewed as unfair and lacking transparency since payment differences are based on unseen potential to provide environmental benefits. Having to contend with farmer resistance would further increase the transaction costs of implementation (Khana et al. 2003).

Due to the high transaction costs associated with targeted policy instruments, policy makers often turn to second-best solutions, such as uniform policy instruments. However, Lankoski and Ollikainen (2003) found that uniform policy instruments resulted in the overproduction of noncommodity outputs from agricultural landscapes and the underproduction of commodity outputs, i.e. too many public environmental goods and too few private agricultural goods produced. Lankoski and Ollikainen (2003) concluded that, under conditions of producer and landscape heterogeneity, targeted policy instruments are needed to achieve the socially optimal joint production of commodity (private) and non-commodity (public) goods on agricultural lands.

\subsection{Uniform versus Targeted Policy Instruments in Previous Literature}

Numerous studies have been conducted to test the notion that agri-environmental policies can be delivered more efficiently or cost effectively by employing spatial and economic targeting to determine the most suitable or relevant geographic areas for policy intervention. Lankoski and Ollikainen (2003) studied the difference in agri-environmental policy outcomes when semiuniform policy instruments were used compared to targeted policy instruments. The policy instruments considered by Lankoski and Ollikainen (2003) included a fertilizer tax and a riparian buffer strip subsidy to address the problem of excess nutrient runoff from agricultural fields. The authors first modelled the policy outcome assuming both the fertilizer tax and buffer strip 
subsidy were implemented as semi-uniform instruments that were crop specific but uniform across all land planted to the same crop. The policy outcome assuming both the fertilizer tax and buffer strip subsidy were administered using benefit-cost targeting was then modelled and compared to the semi-uniform policy outcome. Lankoski and Ollikainen (2003) found that both the buffer strip subsidy and fertilizer tax were higher when the semi-uniform policy instruments were used compared to when the targeted policy instruments were used, resulting in buffer strips that were too large and a fertilizer application rate that was too low compared to the social optimum.

In another study comparing policy delivery methods, Khana et al. (2003) compared sediment abatement outcomes under the American Conservation Reserve Program (CRP) using a parcelspecific rental rate compared to a uniform rental cap. Under the parcel-specific rental rate, Khana et al. (2003) assumed rental payments varied based on the sediment abatement potential of each land parcel. Under the uniform rental cap, a maximum per acre rental rate was set and all offers to retire land at a cost lower than or equal to the rental cap were automatically accepted. Khana et al. (2003) found that the parcel-specific rental rate was more efficient than the uniform rental cap since the parcel-specific rental rate ensured that the land capable of providing the highest level of sediment abatement per dollar spent by the CRP was enrolled first. Van der Horst (2007) explored improvements to the Scottish Farm Woodland Premium Scheme (FWPS) by moving from semi-uniform subsidies to spatially-targeted subsidies for the conversion of private farmland to woodland to provide biodiversity and visual amenity public goods. Current FWPS subsidies are based on land use classifications where each classification garners a unique subsidy rate but all land within a classification receives the same subsidy rate regardless of its potential to provide biodiversity or visual amenity benefits. Van der Horst (2007) modelled and compared the level of biodiversity and visual amenity benefits provided using the current semi-uniform subsidies to the biodiversity and visual amenity outcomes provided when targeted subsidies were used assuming the same budget. The author found that targeted subsidies were more efficient in providing biodiversity and visual amenity benefits under the FWPS compared to the semi-uniform subsidies currently used (Van der Horst 2007).

Boxall et al. (2008) compared the performance of various targeted policy instruments to promote the adoption of nutrient management BMPs in the South Tobacco Creek watershed of Manitoba 
to the performance of the current uniform cost-share subsidy program in achieving nutrient runoff reduction. Boxall et al. (2008) found that using cost targeting through a reverse auction to allocate nutrient management BMP subsidies was more cost effective than the current uniform subsidy program in reducing the quantity of nutrient runoff flowing from the South Tobacco Creek watershed.

\subsection{Economic Targeting Strategies}

There are three primary targeting strategies used in the literature on targeted policy instruments to improve the performance of agri-environmental subsidies: cost targeting, benefit targeting, and benefit-cost targeting. Applied to BMP subsidy programs, cost targeting involves subsidizing those BMP sites with the lowest implementation cost first then moving to progressively higher cost sites until the budget is reached (Babcock et al. 1997). Under a cost targeting strategy, policy makers direct BMP subsidies to the land that can provide the desired environmental benefit at the lowest cost with no regard to the total level of environmental benefit provided (Wu et al. 2001). In contrast, benefit targeting involves subsidizing those BMP sites that can provide the highest level of environmental benefit first and working down until the budget is reached (Babcock et al. 1997). Under a benefit targeting strategy, policy makers subsidize BMP adoption on land that can provide the greatest environmental benefit regardless of the cost (Wu et al. 2001). Finally, benefit-cost targeting involves subsidizing those BMP sites with the highest benefit-cost ratio first and working down to BMP sites with progressively lower benefit-cost ratios until the budget is reached (Babcock et al. 1997). Under a benefit-cost targeting strategy, policy makers subsidize BMP adoption on land that provides the greatest level of environmental benefit per dollar spent on the BMP program (Wu et al. 2001).

Another important branch of the policy targeting literature focuses on determining the distribution of welfare provided by a policy under different targeting scenarios. Wu et al. (2001) analyzed the impact of using alternative targeting strategies to administer conservation purchasing funds on different interest groups including consumers, producers, farm labourers, and environmentalists. These authors predicted environmentalists would prefer benefit-cost targeting because it resulted in the highest level environmental benefits. In contrast, consumers who are not concerned about the environment would prefer benefit targeting because consumer surplus was the highest under this targeting strategy. Labourers and input suppliers would prefer 
benefit targeting because it removed the smallest amount of land from production and resulted in the highest output level. Producers would prefer cost targeting since this strategy resulted in the most land being diverted away from production, leading to the largest reduction in output and therefore the largest shortage-induced price increase (Wu et al. 2001).

Van der Horst (2006) referenced the same targeting tools as cost ranking, benefit ranking, and benefit-cost ranking. Cost ranking is the most widespread tool used in land conservation strategies and results in maximizing the amount of land enrolled in conservation plans, but does not consider the level of environmental benefit provided by the land enrolled. However, increased use of GIS to map ecological goods and services within agricultural landscapes has made benefit ranking and benefit-cost ranking more accessible to governments and conservation organizations (Van der Horst 2006). Van der Horst (2006) noted that benefit-cost ranking is often the optimal policy tool for governments or conservation organizations seeking to increase provision of public environmental benefits since it focuses on maximizing the efficiency or cost effectiveness of limited environmental conservation budgets.

Different governmental and non-governmental conservation organizations use different targeting strategies to select land for conservation or rehabilitation. The U.S. Fish and Wildlife Service uses benefit targeting to select wetlands and other water resources for conservation based on desirable biophysical criteria (Wu et al. 2001). Similarly, the national park system in the U.S. establishes protected areas according to a benefit targeting strategy, selecting only the "crown jewels” of potential protected lands for designation as national protected areas (Babcock et al. 1997). The U.S. Bureau of Reclamation purchases land according to a cost targeting strategy using a decision rule to maximize the quantity of land held, rather than maximizing the environmental amenities provided by the land (Babcock et al. 1997). The U.S. Conservation Reserve Program, administered by the U.S. Department of Agriculture, also follows a cost targeting decision rule by enrolling the least expensive land first regardless of the environmental benefits provided (or not provided) by taking that land out of production (Babcock et al. 1997). The conservation program that most closely follows the optimal benefit-cost targeting strategy is the program run by the Nature Conservancy. The Nature Conservancy negotiates easements and purchases land based on both the environmental benefits provided and the cost of securement (Babcock et al. 1997). 
Land parcels can be classified into one of four regions in the cost-benefit plane identified by Babcock et al. (1997) (Figure 2.1). Region I contains low-cost land that offers a high level of environmental benefit. Region II contains high-cost, high-benefit land. Region III contains lowcost, low-benefit land and Region IV contains high-cost, low-benefit land. Targeting low-cost land obtains land from Regions I and III while targeting high-benefit land obtains land from Regions I and II.

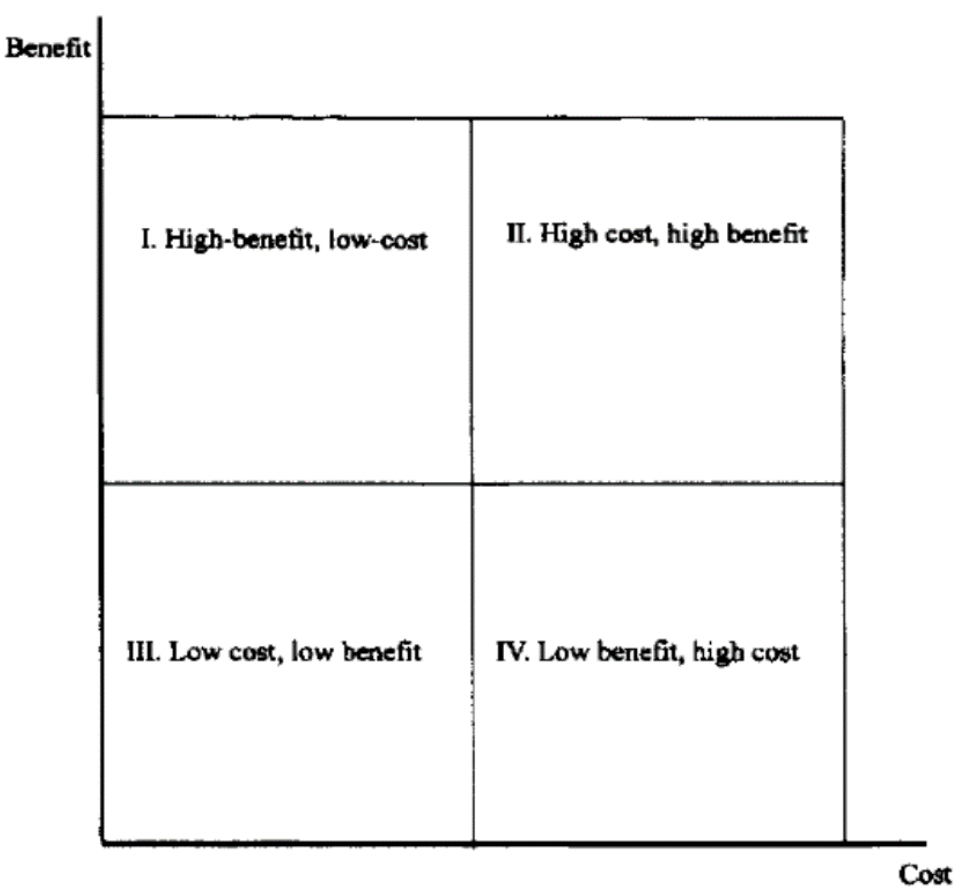

Figure 2.1: Cost-benefit plane.

(Babcock et al. 1997, 326)

According to Babcock et al. (1997) the joint distribution of BMP costs and environmental benefits determines the magnitude of the difference in policy outcomes when alternative targeting tools are used. When BMP costs and environmental benefits are negatively correlated (regions I and IV), outcomes from the three targeting strategies will tend to converge, but a positive correlation between BMP costs and environmental benefits (regions II and III) will tend to increase the disparity in outcomes. Thus, a positive correlation increases the importance of selecting the best possible targeting tool (Babcock et al. 1997).

The relative variability of BMP costs and environmental benefits, in combination with the correlation coefficient between the two, determines the magnitude of the disparity in outcomes 
between targeting strategies (Babcock et al. 1997). If BMP cost variability is greater than environmental benefit variability then cost targeting is more likely to achieve environmental objectives, especially if benefits and costs are positively correlated. However, if environmental benefit variability is greater than BMP cost variability then benefit targeting is more likely to achieve environmental objectives, especially when benefits and costs are positively correlated (Babcock et al. 1997). Regardless of the relative variability of BMP costs and environmental benefits, benefit-cost targeting is widely considered to be the optimal targeting strategy (i.e. the most efficient or cost effective targeting strategy) under conditions of heterogeneous producer costs and landscape characteristics if the level of environmental benefit provided is dependent on specific landscape characteristics (Babcock et al. 1997).

However, a study by Wu et al. (2001) proved that the efficiency or cost effectiveness of benefitcost targeting is dependent on the elasticity of output demand for the output being displaced in favour of providing environmental benefits. When output demand for an agricultural commodity is not perfectly elastic, which is almost always the case, benefit-cost targeting is not guaranteed to maximize the provision of the desired ecological good or service under a fixed payment program budget (Wu et al. 2001). If the demand curve for an agricultural commodity is downward sloping rather than perfectly elastic, an agri-environmental policy that removes land from production seasonally or permanently (such as wetland restoration) may increase commodity prices by reducing production as land is diverted away from commodity production to the provision of non-commodity ecological goods and services (Wu et al. 2001).

If a shortage-induced commodity price increase does occur as a result of diverting agricultural land away from commodity production, this price increase can cause two types of "slippage". First, marginal land that was previously idle may be brought into production, reducing total environmental benefits, and if farmers are subsidized to prevent this marginal land from coming into production then less money is available to subsidize conservation of lands with higher environmental benefit potential (Wu et al. 2001). Second, higher commodity prices increase the value of land in production, which increases the opportunity cost of retiring land to provide environmental benefits. This would likely result in farmers requiring a higher subsidy rate to retire land and therefore fewer parcels of land would be subsidized within the fixed budget ( $\mathrm{Wu}$ 
et al. 2001). These slippage effects reduce the efficiency gains associated with administering agri-environmental payment programs through benefit-cost targeting (Wu et al. 2001).

Slippage effects that encourage production on marginal lands and induce higher subsidy requirements for land retirement are less likely when a uniform subsidy allocation strategy is used under conditions of downward-sloping commodity demand. Under a uniform subsidy allocation strategy, each farmer is given an equal payment to enroll land in the conservation program. Rational farmers will respond by retiring their least productive land to minimize their losses. In other words, rational farmers will practice cost targeting when offered a uniform subsidy payment by retiring their least cost (least productive) marginal land first (Wu et al. 2001). Retiring marginal land has little effect on the overall level of production and therefore is unlikely to lead to shortage-induced commodity price increases. Even if commodity prices do increase, farmers are unlikely to cultivate marginal land since this land is already subsidized to remain out of production (Wu et al. 2001).

Wu et al. (2001) concluded that benefit-cost targeting is guaranteed to maximize the environmental benefits provided by an agri-environmental payment program that requires seasonal or permanent land retirement only if demand for the agricultural output displaced is perfectly elastic. However, if agricultural output demand is downward sloping, the slippage effects discussed above may cause benefit-cost targeting to provide fewer environmental benefits than what would be provided under a uniform agri-environmental payment program (Wu et al. 2001). Therefore, according to this research, to maximize the environmental benefits provided by an agri-environmental payment program that requires seasonal or permanent land retirement, price feedback slippage effects must be considered before a targeting strategy is chosen if the displaced agricultural output demand is downward sloping (Wu et al. 2001).

\subsection{Conclusion}

Agriculture is considered a multifunctional industry because agricultural lands jointly produce both commodity and non-commodity outputs of which many non-commodity outputs are externalities (Lankoski and Ollikainen 2003). One positive externality of agricultural production is the ability of sustainably managed agricultural landscapes to co-produce non-commodity ecological goods and services along with traditional agricultural commodities (Crossman and 
Bryan 2009). However, the provision of public ecological goods and services is dependent on individual management decisions on private agricultural lands (Crossman and Bryan 2009). In recognition of the ability to provide public ecological goods and services on sustainabilitymanaged private agricultural lands, many authors have argued for the use of public funds to provide incentives for land use or land management changes to increase the public environmental benefits that are jointly produced alongside agricultural commodities (Boxall et al. 2008; Bryan and Kandulu 2011; Costanza et al. 1989; Lant et al. 2005).

When natural ecosystems are converted to agricultural land to maximize farm income through commodity production, not only are the positive external benefits flowing from that natural ecosystem lost, the ability of the ecosystem to mitigate negative externalities arising from agricultural production is also lost. For example, when wetlands or low-lying areas in agricultural landscapes are drained they are no longer able to provide nutrient assimilation services and mitigate the negative externality of nutrient runoff from agricultural fields. Many previous authors have identified nutrient runoff, a form of non-point source pollution, as a concerning negative externality of agricultural production and a significant threat to water quality (Pretty 2003; Lankoski and Ollikainen 2003; Tilman et al. 2002; Kurkalova 2015; Khakbazan et al. 2013).

Non-point nutrient pollution of surface waters from agricultural sources is one of the largest water quality issues in Manitoba and is especially problematic in Lake Winnipeg (Bourne et al. 2002; Boxall et al. 2008). The negative effects of nutrient runoff on water quality and aquatic ecosystem health can be addressed through precise application of manure or commercial fertilizer, through land use change to perennial forages or restored wetlands, and through runoff control from livestock yards or agricultural fields (Khakbazan et al. 2013; Yang et al. 2014). Adoption of these BMPs is often subsidized to acknowledge the opportunity cost to farmers of changing business-as-usual practices or removing land from production (Boxall et al. 2008; Bryan and Kandulu 2011).

In Canada the subsidization of agricultural BMPs is administered as part of the federalprovincial/territorial Growing Forward 2 policy framework. BMP subsidy programs in Canada primarily use a uniform cost-share payment structure where all farmers are eligible to receive the same cost-share subsidy to adopt a certain BMP, regardless of how much it will cost the 
individual farmer to implement the BMP or the level of environmental benefit the BMP will provide on the individual farmer's land (Boxall et al. 2008). However, uniform subsidies are often considered to be sub-optimal, inefficient policy instruments to maximize the level of environmental benefits provided under fixed agri-environmental program budgets (Boxall et al. 2008).

Heterogeneity in BMP implementation costs and the provision of environmental benefits due to differing producer and landscape characteristics within a policy area creates the opportunity for efficiency/effectiveness gains by using spatial and economic targeting to administer BMP subsidies (Baker 2012). Many authors have recognized that, under conditions of producer and landscape heterogeneity, it is socially optimal to use targeted policy instruments to address agrienvironmental externalities if environmental improvements are dependent on area-specific characteristics, as is the case for nutrient runoff reduction from agricultural lands (Lankoski and Ollikainen 2003; Burkart and Jha 2012; Hansen and Hansen 2014). Numerous studies have been conducted to test the theory that agri-environmental payment programs can be delivered more efficiently or cost effectively by employing spatial and economic targeting practices to determine the most suitable areas for policy intervention (Van der Horst 2007; Lankoski and Ollikainen 2003; Khana et al. 2003; Boxall et al. 2008). This analysis adds to above-mentioned body of literature using a case study of water retention pond BMPs to reduce phosphorus runoff from agricultural fields in the La Salle sub-watershed of Manitoba. This study compared targeted water retention pond subsidies to the current uniform subsidies to determine the relative performance of each in reducing phosphorus outflows from the La Salle sub-watershed. 


\subsection{Economic Targeting of Agricultural Beneficial Management Practices to Address Phosphorus Runoff in Manitoba}

\subsection{Introduction}

Phosphorus runoff from organic and synthetic fertilizers applied to agricultural fields is a concerning environmental impact of intensive agricultural production (Tilman et al. 2002). Phosphorus runoff from agricultural fields is a form of non-point nutrient pollution. Phosphorus pollution of surface water bodies can lead to large algae blooms that result in anoxic conditions when the algae begin to decay, damaging other species within the aquatic ecosystem in a process known as eutrophication (Tilman et al. 2002). Nutrient pollution from agricultural fields entering surface water bodies has been identified by previous authors as a significant negative externality associated with agricultural production (Pretty 2003; Lankoski and Ollikainen 2003).

In many countries, governments have chosen to address negative externalities associated with agricultural production, including nutrient pollution, through subsidization (Pretty 2003; Lankoski and Ollikainen 2003). Governments offer subsidies to producers to deter the use of production practices that create external costs or to encourage the use of environmentally beneficial management practices (BMPs) that conserve or restore ecological goods and services within agricultural landscapes (AAFC 2012).

In Canada the adoption of agricultural BMPs is subsidized through a joint agreement between the federal and provincial/territorial governments called Growing Forward 2. Growing Forward 2 is a five-year agricultural policy framework under which the federal and provincial/territorial governments invest in cost-share subsidies to promote the adoption of strategic BMPs within each province (Province of Manitoba 2015b). The suite of subsidized BMPs offered under Growing Forward 2 includes nutrient management BMPs that reduce the amount of nutrient pollution from agricultural sources entering surface waterbodies (AAFC 2012). BMPs are currently administered under a uniform subsidy structure where each producer is offered the same cost-share subsidy for each BMP on a first-come, first-serve basis until the budget has been spent. This type of subsidy allocation system, based on policy objectives of ensuring equity and maximizing participation, has been shown to be inefficient in terms of minimizing costs and maximizing environmental benefits provided by agri-environmental policies (Boxall et al. 2008). 
Due to the heterogeneity of agricultural landscapes, the marginal cost of implementing a BMP will vary between different parcels of land as will the marginal environmental benefit provided by applying the BMP. Therefore, policy efficiency may be improved by using differentiated or targeted policy tools. Lankoski and Ollikainen (2003) recognized that under conditions of heterogeneous land quality, it is socially optimal to use differentiated policy instruments to address agricultural externalities if the level of environmental improvement is dependent on specific land characteristics, as is the case for nutrient management BMPs. These differentiated policy instruments are therefore the first-best or most efficient policy solutions (Lankoski and Ollikainen 2003). Khana et al. (2003) also recognized differentiated or targeted policy instruments as the most efficient tools to increase the production of public environmental benefits on private agricultural lands through subsidization. However, because differentiated policy tools are data-intensive and more complicated to administer, policy makers often turn to second-best solutions such as uniform policy instruments (Lankoski and Ollikainen 2003; Khana et al. 2003).

The purpose of this research was to determine the relative performance of targeted nutrient management BMP subsidies in Manitoba compared to the current uniform subsidy structure. This research was conducted as part of the Red-Assiniboine water quality project undertaken by Agriculture and Agri-Food Canada (AAFC) in Manitoba. The Red-Assiniboine water quality project focused on determining the potential for subsidized nutrient management BMPs to reduce the amount of nutrient runoff from agricultural fields entering the Red and Assiniboine Rivers as they flow through Manitoba before draining into Lake Winnipeg. This study focused specifically on using water retention pond BMPs to reduce phosphorus runoff from agricultural fields in the La Salle sub-watershed, part of the Red River drainage basin. Water retention ponds are created within or adjacent to agricultural fields to collect and hold field runoff to facilitate the uptake of excess phosphorus by aquatic plants and sediments before the runoff water is released into nearby waterways.

AAFC researchers mapped potential water retention pond sites within the La Salle sub-watershed and used the Canadian Soil and Water Assessment Tool (CanSWAT) to determine the phosphorus reduction potential of each pond site. My research modelled the pond implementation pattern and resulting phosphorus reduction in the La Salle sub-watershed over 
the time period 2000 to 2011 (hereafter referred to as the "study period”) using three different targeting strategies to allocate BMP subsidies. The relative performance of each targeting strategy was evaluated in terms of the quantity of phosphorus removed under the limited BMP subsidy budget of Growing Forward 2 as it is applied in Manitoba. The targeting strategies used in this research were cost targeting, benefit targeting, and benefit-cost targeting. For the purpose of this analysis it was assumed that the outcome of the cost targeting strategy would closely resemble the outcome of the current uniform allocation strategy, therefore cost targeting was used as a proxy for the uniform allocation strategy.

By comparing the phosphorus reduction outcomes of each targeting strategy under the limited BMP subsidy budget, the most cost effective targeting strategy was determined. The cost effective targeting strategy was compared to the current uniform allocation strategy to reveal the potential efficiency gains associated with targeting the distribution of water retention pond subsidies in the La Salle sub-watershed over the study period. The best targeting strategy to maximize land enrollment or farmer participation in the BMP program was also determined. The optimal level of expenditure on water retention pond subsidies within the La Salle subwatershed was calculated to evaluate whether the existing subsidy budget resulted in overspending or underspending on water retention ponds during the study period. Lastly, common landscape and land use characteristics were identified among ponds with a high benefitcost ratio in order to facilitate faster, less resource-intensive targeting of water retention pond subsidies in similar watersheds.

\subsection{Methodology}

\subsubsection{Budget Calculation}

As mentioned above, this research was conducted in the La Salle sub-watershed, part of the Red River drainage basin. The La Salle sub-watershed is part of the larger La Salle River Watershed, which is one of three watersheds included in the La Salle Redboine Conservation District (CD) (Province of Manitoba 2014). Program funding in the La Salle Redboine CD is divided between the La Salle River Watershed, the Boyne-Norquay Watershed, and the Assiniboine-Cypress Watershed (Province of Manitoba 2014). Within the La Salle River Watershed, program funding is allocated between four program areas: surface water management, source water protection, riparian and wetland protection, and extension (Province of Manitoba 2014). Out of these four 
program areas surface water management is allocated the largest share (Province of Manitoba 2014). Water retention ponds are considered part of the surface water management program.

To develop a baseline budget in the analysis it was assumed that all water retention pond BMP projects within the La Salle sub-watershed were implemented through the Growing AssuranceEcological Goods and Services program of the Growing Forward 2 policy framework as it is applied in Manitoba. This program provides funding for Manitoba conservation districts (CDs) to assist farmers in implementing BMP projects to conserve or enhance ecological goods and services flowing from their land (Province of Manitoba 2015). Therefore, within the La Salle sub-watershed, all water retention ponds were assumed to be implemented as a partnership between an individual farmer and the La Salle Redboine CD with project funding provided by the conservation district.

All budget figures for the La Salle Redboine CD were taken from past publications of Conservation Districts of Manitoba Annual Report, published by the Water Stewardship Division of the Government of Manitoba for every fiscal year between 2004/5 and 2014/15 (Province of Manitoba 2015g). Since the earliest Conservation Districts of Manitoba Annual Report was published for the 2004/5 fiscal year, the average annual surface water management program expenditure in the La Salle Redboine CD between 2004 and 2014 was calculated and used as an estimate of the annual surface water management program expenditure in the $\mathrm{CD}$ for the years 2000, 2001, 2002, and 2003 (see Table A.1 in Appendix A). Surface water management program expenditures for the La Salle River Watershed specifically were only available for the years 2011, 2012, and 2013. During these three years, an average of 34 percent of the total surface water management program expenditures in the La Salle Redboine CD were spent in the La Salle River Watershed (Province of Manitoba 2015g). Therefore, I assumed that for the years 2000 to 2010 inclusive, 34 percent of the annual surface water management program expenditures in the La Salle Redboine CD were spent in the La Salle River Watershed (see Table A.1 in Appendix A).

I further assumed that surface water management program expenditures within the La Salle River Watershed were spent only on water retention pond BMP projects in the La Salle subwatershed. This assumption was made to simplify budget calculations even though the La Salle sub-watershed is only one of multiple sub-watersheds in the La Salle River Watershed and water 
retention ponds are only one of a host of surface water management BMPs offered in Manitoba. The estimated program expenditure on surface water management in the La Salle River Watershed for each year in the study period is hereafter referred to as the realized budget for water retention pond BMP subsidies in the La Salle sub-watershed (Table 3.1). To determine the total budget allocated to water retention pond subsidies in the La Salle sub-watershed over the 12-year study period I summed the annual realized budget figures. The calculated total budget was assumed to be available in full to fund water retention pond BMP projects in the La Salle sub-watershed in year 2000. Therefore, I assumed all water retention ponds selected according to a given targeting strategy were implemented in 2000.

To conduct sensitivity analysis on the estimated water retention pond BMP subsidy budget I compared the pond implementation pattern and total phosphorus (TP) reduction outcome that would have occurred during the study period under the realized budget to the outcomes that would have resulted from increasing the budget by 25, 50, and 100 percent, respectively, during the same period. The annual realized budget and increased budgets assumed to be dedicated to water retention pond BMP subsidies in the La Salle sub-watershed over the study period are presented in Table 3.1. 
Table 3.1: Surface water management program expenditures for the La Salle River Watershed within the La Salle Redboine Conservation District.

\begin{tabular}{|c|c|c|c|c|c|}
\hline \multicolumn{6}{|c|}{ Surface Water Management Program Expenditures } \\
\hline \multirow[t]{2}{*}{ Year } & $\begin{array}{c}\text { La Salle } \\
\text { Redboine CD }\end{array}$ & \multicolumn{4}{|c|}{ La Salle River Watershed Budget (\$) } \\
\hline & & $\begin{array}{c}\text { Realized } \\
\text { Budget }\end{array}$ & $25 \%$ Increase & $50 \%$ Increase & $100 \%$ Increase \\
\hline 2000 & 48,080 & 16,347 & 20,434 & 24,521 & 32,694 \\
\hline 2001 & 48,080 & 16,347 & 20,434 & 24,521 & 32,694 \\
\hline 2002 & 48,080 & 16,347 & 20,434 & 24,521 & 32,694 \\
\hline 2003 & 48,080 & 16,347 & 20,434 & 24,521 & 32,694 \\
\hline 2004 & 84,420 & 28,702 & 35,878 & 43,054 & 57,405 \\
\hline 2005 & 35,346 & 12,017 & 15,022 & 18,026 & 24,035 \\
\hline 2006 & 27,118 & 9,220 & 11,525 & 13,830 & 18,440 \\
\hline 2007 & 22,083 & 7,508 & 9,385 & 11,262 & 15,016 \\
\hline 2008 & 21,642 & 7,358 & 9,197 & 11,037 & 14,716 \\
\hline 2009 & 33,591 & 11,420 & 14,276 & 17,131 & 22,841 \\
\hline 2010 & 18,203 & 6,189 & 7,736 & 9,283 & 12,378 \\
\hline 2011 & 29,844 & 9,163 & 11,453 & 13,744 & 18,326 \\
\hline Total & 464,569 & 156,969 & 196,211 & 235,454 & 313,938 \\
\hline
\end{tabular}

(Province of Manitoba 2015g)

\subsubsection{Cost Calculation}

To evaluate the true cost of implementing a water retention pond in the La Salle sub-watershed both opportunity cost and construction cost were estimated. Opportunity cost is the forgone revenue that would have been realized by using the resource in its next best use. In this analysis I assumed that the opportunity cost of creating a water retention pond was the forgone revenue that would have been earned by keeping the land in agricultural production. Opportunity cost for each pond site was calculated for every year during the study period using the following formula:

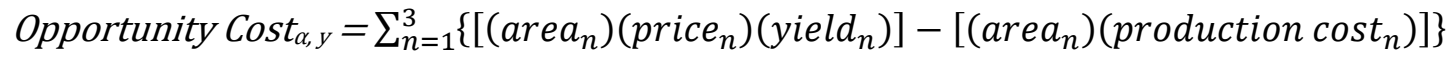

Where $\alpha$ identifies the retention pond and ranges from 1 to 101 and $y$ denotes the year which ranges from 2000 to 2011. The summation symbol indicates that the calculation includes between one and three crops ( $n=1,2$, or 3 ) in a given year which are summed to find the total opportunity cost of retention pond $\alpha$ in year $y$. This was necessary to reflect that a single retention pond flooded a portion of up to three different fields planted to three different crops in 
a single growing season. In order to calculate the opportunity cost of retention pond $\alpha$ in year $y$ data was needed on the area of crop $n$ flooded by retention pond $\alpha$, the market price of crop $n$ in year $y$, the yield of crop $n$ in year $y$, and the production cost of crop $n$ in year $y$. The data used in the opportunity cost calculations are discussed further in the following sections.

The construction cost to build a water retention pond at each of the 101 potential pond sites was calculated using a cost calculator developed by the La Salle Redboine CD. After determining the height and length of the berm needed to create a water retention pond at each potential site, the AAFC research team used the cost calculator to estimate a construction cost for building a water retention pond at each site. Construction cost and opportunity cost were calculated individually and then added to determine the total cost of implementing each of the water retention ponds.

\section{$\underline{\text { Area Calculation }}$}

The pond area used to calculate opportunity cost included only the economically significant area flooded by a pond. Economically significant area was assumed to be the portion of the flooded area dedicated to either annual cropland or pasture, the agricultural land uses present in the La Salle sub-watershed that provide revenue to farmers. I calculated the economically significant area of each potential pond site using a geographic information system (GIS) database created by AAFC in Manitoba that included the dimensions of the area flooded by each pond as well as the underlying land use(s) of the flooded area. The methodology used by AAFC researchers to determine the land use of each quarter section in the La Salle sub-watershed is provided in Appendix B. Quarter sections identified as annual cropland were further categorized according to the dominant cropping system grown on that quarter. A representative crop and crop rotation schedule were assigned to each cropping system (Table 3.2) (Vanrobaeys et al. 2013). I calculated the number of hectares of each potential pond site devoted to a particular cropping system to estimate the opportunity cost for each potential pond as forgone crop-specific revenue. 
Table 3.2: Cropping system, representative crop, and simplified four-year crop rotation in the La Salle sub-watershed.

\begin{tabular}{|c|c|c|}
\hline Cropping System & Representative Crop & Simplified Rotation \\
\hline Oilseed-Spring Cereal & Canola, spring wheat & $\begin{array}{l}\text { Spring wheat- canola- spring } \\
\text { wheat- canola }\end{array}$ \\
\hline Fall Cereal & Winter wheat & $\begin{array}{l}\text { Canola- spring wheat- canola- } \\
\text { winter wheat }\end{array}$ \\
\hline Exposed Pulse & White pea beans & $\begin{array}{l}\text { Spring wheat- canola- spring } \\
\text { wheat- white pea beans }\end{array}$ \\
\hline Pulse Non-Row & Soybeans & $\begin{array}{l}\text { Spring wheat- canola- spring } \\
\text { wheat- soybeans }\end{array}$ \\
\hline Irrigated Potatoes & Potatoes & $\begin{array}{l}\text { Spring wheat- canola- spring } \\
\text { wheat- potatoes }\end{array}$ \\
\hline Perennial Forages & Alfalfa & $\begin{array}{l}\text { Alfalfa- alfalfa- alfalfa- spring } \\
\text { wheat }\end{array}$ \\
\hline
\end{tabular}

(Vanrobaeys et al. 2013)

\section{Yield Calculation}

The majority of yield data were taken from annual Yield Manitoba publications, which have been jointly produced by the Manitoba Agricultural Services Corporation (MASC) and the Manitoba Co-operator since 2000 (MASC and Manitoba Co-operator 2015). Yield data reported in Yield Manitoba are broken down by geographical "risk areas" with a total of 16 risk areas covering the province of Manitoba. The La Salle sub-watershed is contained within risk areas 10, 11, and 12, therefore, the average yield of crop $n$ in the La Salle sub-watershed in year $y$ was calculated as:

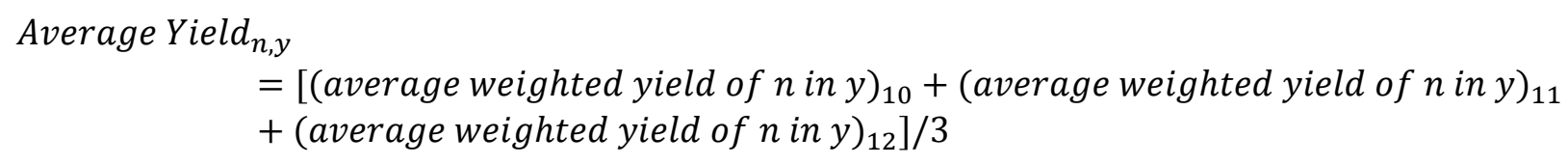

Where $n$ denotes the crop type (e.g. canola, spring wheat, etc.) and $y$ denotes the year. The subscripts 10,11, and 12 denote the risk area. The average yield for crop $n$ in year $y$ within the La Salle sub-watershed was calculated by summing the average weighted yield of crop $n$ in year $y$ for each risk area and then taking the average of this summation. This calculation is based on the assumption that risk areas 10, 11, and 12 each cover an equal proportion of annual cropland in the La Salle sub-watershed. Average weighted yield, as calculated for each risk area in Yield Manitoba, is the weighted average yield for all varieties of a single crop that are grown on more than 500 acres by more than two producers in that risk area (MASC and Manitoba Co-operator 2015). There were no risk-area-specific yield data given for potatoes or alfalfa in Yield 
Manitoba publications so province-wide average annual yield figures were used for these crops (Province of Manitoba 2015e).

\section{Yield Discounting}

Locating water retention ponds in natural depressions allows for not only lower construction costs, but also lower opportunity costs. The 101 potential pond sites identified are natural depressions in the landscape and therefore are the most likely areas to flood or hold excess moisture in years of average or greater-than-average precipitation, which negatively affects crop yield. In the analysis I assumed that nutrient availability was not a limiting factor in obtaining optimal yields within the La Salle sub-watershed since excess nutrient runoff was the reason for BMP implementation. I also assumed that since the identified potential pond sites are natural depressions in the landscape they are unlikely to be negatively affected by lower-than-average annual precipitation. Therefore, excess precipitation was considered the only constraint to obtaining optimal yields.

Optimal water requirement figures (Khakbazan et al. 2011; Province of Manitoba 2015d; Efetha 2011; FAO 2015) were used in conjunction with annual precipitation data (Government of Canada 2015) to determine if the yields of the crops grown on potential pond sites should be discounted due to excess moisture in any year during the study period. The optimal water requirement of a crop, also known as crop water demand, is the amount of water a crop would use in order to achieve its maximum yield if access to water was unlimited (Table 3.3) (Province of Manitoba 2015d). 
Table 3.3: Annual optimal water requirement by crop.

\begin{tabular}{lll} 
& \multicolumn{1}{c}{ Crop Type } & Annual Optimal Water Requirement (mm/year) \\
\hline Canola & $350^{1}$ \\
\hline Spring Wheat & $275-325^{1}$ \\
\hline Winter Wheat & $400-430^{2}$ \\
\hline White Pea Beans & $375^{3}$ \\
\hline Soybeans & $450-700^{4}$ \\
\hline Potatoes & $300-800^{1}$ \\
\hline Alfalfa & $500-650^{1 *}$ \\
\hline
\end{tabular}

${ }^{1}$ Khakbazan et al. 2011; ${ }^{2}$ Efetha 2011; ${ }^{3}$ Province of Manitoba 2015d; ${ }^{4}$ FAO 2015

*Assuming a second cut of alfalfa is desired within a single growing season

To account for the negative impact of excess moisture on crop yield in years that annual precipitation was greater than the optimal water requirement for crop $n$, the average yield of crop $n$ was discounted. Figure 3.1 depicts annual precipitation in the La Salle sub-watershed compared to the annual optimal water requirement of each representative crop. If precipitation in year $i\left(P_{i}\right)$ was greater than the annual optimal water requirement of crop $n\left(W_{n}\right)$ then the average yield of crop $n\left(Y_{n}\right)$ was discounted in year $i$. This equation can be shortened as follows: if $P_{i}>W_{n}$ then $Y_{n}$ was discounted by the determined yield discount rate, $R$. The yield discount rate was calculated using the equation: $R=\left(P_{i}-W_{n}\right) / P_{i}$. The discount rate was then used to calculate the discounted yield $\left(D Y_{n}\right)$ using the equation: $D Y_{n}=Y_{n}-\left(Y_{n} * R\right)$. 


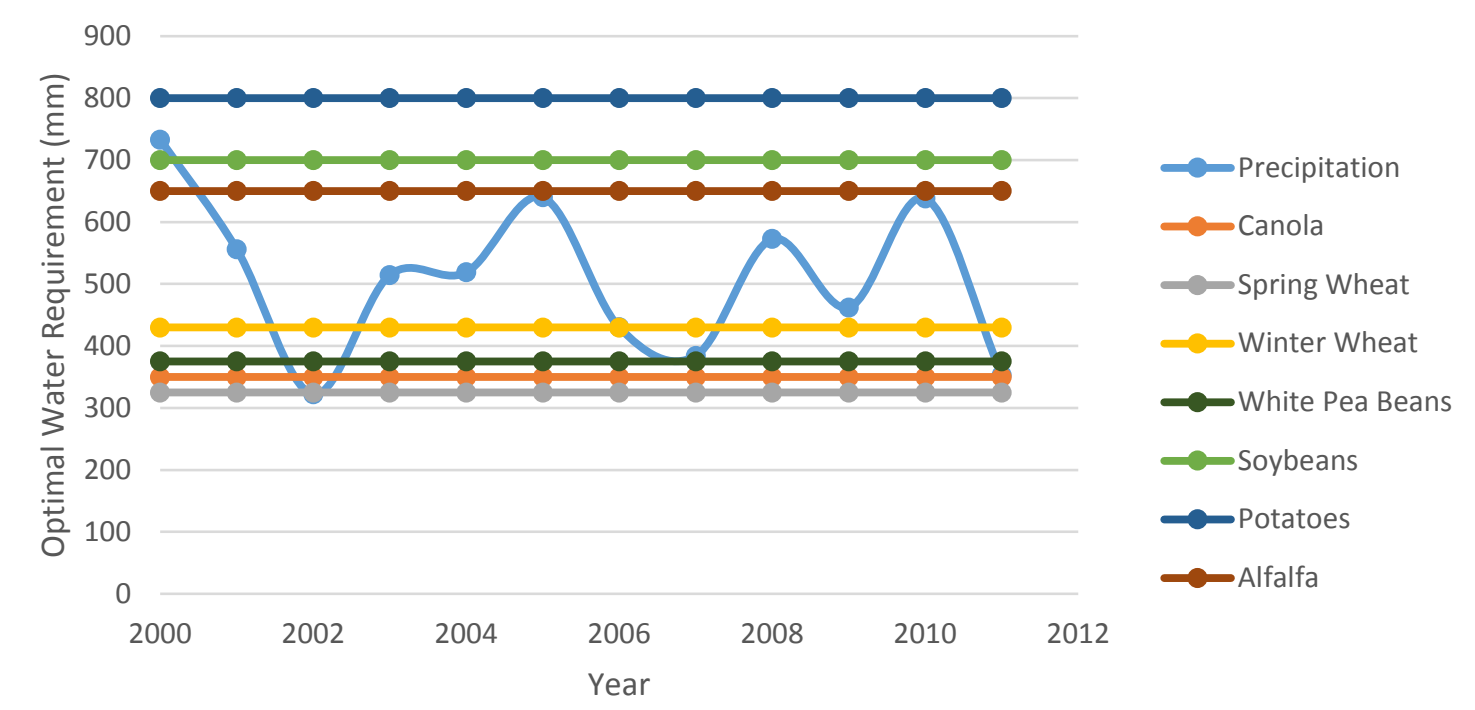

Figure 3.1: Annual precipitation in the La Salle sub-watershed during the study period compared to the annual optimal water requirement of each representative crop.

\section{Crop Price Calculation}

Average annual prices for each crop grown on potential pond sites during the study period were based on Manitoba Agriculture, Food and Rural Development's (MAFRD) Yearbook and State of Agriculture publications (Province of Manitoba 2015e). The annual prices of white pea beans used in this study were the average annual prices of all dry beans grown in Manitoba, of which white pea bean is one of several varieties. The same average annual prices were used for both spring wheat and winter wheat because the Yearbook and State of Agriculture publication only provides average annual prices for "all wheat". All crop prices used in this research represent average farm gate prices available to producers in Manitoba in a given year (Province of Manitoba 2015e).

Annual pasture rental rates were obtained from historic publications of Guidelines for Estimating Cow-Calf Production Costs in Manitoba (Province of Manitoba 2015f). The figures used for annual pasture rental rates were the historic rental rates for Prairie Farm Rehabilitation Administration (PFRA) community pastures in Manitoba based on grazing 150 cattle for 140 days per year (Province of Manitoba 2015f). Guidelines for Estimating Cow-Calf Production Costs in Manitoba publications were only available dating back to 2006. Therefore, I assumed the rental rate for PFRA community pastures remained constant from 2000 to 2006 at the 
reported 2006 rate. I also assumed that the acres/cow grazing ratio and the number of grazing days on pasture remained constant throughout the entire study period.

\section{Crop Production Cost Calculation}

The cost of production reported for each crop grown on potential pond sites during the study period was the average annual cost of producing the crop in Manitoba (Province of Manitoba 2015e). Average annual crop production costs reflect the historic operating (variable) costs of production, excluding labour. Variable costs of production include costs for seed and treatment, fertilizer, herbicide, fungicide, insecticide, fuel, machinery operating, machinery leases, crop insurance, land taxes, post-harvest drying, and interest on loans taken to cover operating costs (Province of Manitoba 2015e).

Crop production cost data for all crops except potatoes were taken from MAFRD's Yearbook and State of Agriculture publications (Province of Manitoba 2015e) while potato production cost values were taken from Khakbazan et al. (2010). Potato production cost figures represent the total operating (variable) costs, not including labour, for producing irrigated processing potatoes. The same average annual cost of production was used for both spring wheat and winter wheat because the Yearbook and State of Agriculture reported the average annual cost of production for "all wheat" only. The cost of production used for white pea beans was the average annual cost of production calculated for all dry bean varieties grown in Manitoba (Province of Manitoba 2015e). The annual cost of production for pasture land represented the operating (variable) costs of providing unimproved pasture in the year 2007 (Province of Manitoba 2015f). I assumed the cost of production for unimproved pasture remained constant every year during the study period at the 2007 level.

\subsubsection{Benefit Calculation}

The quantity of total phosphorus (TP) removed from surface runoff by each water retention pond during the study period was estimated by AAFC researchers as part of the Red-Assiniboine water quality project. The average annual TP load flowing from each of the 16 sub-basins within the La Salle sub-watershed over the time period 1993 to 2013 was estimated using the Canadian Soil and Water Assessment Tool (CanSWAT). This average annual TP load was assumed to be the baseline annual TP load flowing from each sub-basin. The CanSWAT model was then used to 
estimate the average annual TP load flowing from each of the 16 sub-basins during the study period assuming all 101 potential water retention ponds were implemented. The reduction in annual TP load attributed to the implementation of all water retention ponds was then calculated for each sub-basin as the difference between the baseline average annual TP outflow and the average annual TP outflow after pond implementation. This sub-basin specific annual TP reduction was broken down further to estimate the quantity of annual TP reduction contributed by each water retention pond in a sub-basin by assigning a weight to each pond based on the drainage area and volume of the pond. The pond weight was then multiplied by the sub-basin level annual TP reduction to determine the annual TP reduction provided by each pond, which was then multiplied by 12 to estimate the total TP reduction achieved by that pond over the 12year study period.

In order to represent the costs and benefits of pond implementation in comparable terms, a monetary value was assigned to the environmental benefit provided by each pond. For the purpose of this analysis I assumed that TP removal was the only environmental benefit provided by water retention ponds. I assumed that the value of removing TP from field runoff through a water retention pond was equal to the cost of removing TP through a water treatment facility at the watershed outlet. Sohngen et al. (2015) estimated the cost of TP removal to be $\$ 57$ per kilogram in their study of TP outflows from five American watersheds in Ohio and Michigan that drain into Lake Erie. This value can be viewed as the replacement cost of water retention ponds assuming that the ponds perform the same nutrient removal service as a water treatment facility. I assumed a constant marginal benefit of TP removal of $\$ 57$ per kilogram regardless of the total quantity of TP removed since a demand curve for TP reduction in the La Salle subwatershed has not been estimated.

\subsubsection{Net Present Value Calculation}

The opportunity cost and TP reduction benefit of each pond were calculated for each year of the study period. To facilitate comparison of costs and benefits between ponds, the net present value (NPV) of the total opportunity cost and the total TP reduction benefit of each pond were estimated in year 2000 dollars. Calculating the NPV of costs and benefits associated with BMP implementation was suggested by Baker (2012) who noted that discounted future costs and benefits of BMPs must be considered in order to get a true picture of the net benefits provided. 
The net present value of costs and benefits were calculated using the following formulas:

$$
N P V_{\alpha}=\sum_{i=0}^{11} \frac{o C_{i}}{(1+r)^{i}} \quad N P V_{\alpha}=\sum_{i=0}^{11} \frac{T P \text { Removal }_{i}}{(1+r)^{i}}
$$

Where $O C_{i}$ is the opportunity cost of pond $\alpha$ in year $i$ and TP Removal $i$ is the quantity of TP removed by pond $\alpha$ in year $i$, where $i$ ranges from 0 to 11 and $\alpha$ ranges from 1 to 101 . The variable $r$ represents the discount rate applied to future opportunity costs and TP removal benefits that occurred after pond implementation in year 2000.

Opportunity costs and TP removal benefits resulting from water retention pond implementation were discounted to account for society's positive time preference for spending in the current time period rather than the future time period and to account for sizable risk perceptions associated with future monetary gains in agriculture. Perceptions of future risk are especially relevant in the agriculture industry where weather unpredictability adds a large element of risk to expected yields and therefore expected returns. NPV calculations were completed using four discount rates (zero, three, six, and nine percent) to account for the distribution of society's positive time preference and future risk perception. However, the results highlighted in this report use a social discount rate of six percent. A discount rate representing a societal positive time preference was used instead of a private discount rate since this research focused on the ability of publically subsidized water retention ponds to provide the public ecological service of phosphorus reduction. In similar studies that calculated the present value of future costs and benefits resulting from agri-environmental policy implementation Costanza et al. (1989) used multiple discount rates between three and eight percent, Hansen et al. (2015) worked with a four percent discount rate, Walpole and Sinden (1997) and Bourgeois et al. (2014) used discount rates of five percent, while Roberts and Leitch (1997) and Khakbazan et al. (2013) applied discount rates of six percent. Construction cost of a pond was assumed to be a one-time cost incurred in year 2000 and therefore was not discounted.

\subsubsection{Targeting Strategies}

Three targeting strategies were modelled and compared in order to test the hypothesis that water retention pond BMP subsidies can be allocated more efficiently or cost-effectively if a targeting strategy is used rather than the current uniform allocation strategy. Under a cost targeting strategy those parcels of land that can provide the desired environmental benefit at the lowest 
cost are selected for subsidization first (Wu et al. 2001). To implement cost targeting of water retention pond subsidies in the La Salle sub-watershed I ranked the 101 potential pond sites from lowest to highest total cost of implementation. Ponds were selected for subsidization beginning with the lowest cost ponds and moving to subsequently higher cost ponds until the total budget allocation for water retention pond subsidies during the study period was reached.

Under a benefit targeting strategy those parcels of land that can provide the greatest environmental benefit are subsidized first regardless of the cost (Wu et al. 2001). Wu et al. (2001) differentiated between benefit targeting, in which there is no budget constraint considered, and benefit-maximizing targeting which maximizes total environmental benefits under a fixed budget. In my research I use the term "benefit targeting” to label what Wu et al. (2001) would refer to as benefit-maximizing targeting since there is a fixed budget under Growing Forward 2 with which to subsidize BMP implementation in Manitoba. To implement benefit targeting of water retention pond subsidies in the La Salle sub-watershed I ranked the potential pond sites from highest to lowest TP reduction potential and then selected ponds for subsidization beginning with the highest TP-reducing ponds and moving to subsequently lower TP-reducing ponds until the total budget allocation was reached.

Lastly, a benefit-cost targeting strategy prioritizes the land with the highest benefit-cost ratio in terms of providing the greatest level of environmental benefit per dollar spent (Wu et al. 2001). To implement benefit-cost targeting of water retention pond subsidies in the La Salle subwatershed I ranked the potential pond sites from highest to lowest benefit-cost ratio and then selected ponds for subsidization beginning with those having the highest benefit-cost ratio and moving to subsequently lower benefit-cost ratios until the total budget allocation was reached.

I assumed the outcome of the cost targeting strategy was equivalent to the outcome of the current uniform allocation strategy. The uniform allocation strategy distributes BMP subsidies on a first-come, first-serve basis where each farmer is eligible for the same subsidy regardless of the suitability of his or her land to provide the desired environmental benefit with the BMP in place. The outcome of the uniform allocation strategy would closely resemble the outcome of the cost targeting strategy because the farmers most likely to apply for a BMP subsidy would be those who are able to implement the BMP at a cost equal to or less than the subsidy (i.e. those farmers with the lowest cost of BMP implementation). Since the uniform allocation strategy would lead 
to the enrollment of the lowest cost producers, I assigned cost targeting as a proxy for the current uniform allocation strategy.

The benefit-cost ratios used in benefit-cost targeting were measured as the quantity of TP reduced per dollar of total cost. Therefore, in this study benefit-cost targeting was based on cost effectiveness ratios rather than traditional monetary benefit-cost ratios since an economic valuation of the phosphorus removal services provided by water retention ponds in the La Salle sub-watershed has not been conducted. As a result, benefits were measured in biophysical units while costs were measured in monetary units when constructing benefit-cost ratios in this analysis. Benefit-cost targeting using cost effectiveness ratios was also used by Hansen et al. (2015) in their study of targeted wetland restoration due to a lack of reliable data on the economic value of restored wetlands. Individual ponds with a total cost greater than $\$ 100,000$ were excluded from all targeting strategies because they were considered too expensive given the fixed budget of the BMP subsidy program.

\subsection{Results and Discussion}

\subsubsection{Pond Implementation Patterns}

The three economic targeting strategies discussed above were applied to the La Salle subwatershed to simulate the pond implementation pattern and resulting reduction in total phosphorus (TP) outflow over the study period 2000 to 2011. The pond implementation pattern

of each targeting strategy, assuming a discount rate of six percent, is presented in Figure 3.2. Figures C.1 to C.9 in Appendix C show the pond implementation pattern of each targeting strategy using discount rates of zero, three, and nine percent. Those ponds highlighted in green are the ponds implemented under the realized budget. Those ponds highlighted in orange, purple, and red are the additional ponds implemented as the budget was increased by 25,50 , and 100 percent, respectively. The maps in Figure 3.2 show that relatively few ponds were implemented under the realized budget using benefit targeting compared to the number of ponds implemented under the realized budget using cost or benefit-cost targeting. Similar pond implementation patterns emerged when cost targeting and benefit-cost targeting were applied, but the implementation pattern under benefit targeting differed substantially. Benefit targeting resulted in the implementation of mid-sized to large ponds while the majority of ponds implemented using cost targeting or benefit-cost targeting were small to mid-sized. 

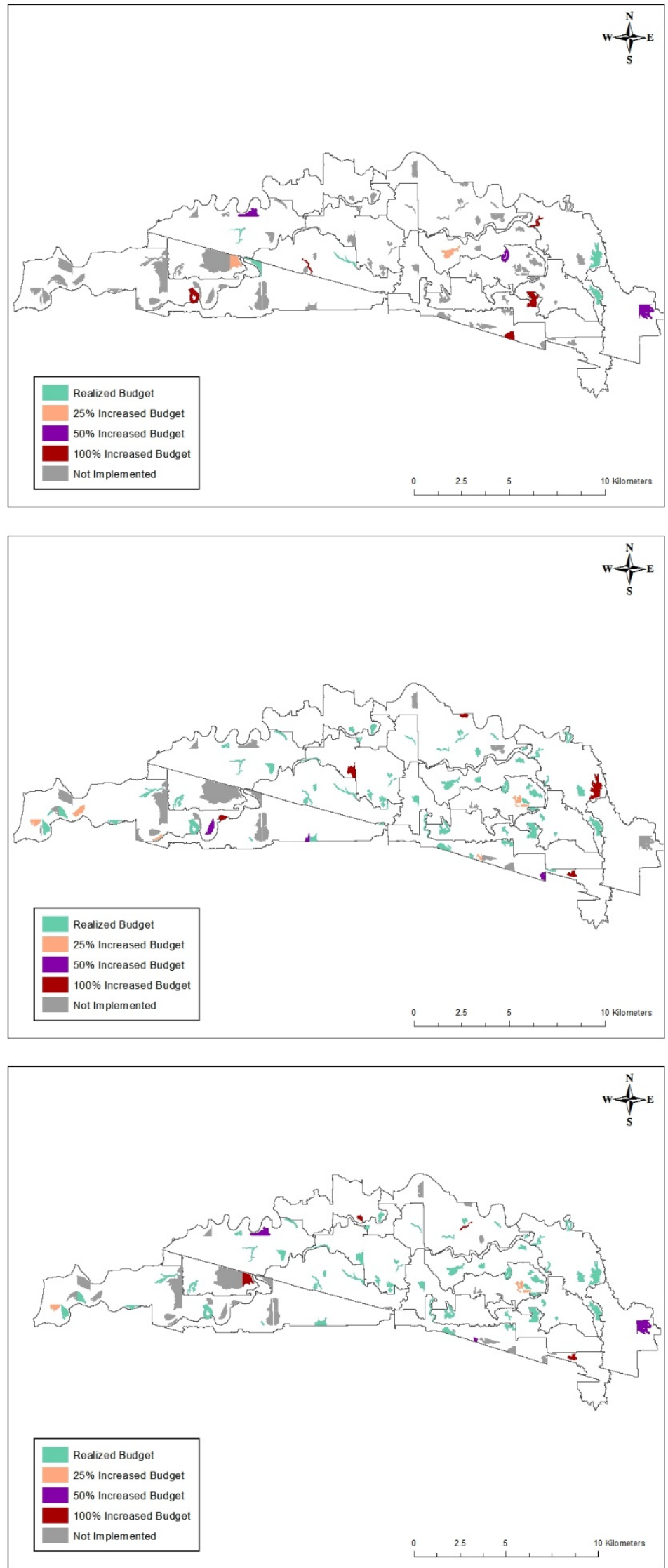

Figure 3.2: Pond implementation pattern under benefit targeting (top), cost targeting (middle), and benefit-cost targeting (bottom) using a discount rate of six percent. 


\subsubsection{Targeting Strategy Cost Effectiveness}

The pond implementation pattern under each targeting strategy was used to estimate the quantity of TP removed from surface water flowing out of the La Salle sub-watershed during the study period. A cost effective agri-environmental policy was defined by Kurkalova (2015) and Van der Horst (2006) as a policy that maximizes the level of environmental benefit provided within a fixed budget. In the present research, cost effectiveness was based on the quantity of TP reduction achieved in the La Salle sub-watershed during the study period within the fixed BMP subsidy budget provided by the La Salle Redboine Conservation District for water retention pond implementation. Benefit-cost targeting was found to be the most cost effective under the fixed BMP subsidy budget for all budget scenarios and discount rates tested, followed by cost targeting and finally benefit targeting (Figure 3.3).

Benefit-cost targeting provided the greatest quantity of TP reduction under all budget scenarios and discount rates. For example, as shown in Figure 3.3, using the 25 percent increased budget and assuming a discount rate of six percent the quantity of TP removed from the La Salle subwatershed during the study period under benefit-cost targeting was 8,015 kilograms, compared to 7,433 kilograms of TP removed under cost targeting and 3,212 kilograms removed under benefit targeting. Table D.1 in Appendix D reports the number of ponds implemented, pond area flooded, quantity of TP reduced, and resulting level of TP output from the La Salle subwatershed during the study period under all three targeting strategies analyzed using each budget scenario and discount rate. 


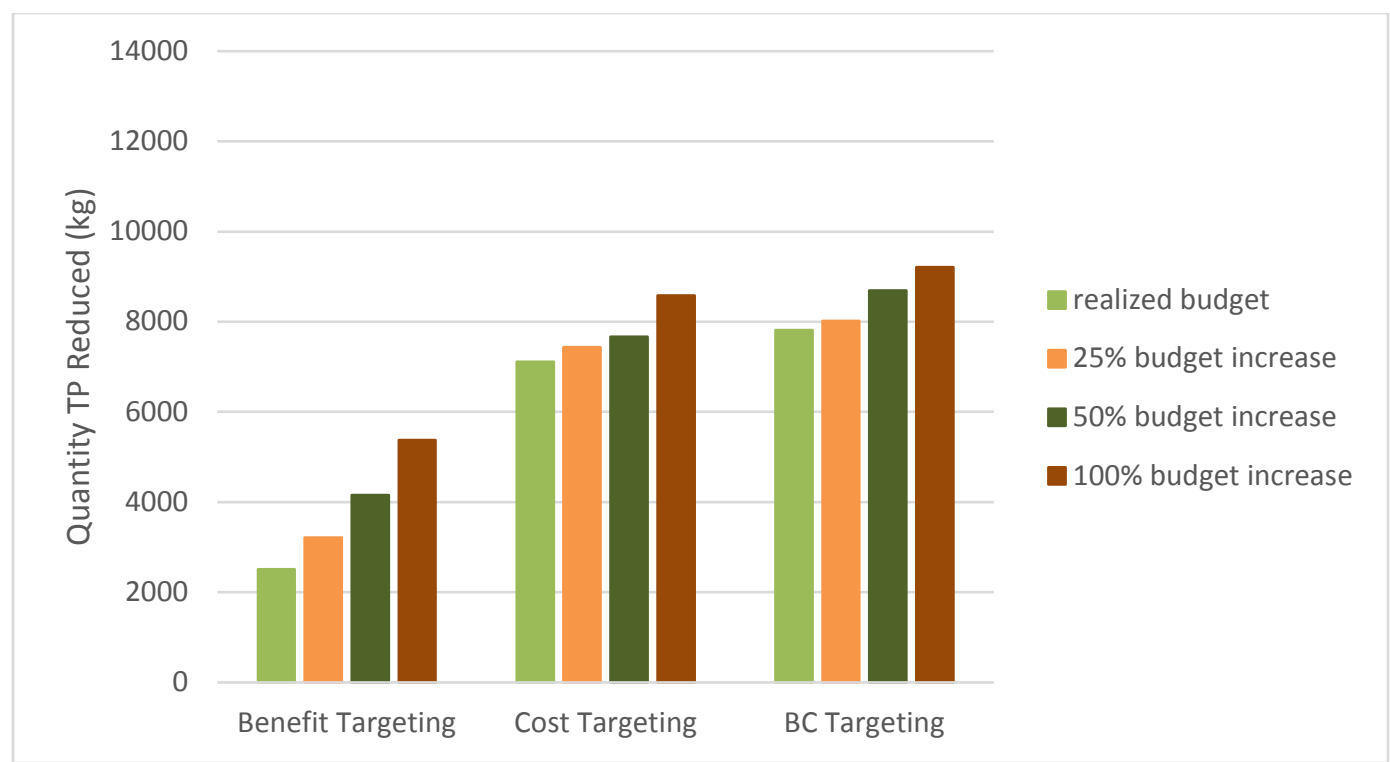

Figure 3.3: Quantity of TP runoff reduced in the La Salle sub-watershed during the study period under different targeting strategies and budget constraints using a discount rate of six percent. Figures E.1, E.2, and E.3 in Appendix E provide the same comparison at discount rates of zero, three, and nine percent.

Benefit-cost targeting, as the most cost effective targeting strategy, provided the lowest average cost per kilogram of TP removed for all budget scenarios and discount rates tested. Using a discount rate of six percent and the 100 percent increased budget, the average cost of TP removal from the La Salle sub-watershed during the study period was \$33 per kilogram under benefit-cost targeting, \$35 per kilogram under cost targeting, and \$57 per kilogram under benefit targeting (Figure 3.4). The average cost of TP removal increased within each targeting strategy as the budget increased. For example, assuming cost targeting was used with a discount rate of six percent, the average cost of TP removal increased from \$21 per kilogram under the realized budget to \$26 per kilogram, \$30 per kilogram, and \$35 per kilogram when the budget was increased by 25, 50, and 100 percent, respectively (Figure 3.4). 


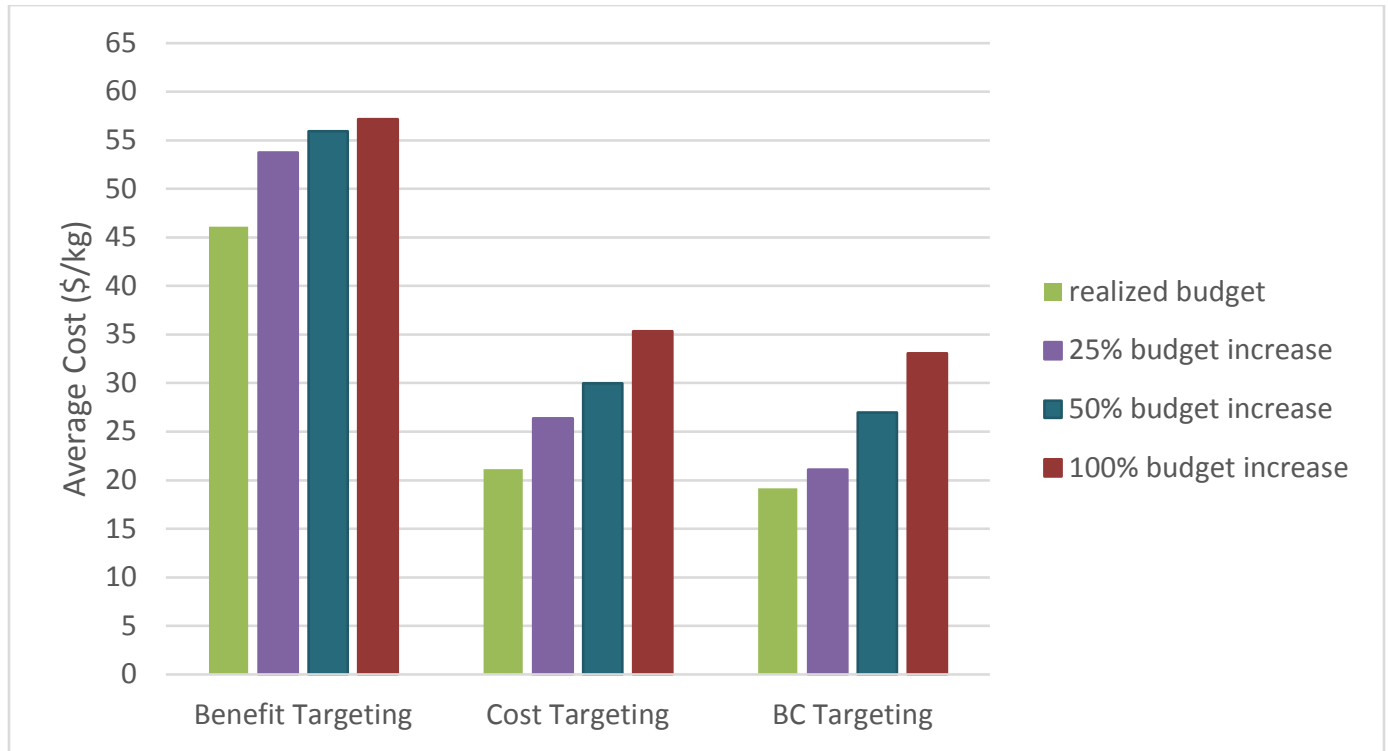

Figure 3.4: Average cost of TP removal in the La Salle sub-watershed during the study period under different targeting strategies and budget constraints using a discount rate of six percent. Figures F.1, F.2, and F.3 in Appendix F provide the same information using discount rates of zero, three, and nine percent.

Benefit-cost targeting has been recognized by many previous authors as the most efficient or cost effective targeting strategy to allocate limited agri-environmental subsidy funds. Crossman and Bryan (2009) found benefit-cost targeting to be the most efficient approach to increase natural capital stocks within the agriculturally dominated Lower Murray region of South Australia. Cook and Norman (1996) advocated for the use of benefit-cost targeting to screen applicants to the English Countryside Stewardship Scheme to ensure funding was given to those applicants whose land provided the greatest environmental benefits per pound spent on the program. Van der Horst (2007) concluded that efficiency gains were possible in Scotland's Farm Woodland Premium Scheme, which offers farmers annual payments for the conversion of farmland to woodland, by targeting areas with the highest benefit-cost ratios for farmland conversion. Hansen et al. (2015) concluded efficiency gains were possible in the U.S. Wetlands Reserve Program if benefit-cost targeting was used to select wetlands for conservation under the fixed budget. Khana et al. (2003) found that benefit-cost targeting through location-specific marginal value payments was more efficient than cost targeting through a rental cap payment system in selecting parcels of land for retirement under the American Conservation Reserve Program (CRP). Similarly, Babcock et al. (1997) identified benefit-cost targeting as the most efficient policy tool to renew CRP contracts. 


\subsubsection{Efficiency Gains from Targeting}

Babcock et al. (1997) found that the relative variability of costs and benefits, in combination with the correlation coefficient between the two, can be used to determine the magnitude of efficiency losses from using suboptimal targeting tools. These authors argued that when the economic costs and environmental benefits associated with an agri-environmental policy are negatively correlated outcomes from the three targeting strategies tend to converge, but a positive correlation between costs and benefits increases the disparity in outcomes between targeting strategies. Therefore, a positive correlation between the costs and benefits of an agrienvironmental policy increases the importance of selecting the most efficient targeting tool (Babcock et al. 1997). I found the level of environmental benefit provided by water retention ponds in the La Salle sub-watershed, interpreted as TP removal, to be positively correlated with the level of expenditure on water retention ponds, producing a correlation coefficient of 0.98 . Since the economic costs and environmental benefits of water retention ponds were highly positively correlated, the difference in TP reduction outcomes provided by each targeting strategy, as seen in Figure 3.3, fits with the expected disparity in environmental outcomes predicted by Babcock et al. (1997). This result highlights the importance of selecting the most efficient targeting strategy to allocate water retention pond subsidies in the La Salle subwatershed.

Variability of costs and benefits also plays a role in determining the relative environmental performance of different targeting strategies. Babcock et al. (1997) reported that if cost variability is greater than benefit variability, cost targeting results in the second-best environmental outcome after benefit-cost targeting, especially if benefits and costs are positively correlated. However, if cost variability is less than benefit variability benefit targeting results in the second-best environmental outcome, especially if benefits and costs are positively correlated (Babcock et al. 1997). I calculated the standard deviation of total cost for individual water retention ponds in the La Salle sub-watershed to be between $\$ 50,707$ (at a discount rate of nine percent) and $\$ 55,284$ (at a discount rate of zero). The standard deviation of the monetary TP reduction benefit provided by individual water retention ponds was between $\$ 7,871$ (at a discount rate of nine percent) and $\$ 13,879$ (at a discount rate of zero). Since cost variability was greater than benefit variability and costs and benefits were positively correlated, my finding that 
cost targeting provided the second best TP reduction outcome in the La Salle sub-watershed after benefit-cost targeting was consistent with the results presented by Babcock et al. (1997).

The efficiency loss from using a suboptimal targeting strategy can be calculated as the difference in environmental benefit provided by the suboptimal strategy and that provided by the most efficient targeting strategy (Babcock et al. 1997). I calculated the environmental benefit, measured as the quantity of TP removed from the La Salle sub-watershed during the study period, provided by the most efficient benefit-cost targeting strategy to be between 6,916 kilograms (using a discount rate of nine percent) and 10,770 kilograms (using a discount rate of zero) under the realized budget. The environmental benefits provided by the suboptimal targeting strategies under the realized budget were considerably lower: between 6,275 kilograms (using a discount rate of nine percent) and 8,267 kilograms (using a discount rate of zero) of TP removed under cost targeting and between 2,165 kilograms (using a discount rate of nine percent) and 3,817 kilograms (using a discount rate of zero) of TP removed under benefit targeting. Based on these calculations, shifting from the current uniform allocation strategy (cost targeting was used as a proxy) for water retention pond subsidies to a benefit-cost targeting strategy provided efficiency gains equal to an additional 641 kilograms (using a discount rate of nine percent) to 2,503 kilograms (using a discount rate of zero) of TP removed from the La Salle sub-watershed over the study period under the realized budget.

\subsubsection{Alternative Objectives: Maximizing Participation or Land Enrollment}

Efficiency or cost effectiveness is not always the primary objective of agri-environmental policy, sometimes the goal is to maximize farmer participation or land enrollment. Cost targeting, a proxy for the current uniform allocation strategy, resulted in the greatest number of ponds established under all budget scenarios and discount rates tested while benefit-cost targeting resulted in the greatest quantity of land taken out of production to establish water retention ponds. A policy objective to maximize farmer participation in the water retention pond BMP program would favour the less efficient cost targeting strategy to maximize the number of ponds established, resulting in a suboptimal level of TP reduction in the La Salle sub-watershed during the study period. However, a policy objective to maximize land enrollment in the BMP program would favour the most efficient (cost effective) benefit-cost targeting strategy to maximize the amount of land converted to water retention ponds. Benefit targeting resulted in the fewest 
ponds and the least amount of land taken out of production. Considering the realized budget and a discount rate of six percent, cost targeting resulted in 316 hectares flooded to create 63 water retention ponds, benefit-cost targeting flooded 343 hectares to create 58 ponds, and benefit targeting flooded 66 hectares to create 5 ponds (Figure 3.5).

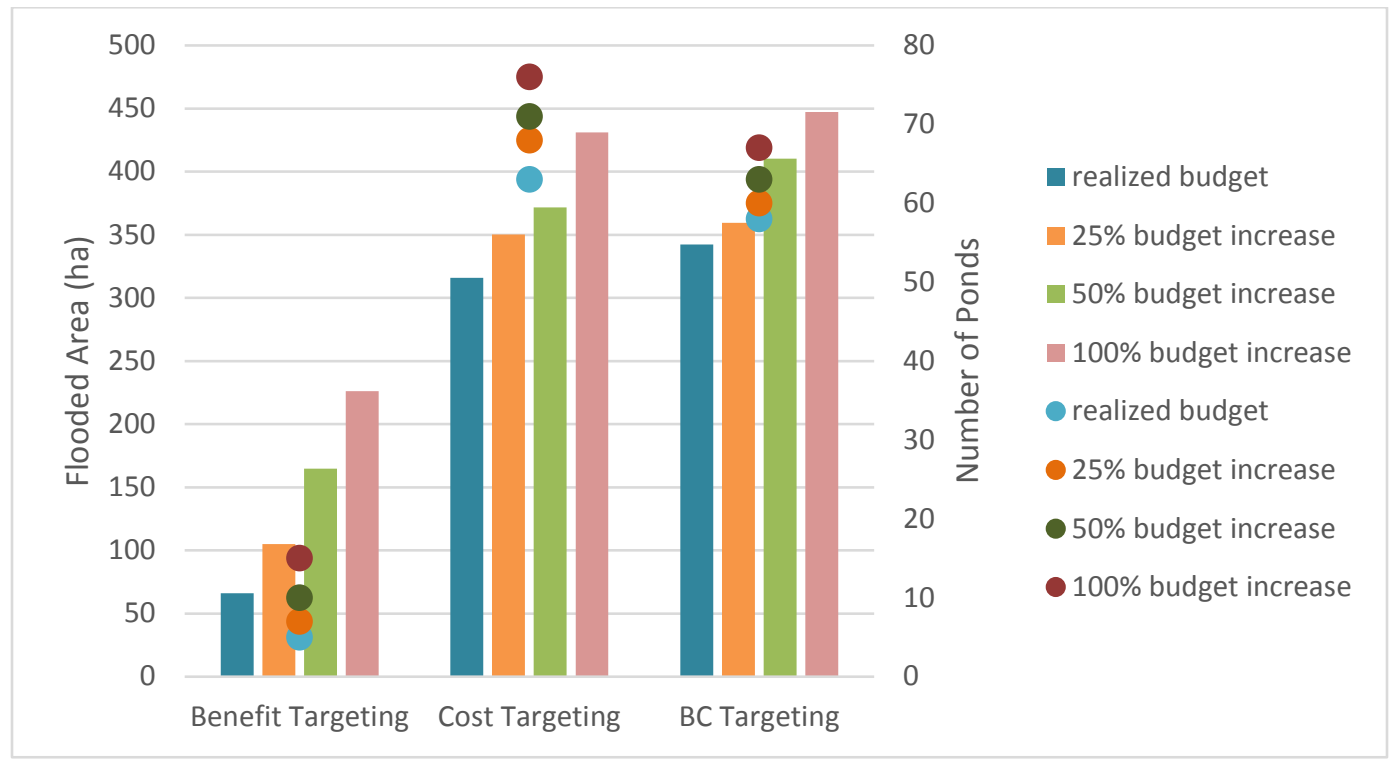

Figure 3.5: Flooded area (bar graph) compared to number of ponds (scatter plot) in the La Salle sub-watershed during the study period under different targeting strategies and budget constraints using a discount rate of six percent. Figures G.1, G.2, and G.3 in Appendix G provide the same comparison using discount rates of zero, three, and nine percent.

\subsubsection{Budget Sensitivity Analysis}

As was expected, increasing the budget led to increases in the pond area flooded, the number of retention ponds established, and the quantity of TP removed from the La Salle sub-watershed during the study period. However, the increases in the number of ponds implemented, hectares flooded, and kilograms of TP removed were not proportional to the corresponding budget increases. The percentage increases in the number of ponds established and the area flooded were found to be less than the corresponding budget increase when cost targeting or benefit-cost targeting were used with any discount rate. For example, using a discount rate of six percent with benefit-cost targeting, increasing the realized budget by 25, 50, and 100 percent led to a three, nine, and 16 percent increase, respectively, in the number of ponds established and a five, 20, and 31 percent increase, respectively, in the pond area flooded. However, when benefit targeting was used with any discount rate the percentage increases in the number of ponds established and the area flooded were always greater than the corresponding percentage increase 
in budget. For example, when benefit targeting was used with a six percent discount rate, increasing the realized budget by 25, 50, and 100 percent led to a 40, 100, and 200 percent increase, respectively, in the number of ponds established and a 59, 149, and 242 percent increase, respectively, in the pond area flooded.

The higher percentage increases in the number of ponds established and the area flooded resulting from predefined budget increases under benefit targeting relative to cost targeting and benefit-cost targeting can be explained by differences in the absolute number of ponds established and hectares flooded under the different targeting strategies. The number of ponds established and hectares flooded under benefit targeting were much lower than the number of ponds established and hectares flooded under cost targeting or benefit-cost targeting for each predefined budget scenario. Therefore, a small increase in the number of ponds or hectares flooded translated into a large percentage change under benefit targeting but a much smaller percentage change under the other two targeting strategies. For example, implementing an additional five ponds under cost targeting at a six percent discount rate increased the number of ponds implemented from 63 to 68 and increased the pond area flooded from 316 hectares to 350 hectares, representing an eight percent increase in the number of ponds and an 11 percent increase in the pond area flooded. Whereas implementing an additional five ponds under benefit targeting at a six percent discount rate increased the number of ponds implemented from five to ten and increased the pond area flooded from 66 hectares to 165 hectares, representing a 100 percent increase in the number of ponds established and a 149 percent increase in the pond area flooded.

Similarly, the percentage increase in the quantity of TP removed was always less than the corresponding budget increase when cost targeting or benefit-cost targeting were used with any discount rate. For example, when cost targeting was used with a six percent discount rate, increasing the realized budget by 25, 50, and 100 percent led to a five, eight, and 21 percent increase, respectively, in the quantity of TP removed. Once again benefit targeting often resulted in a greater percentage increase in the quantity of TP removed compared to the corresponding percentage increase in budget, especially at the higher discount rates of six and nine percent. For example, when benefit targeting was used with a six percent discount rate, increasing the realized 
budget by 25, 50, and 100 percent resulted in a 28, 66, and 114 percent increase, respectively, in the quantity of TP removed.

The higher percentage increases in the quantity of TP removed resulting from predefined budget increases under benefit targeting relative to cost targeting and benefit-cost targeting can be explained by the selection attributes of each targeting strategy. Benefit targeting selects ponds for implementation based on TP reduction potential alone. By definition benefit targeting ensures the ponds selected for implementation are those that can provide the greatest quantity of TP reduction. Therefore, under benefit targeting each additional pond that is implemented in response to a budget increase has a high TP reduction potential and so the percentage increase in the quantity of TP removed is often greater than the preceding percentage increase in budget. Additional ponds selected after a budget increase under cost targeting or benefit-cost targeting are chosen based on attributes other than their TP reduction potential and thus these ponds are not necessarily high TP-reducing ponds, resulting in lower percentage increases in the quantity of TP removed following a given percentage increase in budget.

Please see Table D.2 in Appendix D for a full comparison of percentage changes in the number of ponds established, the pond area flooded, and the quantity of TP removed resulting from predetermined percentage increases in the BMP subsidy budget under each targeting strategy and discount rate.

\subsubsection{Calculating the Optimal Level of Expenditure on Water Retention Ponds}

In addition to calculating the quantity of TP reduction that would have resulted under each targeting strategy using the four fixed budget scenarios, I also calculated the optimal level of expenditure on water retention ponds in the La Salle sub-watershed during the study period and the resulting level of TP reduction under each targeting strategy. The optimal level of expenditure was calculated as the point where the marginal cost and marginal benefit of the last kilogram of TP removed were equal (the point of intersection between the marginal cost and marginal benefit curves). In order to calculate the optimal level of expenditure it was necessary to consider both the costs and benefits of each pond in monetary terms. This required assigning a monetary value to the environmental benefits provided by each pond. For the purpose of this analysis, I made the strong assumption that TP removal was the only environmental benefit provided by water retention ponds. 
In order to construct a marginal benefit curve, I assumed that the marginal benefit of removing TP from field runoff by water retention ponds was equal to the replacement cost of removing TP through a water treatment facility at the watershed outlet. This replacement cost was estimated to be $\$ 57$ per kilogram of TP removed by Sohngen et al. (2015) in their study of TP outflows from five American watersheds in Ohio and Michigan that drain into Lake Erie. I assumed the marginal benefit of TP removal remained constant at \$57 per kilogram regardless of the overall quantity of TP removed. To estimate a marginal cost curve, I first modelled a total cost curve for each targeting strategy. By taking the first derivative of the total cost curve I estimated a marginal cost curve for each targeting strategy using each discount rate.

To illustrate, the marginal cost and marginal benefit curves estimated for TP removal under cost targeting with a six percent discount rate are depicted in Figure 3.6 below. The optimal level of TP reduction occurs at the point of intersection between the marginal benefit and marginal cost curves. In this example, the optimal level of expenditure on water retention ponds in the La Salle sub-watershed during the study period was calculated to be $\$ 270,313$ and the resulting level of TP reduction was 8,363 kilograms. The optimal level of expenditure was compared to the realized budget under each targeting strategy and discount rate to determine if the realized budget resulted in overspending or underspending on water retention pond subsidies in the La Salle sub-watershed during the study period.

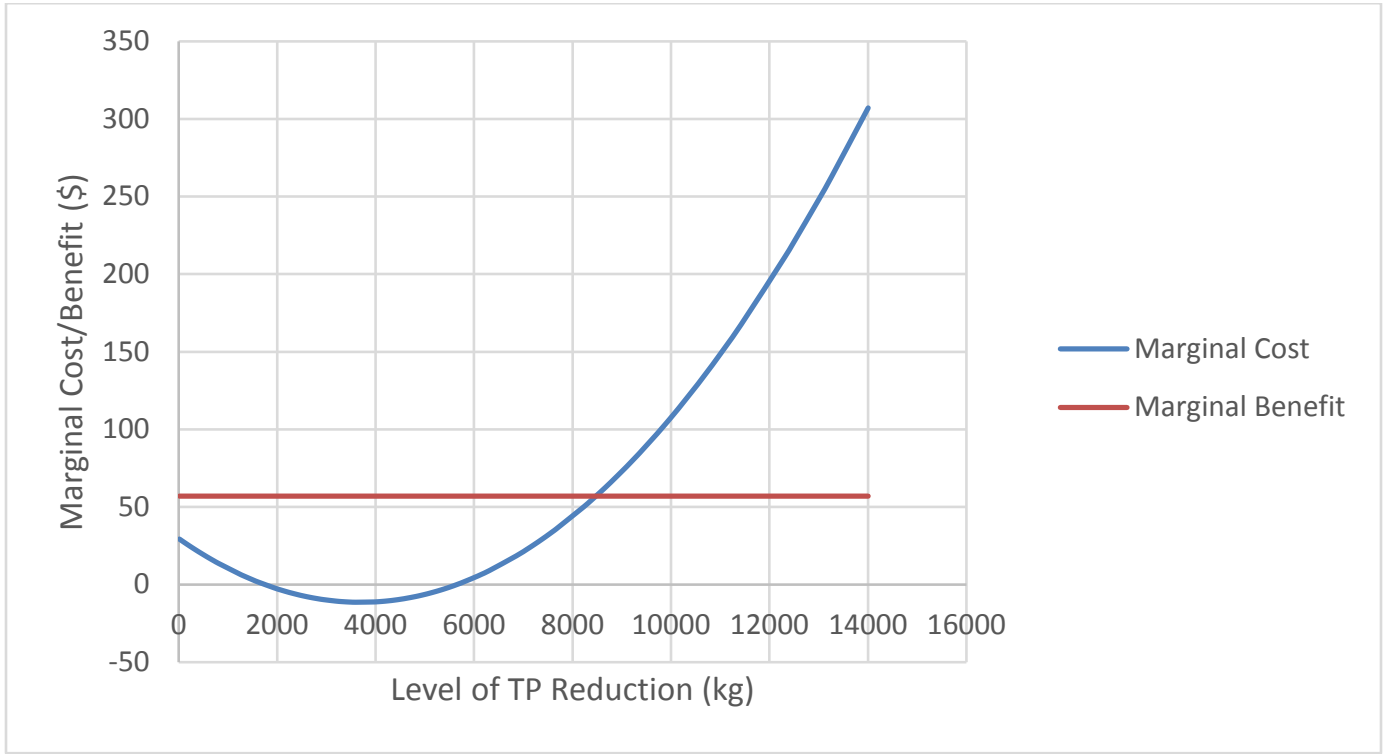

Figure 3.6: Marginal cost and marginal benefit of TP removal in the La Salle sub-watershed during the study period under cost targeting with a discount rate of six percent. 
Under cost targeting the optimal level of expenditure was 72 percent greater than the realized budget using a discount rate of six percent, but at discount rates of three and nine percent the optimal level of expenditure was seven percent and 30 percent less, respectively, than the realized budget (Figure 3.7). Assuming policy makers have the objective of optimizing the level of expenditure, as defined above, these results suggest that the realized budget often resulted in overspending on water retention ponds in the La Salle sub-watershed during the study period when cost targeting was used. Similarly, when benefit-cost targeting was used with discount rates of three, six, and nine percent the optimal level of expenditure was 53 percent, 58 percent, and 60 percent less, respectively, than the realized budget (Figure 3.7). These results suggest overspending on water retention ponds under benefit-cost targeting as well. Under benefit targeting using discount rates of three, six, and nine percent the optimal level of expenditure was 195 percent, 180 percent, and 93 percent greater, respectively, than the realized budget (Figure 3.7). These results suggest that the realized budget consistently resulted in underspending on water retention ponds in the La Salle sub-watershed during the study period when benefit targeting was used.

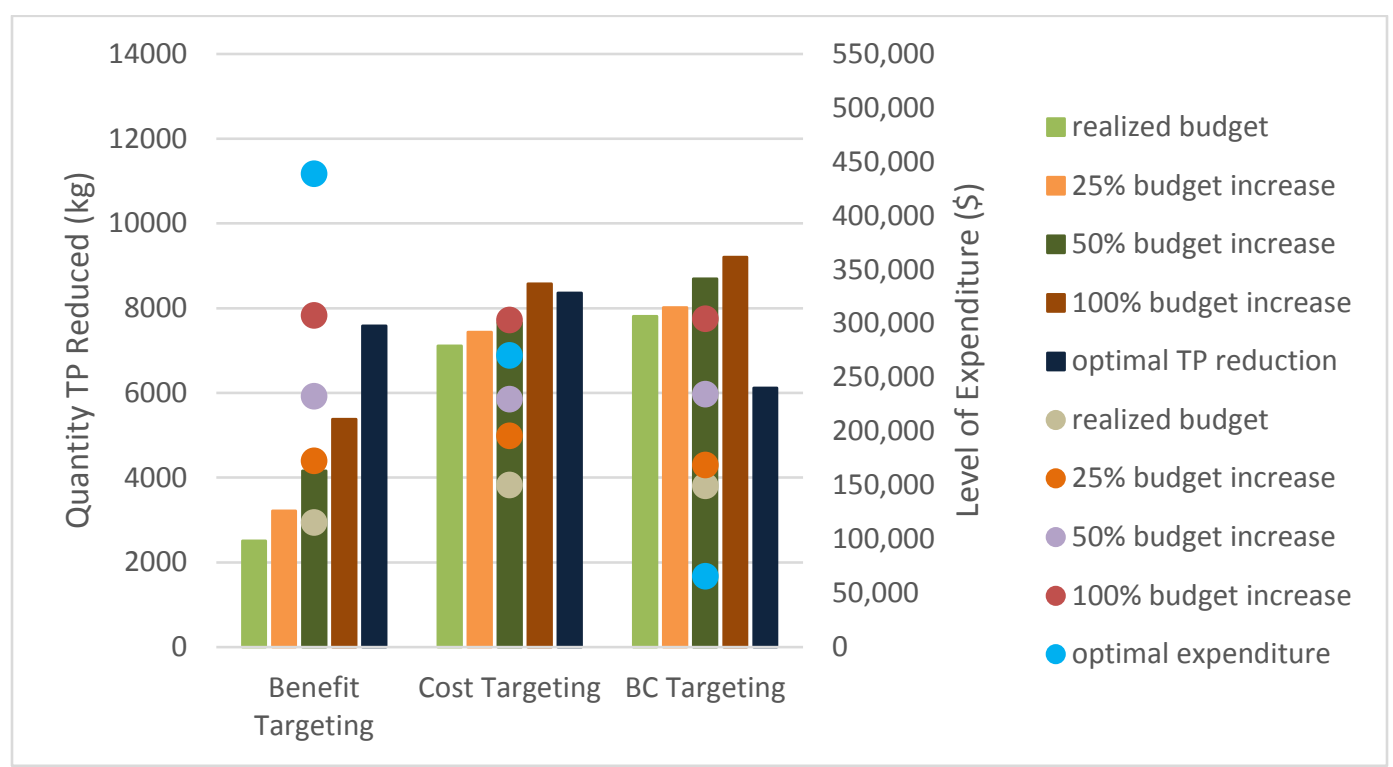

Figure 3.7: Quantity of TP reduced (bar graph) compared to level of expenditure (scatter plot) in the La Salle sub-watershed during the study period under different targeting strategies using a discount rate of six percent. Figures H.1, H.2, and H.3 in Appendix H provide the same comparison using discount rates of zero, three, and nine percent. 


\subsubsection{Common Characteristics among Ponds with a High Benefit-Cost Ratio}

In order to apply the knowledge generated in this research to facilitate benefit-cost targeting in other watersheds with similar landscape and land use characteristics it is necessary to identify traits common to water retention ponds with relatively high benefit-cost ratios. These traits can be used to select potential pond sites with high benefit-cost ratios in other similar watersheds, drastically reducing the time and resources required to undertake benefit-cost targeting. Within the La Salle sub-watershed, just over half (54 percent) of the potential pond sites had a benefitcost ratio greater than one. Figure 3.8 shows the distribution of ponds in the La Salle subwatershed with a benefit-cost ratio greater than one and those with a benefit-cost ratio less than one measured at a six percent discount rate (see Figures I.1, I.2, and I.3 in Appendix I to view the pond distributions according to benefit-cost ratio when discount rates of zero, three, and nine percent were used).

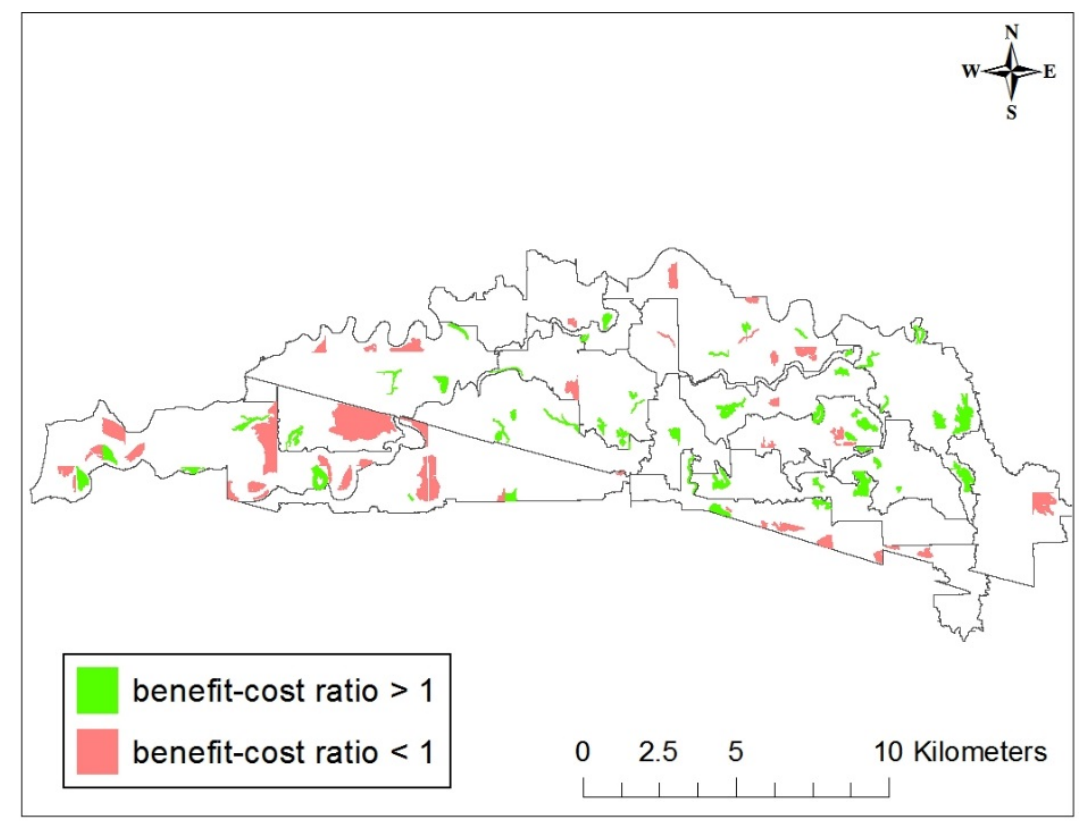

Figure 3.8: Distribution of ponds in the La Salle sub-watershed according to benefit-cost ratio assuming a discount rate of six percent.

Pond location within the sub-watershed appeared to influence the benefit-cost ratio of a water retention pond in the La Salle sub-watershed. Ponds with a benefit-cost ratio greater than one seemed to be concentrated closer to the outlet of the sub-watershed in the southeast corner. Large ponds located around the perimeter of the sub-watershed often had benefit-cost ratios less than one. The economically significant area flooded by ponds with a benefit-cost ratio greater 
than one varied between 0.78 and 27 hectares while the economically significant area flooded by ponds with a benefit-cost ratio less than one was between 0.69 and 131 hectares. The economically significant area of a pond included all flooded land classified as annual cropland or pasture, i.e. land uses that provide revenue to the owner. Due to the wide variation in size of the economically significant area flooded, pond size did not appear to be an important factor in determining the benefit-cost ratio. Similarly, the size of a pond's catchment area seemed to have no effect on the pond's benefit-cost ratio as catchment area size varied from 28 to 642 hectares among ponds with a benefit-cost ratio greater than one and from 16 to 1,082 hectares among ponds with a benefit-cost ratio less than one.

An important factor in determining the benefit-cost ratio of a pond was the crop rotation planted on the flooded area. Within the La Salle sub-watershed ponds that flooded areas planted to highvalue crops tended to have benefit-cost ratios less than one, while ponds that flooded areas planted to low-value crops tended to have benefit-cost ratios greater than one. For example, of the ponds in which the majority of flooded land was planted to a pulse non-row crop rotation (spring wheat-canola-spring wheat-soybeans), 67 percent had a benefit-cost ratio less than one.

Of the ponds in which the majority of flooded land was planted to an exposed pulse crop rotation (spring wheat-canola-spring wheat-white pea beans), 80 percent had a benefit-cost ratio less than one. Lastly, of the ponds in which the majority of flooded land was planted to a potato crop rotation (spring wheat-canola-spring wheat-potato), 100 percent had a benefit-cost ratio less than one. Therefore, pond sites that flood land planted to high value crop rotations, such as pulse non-row, exposed pulse, and potato rotations, should be avoided under benefit-cost targeting as these ponds are likely to have benefit-cost ratios less than one.

In contrast, pond sites that flood land planted to low value crop rotations, such as perennial forage or pasture, should be pursued under benefit-cost targeting as these ponds are likely to have benefit-cost ratios greater than one. For example, of the ponds in the La Salle subwatershed in which the majority of flooded land was planted to a perennial forage crop rotation (spring wheat followed by three years of alfalfa), 100 percent had a benefit-cost ratio greater than one. Similarly, of the ponds in which the majority of flooded land was in pasture, 100 percent had a benefit-cost ratio greater than one. 


\subsubsection{Potential Sources of Bias}

When considering the results presented above it is important to be aware of potential biases in the models and calculations underlying these results. I identified six potential sources of bias that may have influenced the results of this research. First, the budget allocated to water retention pond subsidies in the La Salle sub-watershed during the study period was likely overestimated. I assumed that the entire budget allocated by the La Salle Redboine Conservation District to surface water management programs in the La Salle River Watershed was spent only on water retention pond BMP projects in the La Salle sub-watershed even though there are multiple sub-watersheds in the La Salle River Watershed and numerous other surface water management BMPs offered in Manitoba. The implication of an overestimated budget is that too many ponds were selected under each targeting strategy and therefore the calculated quantity of TP reduction under each targeting strategy may be overstated.

Second, I included only the construction cost of building a water retention pond and the opportunity cost of taking cropland or pasture land out of production to create a pond when calculating the total cost of each pond site. However, there are other private costs imposed on producers who choose to implement a water retention pond BMP. For example, implementing a water retention pond within a cropped field creates a nuisance cost by forcing farmers to maneuver farming equipment around the pond. By not including nuisance costs or other private costs imposed on adopting producers the total cost of each pond may be underestimated, resulting in overstated estimates of the number of ponds implemented and quantity of TP reduced for each targeting strategy.

Third, the yield values used to calculate the opportunity cost of each water retention pond may be overstated or understated. Annual yield values were calculated as the average annual yield across three geographic risk areas of Manitoba. By averaging yield data from the three risk areas the variability in annual yield between risk areas was lost, leading to yield estimates that may be higher or lower than the realized annual yield in the La Salle sub-watershed. Risk area specific yield data was not available for all crops grown in the La Salle sub-watershed. As a result, provincial average annual yield estimates were used for potatoes and alfalfa, further increasing the probability of over- or under-estimated annual yield figures for these crops grown in the La Salle sub-watershed due to even less geographically precise yield data. Potential over- or under- 
estimated annual yields create uncertainty around the calculated opportunity cost of each potential pond site.

Fourth, the methodology used to discount yield in years where the level of precipitation was greater than the optimal water requirement of a crop may have led to overestimated annual yields. Whenever a range was reported for the optimal water requirement of a crop, the upper limit of this range was used for yield discounting calculations. The use of the upper limit of optimal water requirement values may have resulted in overestimated annual yields even after discounting since the yield of crop $n$ was only discounted in years where total precipitation was greater than the upper limit of annual water demand for crop $n$. Overestimated annual yields may have resulted in overstated opportunity costs for some or all of the potential pond sites leading to understated estimates of the number of ponds implemented and quantity of TP reduced for each targeting strategy.

Fifth, crop production cost figures used to calculate the opportunity cost of each water retention pond may have been underestimated. The average annual crop production cost figures used reflect the historic operating (variable) costs of production excluding labour. The exclusion of labour costs implies that crop production costs were understated, which may have resulted in overestimated opportunity costs and therefore understated estimates of the number of ponds implemented and quantity of TP reduced for each targeting strategy.

Sixth, the assumption of full subsidization creates uncertainty around the estimated number of ponds and quantity of TP reduced under each targeting strategy. This research assumed that the total cost of a water retention pond in the La Salle sub-watershed was fully subsidized by the La Salle Redboine CD when in reality funding for BMP projects under the Growing AssuranceEcological Goods and Services program follows a cost-share formula where the CD will fund 70 percent of project construction costs up to a maximum amount (La Salle Redboine Conservation District 2015). Assuming water retention pond subsidies equal to only 70 percent of construction costs would have resulted in more ponds implemented and a greater quantity of TP reduced using the given budget under each targeting strategy, assuming every producer offered a 70 percent cost-share subsidy accepted it. However, it is unlikely that all producers offered would accept a 70:30 cost-share subsidy to implement a water retention pond since only a portion of their construction costs and none of their opportunity costs would be covered. 
Therefore, the effect of assuming a full subsidy rather than a cost-share subsidy on the number of ponds implemented and the quantity of TP reduced is uncertain.

The overall impact of these potential biases is uncertain and depends on the ability of biases of opposite direction to counteract each other. The high threshold to discount yields in years of excess moisture and the exclusion of labour from crop production costs may have resulted in overstated opportunity costs, which increased the total cost of each pond and exerted a downward bias on the number of ponds established and the resulting quantity of TP reduced under the fixed budget. Similarly, the assumption of full cost subsidies rather than cost-share subsidies may have resulted in a downward bias on the number of ponds established and the resulting quantity of TP reduced under the fixed budget. However, the overestimated budget and the exclusion of nuisance or other private costs when calculating the total cost of each pond may have partially or completely counteracted these effects by exerting an upward bias on the number of ponds established and the resulting quantity of TP reduced.

\subsection{Conclusion}

This study determined that water retention pond BMP subsidies within the La Salle subwatershed in Manitoba were administered more efficiently (cost effectively) when a targeting strategy was used to allocate the subsidies rather than the current uniform allocation strategy. Beyond determining potential efficiency gains from targeting water retention pond subsidies, this research compared targeting strategies to determine which was the most cost effective in reducing TP outflow from the La Salle sub-watershed under the limited subsidy budget. The best targeting strategy to maximize land enrollment or farmer participation in the BMP program was also determined. The optimal level of expenditure on water retention pond subsidies within the La Salle sub-watershed was calculated to evaluate whether the existing subsidy budget resulted in overspending or underspending on water retention ponds during the study period. Lastly, common landscape and land use characteristics were identified among ponds with a high benefit-cost ratio in order to facilitate faster, less resource-intensive targeting of water retention pond subsidies in similar watersheds.

The results of this research support the hypothesis of Babcock et al. (1997) that a positive correlation between economic costs and environmental benefits increases the disparity in environmental outcomes from different targeting strategies and therefore increases the 
importance of selecting the most efficient or cost effective targeting tool. This research found the economic costs and environmental benefits of water retention ponds to be highly positively correlated and calculated a substantial disparity in TP reduction outcomes provided by the three targeting strategies, in line with the expected disparity in environmental outcomes predicted by Babcock et al. (1997). Benefit-cost targeting was found to be the most cost effective targeting strategy under the fixed BMP subsidy budget for all budget scenarios and discount rates tested, followed by cost targeting and finally benefit targeting. As the most cost effective targeting strategy, benefit-cost targeting provided the lowest average cost per kilogram of TP removed for all budget scenarios and discount rates. These findings are consistent with existing literature; many previous authors have identified benefit-cost targeting as the most efficient or cost effective targeting strategy to allocate limited agri-environmental subsidy funds (Crossman and Bryan 2009; Cook and Norman 1996; Van der Horst 2007; Hansen et al. 2015; Khana et al. 2003; Babcock et al. 1997).

The results of this study support the theory presented by Babcock et al. (1997) that there are environmental gains to be made by selecting the most efficient or cost effective targeting strategy to allocate agri-environmental subsidies. In fact, the results of this study indicate that using benefit-cost targeting rather than the current uniform subsidy structure (cost targeting was used as a proxy) to allocate water retention pond subsidies in the La Salle sub-watershed provided efficiency gains equal to an additional 641 kilograms (using a discount rate of nine percent) to 2,503 kilograms (using a discount rate of zero) of TP removed from the La Salle sub-watershed over the study period using the realized budget. However, efficiency or cost effectiveness is not always the primary objective of agri-environmental policy, sometimes the goal is to maximize farmer participation or land enrollment. Cost targeting, a proxy for the current uniform allocation strategy, maximized participation by establishing the most ponds under all budget scenarios and discount rates tested while benefit-cost targeting resulted in the greatest amount of land enrolled in the water retention pond BMP program.

In order to evaluate the appropriateness of the existing BMP subsidy budget, the optimal level of expenditure on water retention ponds in the La Salle sub-watershed over the study period was calculated for each targeting strategy. The optimal level of expenditure was compared to the realized budget to determine if the realized budget resulted in over- or under-spending on water 
retention pond subsidies in the La Salle sub-watershed during the study period. The optimal level of expenditure when cost targeting was used with discount rates of three and nine percent was found to be less than the realized budget. Similarly, when benefit-cost targeting was used with discount rates of three, six, and nine percent the optimal level of expenditure was found to be less than the realized budget. Assuming policy makers strive for the optimal level of expenditure, these results suggest that the realized budget often resulted in overspending on water retention ponds in the La Salle sub-watershed when cost targeting or benefit-cost targeting were used. However, the optimal level of expenditure under benefit targeting at any discount rate was always greater than the realized budget, suggesting the realized budget consistently resulted in underspending on water retention ponds in the La Salle sub-watershed during the study period when benefit targeting was used.

Common landscape and land use characteristics were identified among ponds with a high benefit-cost ratio in order to facilitate faster, less resource-intensive targeting of water retention pond subsidies in similar watersheds. Location within the sub-watershed appeared to influence the benefit-cost ratio of a water retention pond in the La Salle sub-watershed. Ponds with a benefit-cost ratio greater than one were concentrated closer to the outlet of the sub-watershed, while large ponds located around the perimeter of the sub-watershed often had benefit-cost ratios less than one. Another important factor in determining the benefit-cost ratio of a pond was the crop rotation planted on the flooded area. Within the La Salle sub-watershed ponds that flooded areas planted to high-value crop rotations, such as pulse non-row, exposed pulse, or potato rotations, tended to have benefit-cost ratios less than one. Conversely, ponds that flooded areas planted to low-value crop rotations or land uses, such as perennial forage or pasture, tended to have benefit-cost ratios greater than one. Therefore, pond location within the watershed and the value of the crop rotation(s) planted on a potential pond site were recommended as important factors to consider when targeting water retention pond subsidies in similar watersheds.

Lastly, potential sources of bias in the reported results were identified. However, the overall impact of these potential biases was uncertain. Biases exerting both upward and downward pressure on the number of ponds established and the resulting quantity of TP reduced were identified. Therefore, the overall impact of these biases depends on their relative magnitudes and the ability of biases acting in opposite directions to mitigate each other. 


\subsection{Synthesis}

\subsection{Academic and Policy Contributions}

Broadly speaking, this research contributes to the existing literature on incentive-based policy instruments to address agricultural externalities. It reinforces previous findings in the literature that demonstrate efficiency gains when targeted policy instruments replace uniform or semiuniform policy instruments to encourage the provision of public ecological goods and services on private agricultural lands. The results of this study support conclusions drawn by previous authors who have compared multiple targeting strategies to administer agri-environmental subsidies and found benefit-cost targeting to be the most efficient or cost effective targeting strategy.

More specifically, this research adds to the literature on using BMP subsidies to reduce nonpoint nutrient pollution from agricultural sources. A Canadian case study of a nutrient management BMP to reduce non-point nutrient pollution is provided in the Lake Winnipeg drainage basin, an area where nutrient runoff from agricultural fields is known to cause eutrophication. This study demonstrates the ability of water retention pond BMPs to reduce nonpoint phosphorus pollution from agricultural runoff within the Lake Winnipeg drainage basin in Manitoba and provides evidence that using benefit-cost targeting to allocate water retention pond BMP subsidies is more cost effective than the current uniform BMP subsidy structure.

Policy contributions include providing useful information for federal and provincial policy makers to review BMP subsidy allocation strategies before the release of the next federalprovincial/territorial agricultural policy framework in 2018. This research provides insights on the potential efficiency gains available if BMP subsidies are allocated according to a benefit-cost targeting strategy rather than the current uniform allocation strategy. This research may also be useful to AAFC researchers and local conservation district administrators in Manitoba who want to expand water retention pond BMPs or similar nutrient management BMPs to other agricultural watersheds. Suggestions are provided on the landscape and land use characteristics to look for in order to successfully apply benefit-cost targeting to allocate water retention pond BMPs in similar watersheds. As well, the methodology presented in this study could be used to administer other nutrient management BMPs in other agricultural watersheds using benefit-cost 
targeting. AAFC researchers could follow the presented methodology to predict potential efficiency gains from replacing current uniform subsidies with benefit-cost targeted subsidies for other nutrient management BMPs in Manitoba watersheds.

Lastly, the methodology to calculate the optimal level of expenditure on water retention pond BMP subsidies presented in this study could be used by conservation district administrators to ensure future budget allocations do not result in over- or under-spending on water retention pond BMPs within their jurisdiction. This methodology could also be applied to prevent over- or under-spending on other nutrient management BMPs administered by conservation districts within the La Salle sub-watershed or other watersheds of Manitoba.

\subsection{Future Research}

\subsubsection{Estimating Demand for Phosphorus Removal in the La Salle Sub-watershed}

Although non-point phosphorus pollution from agricultural sources has long been recognized as a problem in the major tributaries that flow into Lake Winnipeg, a monetary value for reducing phosphorus outflows has not been estimated in any Manitoba watershed to the best of my knowledge. Estimating stakeholders' willingness to pay for phosphorus removal in the La Salle sub-watershed would necessitate the use of non-market valuation techniques and therefore was determined to be beyond the scope of this study. By undertaking a non-market valuation study to estimate a willingness to pay for phosphorus removal from field runoff in the La Salle subwatershed, future researchers could construct a demand curve to replace the constant marginal benefit value used in this study. The estimation of a demand curve for phosphorus removal would allow for a more accurate calculation of the optimal level of expenditure on water retention pond BMPs in the La Salle sub-watershed under each of the proposed targeting strategies.

\subsubsection{Consideration of Transaction Costs}

Previous authors have identified increased transaction costs associated with moving from uniform agri-environmental payment programs to differentiated or targeted programs.

Kurkalova (2015) noted the high transaction costs required to successfully target agrienvironmental payment programs often cause policy makers to turn to sub-optimal uniform payment structures that are less efficient. This sentiment was mirrored by Khana et al. (2003) in 
their study comparing the use of a benefit-cost targeting strategy to a uniform rental cap in allocating funds under the American Conservation Reserve Program. Transaction costs include expenses incurred for research, information gathering, data analysis, enactment of enabling legislation, as well as policy design, implementation, administration, and enforcement (Khana et al. 2003). Khana et al. (2003) found these costs were substantially higher under the benefit-cost targeting strategy since the implementation of this strategy required in-depth knowledge of the biophysical characteristics of each land parcel in the policy area and its potential to provide the desired environmental benefit.

Additionally, Khana et al. (2003) hypothesized that a targeted policy would elicit greater resistance from farmers. A targeted policy may be perceived as unfair and lacking transparency since payment differences are based on unseen potential to provide environmental benefits. Farmer resistance is another transaction cost associated with implementing a targeted policy (Khana et al. 2003). Khana et al. (2003) concluded that high transaction costs could significantly reduce the efficiency gains achieved by moving from a uniform payment structure to differentiated payments based on benefit-cost targeting.

I did not attempt to quantify the transaction costs associated with using a benefit-cost targeting strategy to allocated water retention pond BMP subsidies in the La Salle sub-watershed.

Quantifying these transaction costs would allow future researchers to determine if these costs are large enough to negate the efficiency gains obtained by moving from the uniform allocation strategy to a benefit-cost targeting strategy to distribute water retention pond subsidies in the La Salle sub-watershed.

\subsubsection{Determining Price Feedback Slippage Effects of Benefit-Cost Targeting}

According to Wu et al. (2001), in order to maximize the environmental benefits provided by an agri-environmental payment program that requires seasonal or permanent land retirement, price feedback slippage effects must be considered before a targeting strategy is chosen if the demand for the displaced agricultural output is downward sloping (Wu et al. 2001). If demand for the displaced agricultural commodity is downward sloping, a shortage-induced commodity price increase can occur as a result of diverting agricultural land away from commodity production, causing two types of price feedback slippage. First, marginal land that was previously idle may be brought into production, reducing total environmental benefits, and if farmers are subsidized 
to prevent this marginal land from coming into production then less money is available to subsidize lands with higher environmental benefit potential (Wu et al. 2001). Second, higher commodity prices increase the value of land in production, which increases the opportunity cost of retiring land to provide environmental benefits. This may result in farmers requiring a higher subsidy rate to retire land and therefore fewer parcels of land being subsidized within a fixed program budget (Wu et al. 2001). These slippage effects reduce the efficiency gains associated with administering agri-environmental payment programs through benefit-cost targeting (Wu et al. 2001).

Price feedback slippage effects were not considered in this research even though water retention ponds require land retirement and the displaced agricultural commodities have downward sloping demand curves. These slippage effects were assumed to be negligible in the La Salle sub-watershed since the amount of land taken out of production to create water retention ponds was a very small proportion of the total amount of active agricultural land in the sub-watershed. Even if all potential water retention ponds in the La Salle sub-watershed were implemented, only 875 of 19,153 hectares, or 4.6 percent, of active agricultural land in the sub-watershed would be removed from agricultural production. However, quantification of these slippage effects may be necessary if considering benefit-cost targeting to allocate water retention pond subsidies at a larger regional or provincial scale.

\subsubsection{Determining Characteristics that Affect the Benefit-Cost Ratio}

Regression analysis could be conducted to determine the pond and landscape characteristics that have a significant effect on the magnitude of the benefit-cost ratio of a water retention pond in the La Salle sub-watershed. The dependent variable, the pond benefit-cost ratio, could be regressed on the independent variables identified in this study, including the presence of lowvalue or high-value crop rotations, the size of the flooded area, the size of the catchment area, the location of the pond within the sub-watershed, and the distance of the pond from the subwatershed outlet. The coefficients produced by regression analysis would provide insight as to whether the independent variables identified in this study do in fact have a statistically significant effect on the benefit-cost ratio of a pond and whether the direction of this effect matches the positive or negative influence I predicted for each independent variable. 


\subsection{References Cited}

Agriculture and Agri-Food Canada. 2012. The Economics of Beneficial Management Practices:

Evaluating BMP Performance at the Watershed Scale. Ottawa: Ministry of Agriculture and AgriFood Canada.

Babcock, Bruce A., P.G. Lakshminarayan, JunJie Wu, and David Zilberman. 1997. Targeting Tools for the Purchase of Environmental Amenities. Land Economics 73(3): 325-339.

Baker, Laurie. 2012. Watershed Evaluation of BMPs Economic Results. Ottawa: Ministry of Agriculture and Agri-Food Canada.

Bourgeois, Cyril, Nosra Ben Fradj, and Pierre-Alain Jayet. 2014. How Cost-Effective is a Mixed Policy Targeting the Management of Three Agricultural N-pollutants? Environmental Modeling and Assessment 19: 389-405.

Bourne, A., N. Armstrong, and G. Jones. 2002. A Preliminary Estimate of Total Nitrogen and Total Phosphorus Loading to Streams in Manitoba, Canada. Winnipeg, MB: Water Quality Management Section, Government of Manitoba. Manitoba Conservation Report No. 2002-04.

Boxall, Peter, Marian Weber, Orsolya Perger, Marius Cutlac, and Antony Samarawickrema. 2008. Results from the Farm Behaviour Component of the Integrated Economic-Hydrologic Model for the Watershed Evaluation of Beneficial Management Practices Program. University of Alberta: Department of Rural Economy.

Brander, Luke M., Raymond J.G.M. Florax, and Jan E. Vermaat. 2006. The Empirics of Wetland Valuation: a Comprehensive Summary and a Meta-Analysis of the Literature. Environmental and Resource Economics 33: 223-250.

Bryan, Brett A. and John M. Kandulu. 2011. Designing a Policy Mix and Sequence for Mitigating Agricultural Non-Point Source Pollution in a Water Supply Catchment. Water Resources Management 25: 875-892.

Burkart, Christopher S. and Manoj K. Jha. 2012. Site-Specific Simulation of Nutrient Control Policies: Integrating Economic and Water Quality Effects. Journal of Agricultural and Resource Economics 37(1): 20-33.

Cook, Hadrian F. and Charlotte Norman. 1996. Targeting Agri-Environmental Policy: An Analysis Relating to the use of Geographical Information Systems. Land Use Policy 13(3): 217228.

Costanza, Robert, Stephen C. Farber, and Judith Maxwell. 1989. Valuation and Management of Wetland Ecosystems. Ecological Economics 1: 335-361.

Crossman, Neville D. and Brett A. Bryan. 2009. Identifying cost-effective hotspots for restoring natural capital and enhancing landscape multifunctionality. Ecological Economics 68: 654-668. 
Efetha, Alan. 2011. Irrigation Scheduling for Winter Wheat in Southern Alberta. Edmonton: Alberta Agriculture and Forestry, Government of Alberta.

http://www1.agric.gov.ab.ca/\$Department/deptdocs.nsf/all/agdex13535.

Food and Agriculture Organization of the United Nations (FAO). 2015. Crop Water Information: Soybean. FAO: Water Development and Management Unit. http://www.fao.org/nr/water/cropinfo_soybean.html.

Government of Canada. 2015. Climate Station Results: Portage Southport. Ottawa: Environment and Climate Change Canada.

http://climate.weather.gc.ca/advanceSearch/searchHistoricDataStations_e.html?searchType=stnP rov\&timeframe=1\&lstProvince=MB\&optLimit=yearRange\&StartYear=1999\&EndYear=2013\& Year=2016\&Month=1\&Day=6\&selRowPerPage=25\&cmdProvSubmit=Search\&startRow=126.

Hansen, LeRoy, Daniel Hellerstein, Marc Ribaudo, James Williamson, David Nulph, Charles Loesch, and William Crumpton. 2015. Targeting Investments to Cost Effectively Restore and Protect Wetland Ecosystems: Some Economic Insights. Washington D.C.: U.S. Department of Agriculture, Economic Research Service.

Hansen, Line Block and Lars Garn Hansen. 2014. Can Non-point Phosphorus Emissions from Agriculture be Regulated Efficiently Using Input-Output Taxes? Environmental and Resource Economics 58: 109-125.

Khakbazan, Mohammad, Cliff Hamilton, Jim Yarotski, and Jane Elliott. 2013. South Tobacco Creek Economic Analysis of Beneficial Management Practices- WEBs Project. Ottawa: Ministry of Agriculture and Agri-Food Canada.

Khakbazan, Mohammad, Cliff Hamilton, Ramona Mohr, and Cynthia Grant. 2011. Water and Nutrient Crop Sufficiency Models for Potato, Wheat, Canola, Oats, Alfalfa, and Corn. The Americas Journal of Plant Science and Biotechnology 5 (Special Issue 2): 45-60.

Khakbazan, M., R.M. Mohr, K.M. Volkmar, D.J. Tomasiewicz, A.P. Moulin, D.A. Derksen, B.R. Irvine, D. McLaren, and M.A. Monreal. 2010. The economics of irrigated potato crop rotation in Manitoba. American Journal of Potato Research 87: 446-457.

Khana, Madhu, Wanhong Yang, Richard Farnsworth, and Hayri Onal. 2003. Cost-Effective Targeting of Land Retirement to Improve Water Quality with Endogenous Sediment Deposition Coefficients. American Journal of Agricultural Economics 85(3): 538-553.

Kurkalova, Lyubov A. 2015. Cost-Effective Placement of Best Management Practices in a Watershed: Lessons Learned from Conservation Effects Assessment Project. Journal of the American Water Resources Association: 1-14.

La Salle Redboine Conservation District. 2015. District Programs. http://www.lasalleredboine.com/programs.html. 
La Salle River Watershed Planning Authority. 2010. La Salle River Integrated Watershed Management Plan. Winnipeg, MB: Water Stewardship Division, Government of Manitoba. https://www.gov.mb.ca/waterstewardship/iwmp/la_salle_river/la_salle_river.html.

Lankoski, Jussi and Markku Ollikainen. 2003. Agri-environmental externalities: a framework for designing targeted policies. European Review of Agricultural Economics 30(1): 51-75.

Lant, Christopher L., Steven E. Kraft, Jeffrey Beaulieu, David Bennett, Timothy Loftus, and John Nicklow. 2005. Using GIS-based Ecological-Economic Modeling to Evaluate Policies Affecting Agricultural Watersheds. Ecological Economics 55: 467-484.

Manitoba Agricultural Services Corporation (MASC) and Manitoba Co-operator. 2015. Yield Manitoba (2000-2015). Winnipeg: Manitoba Agriculture, Food, and Rural Development, Government of Manitoba. http://www.mmpp.com/mmpp.nsf/mmpp_index.html.

Pannell, David J. 2008. Public Benefits, Private Benefits, and Policy Mechanism Choice for Land-Use Change for Environmental Benefits. Land Economics 84(2): 225-240.

Pretty, Jules. 2003. The Externalities and Multifunctionality of Agriculture. EuroChoices 2(3): 40-45.

Province of Manitoba. 2014. Manitoba Conservation Districts Program 2013-14 Annual Report. Winnipeg: Conservation and Water Stewardship, Government of Manitoba.

Province of Manitoba. 2015a. Financial Assistance: Growing Assurance- Environment. Winnipeg: Manitoba Agriculture, Food, and Rural Development, Government of Manitoba. http://www.gov.mb.ca/agriculture/environment/environmental-farm-plan/growing-assuranceenvironment.html.

Province of Manitoba. 2015b. Financial Assistance: Growing Assurance- Ecological Goods and Services. Winnipeg: Manitoba Agriculture, Food, and Rural Development, Government of Manitoba. http://www.gov.mb.ca/agriculture/environment/ecological-goods-andservices/growing-assurance-egs.html.

Province of Manitoba. 2015c. Manitoba’s Conservation Districts. Winnipeg: Water Stewardship Division, Government of Manitoba. http://www.gov.mb.ca/conservation/waterstewardship/agencies/cd/\#cd\%20contacts.

Province of Manitoba. 2015d. Agricultural Climate of Manitoba. Winnipeg: Manitoba Agriculture, Food, and Rural Development, Government of Manitoba. https://www.gov.mb.ca/agriculture/weather/agricultural-climate-of-mb.html.

Province of Manitoba. 2015e. Crop Production Statistics in Manitoba. Winnipeg: Manitoba Agriculture, Food, and Rural Development, Government of Manitoba. http://www.manitoba.ca/agriculture/market-prices-and-statistics/yearbook-and-state-ofagriculture/-statistics-tables.html. 
Province of Manitoba. 2015f. Production Economics- Cost of Production Budgets. Winnipeg: Manitoba Agriculture, Food, and Rural Development, Government of Manitoba. https:/www.gov.mb.ca/agriculture/business-and-economics/financial-management/cost-ofproduction.html.

Province of Manitoba. 2015g. Reports, Studies, Plans and Publications. Conservation Districts Annual Report (2004/5-2013/14). Winnipeg: Water Stewardship Division, Government of Manitoba. http://www.gov.mb.ca/waterstewardship/reports/\#historical.

Roberts, Lisa A. and Jay A. Leitch. 1997. Economic Valuation of some Wetland Outputs of Mud Lake, Minnesota-South Dakota. Fargo, ND: Department of Agricultural Economics, North Dakota State University.

Sohngen, Brent, Kevin W. King, Gregory Howard, John Newton, and D. Lynn Forster. 2015. Nutrient prices and concentrations in Midwestern agricultural watersheds. Ecological Economics 112: 141-149.

Tilman, David, Kenneth G. Cassman, Pamela A. Matson, Rosamond Naylor, and Stephen Polasky. 2002. Agricultural Sustainability and Intensive Production Practices. Nature 418: 671677.

Van der Horst, Dan. 2006. Spatial cost-benefit thinking in multi-functional forestry; towards a framework for spatial targeting of policy interventions. Ecological Economics 59: 171-180.

Van der Horst, Dan. 2007. Assessing the Efficiency Gains of Improved Spatial Targeting of Policy Interventions; the example of an agri-environmental scheme. Journal of Environmental Management 85: 1076-1087.

Vanrobaeys, Jason, Patsy Michiels, and Marcos Cordeiro. 2013. Summary of Data Analysis and Data Input for the SWAT model in the Red Assiniboine Project (draft). Brandon, MB: Agriculture and Agri-Food Canada.

Walpole, S.C. and J.A. Sinden. 1997. BCA and GIS: Integration of Economic and Environmental Indicators to aid Land Management Decisions. Ecological Economics 23: 45-57.

Wu, JunJie, David Zilberman, and Bruce Babcock. 2001. Environmental and Distributional Impacts of Conservation Targeting Strategies. Journal of Environmental Economics and Management 41(3): 333-350.

Yang, Qi, Luis F. Leon, William G. Booty, Isaac W. Wong, Craig McCrimmon, Phil Fong, Patsy Michiels, Jason Vanrobaeys, and Glenn Benoy. 2014. Land Use Change Impacts on Water Quality in Three Lake Winnipeg Watersheds. Journal of Environmental Quality 43: 1690-1701. 


\section{Appendix A}

Surface water management program expenditures for the La Salle Redboine Conservation District and its watersheds 
Table A.1: Surface water management program expenditures for the La Salle Redboine Conservation District and its watersheds.

\begin{tabular}{|l|l|l|l|l|}
\hline \multicolumn{3}{|c|}{ Yurface Water Management Program Expenditures } \\
& $\begin{array}{c}\text { Total Conservation } \\
\text { District }\end{array}$ & \multicolumn{3}{c|}{ Individual Watersheds } \\
\hline & La Salle Redboine CD & $\begin{array}{l}\text { La Salle River } \\
\text { Watershed (\$) }\end{array}$ & $\begin{array}{l}\text { Boyne-Norquay } \\
\text { Watershed (\$) }\end{array}$ & $\begin{array}{l}\text { Assiniboine-Cypress } \\
\text { Watershed (\$) }\end{array}$ \\
\hline $\mathbf{2 0 0 0}$ & 48080.39 & 16347.33 & 27405.82 & 3846.43 \\
\hline $\mathbf{2 0 0 1}$ & 48080.39 & 16347.33 & 27405.82 & 3846.43 \\
\hline $\mathbf{2 0 0 2}$ & 48080.39 & 16347.33 & 27405.82 & 3846.43 \\
\hline $\mathbf{2 0 0 3}$ & 48080.39 & 16347.33 & 27405.82 & 3846.43 \\
\hline $\mathbf{2 0 0 4}$ & 84420.00 & 28702.80 & 48119.40 & 6753.60 \\
\hline $\mathbf{2 0 0 5}$ & 35346.00 & 12017.64 & 20147.22 & 2827.68 \\
\hline $\mathbf{2 0 0 6}$ & 27118.00 & 9220.12 & 15457.26 & 2169.44 \\
\hline $\mathbf{2 0 0 7}$ & 22083.00 & 7508.22 & 12587.31 & 1766.64 \\
\hline $\mathbf{2 0 0 8}$ & 21642.00 & 7358.28 & 12335.94 & 1731.36 \\
\hline $\mathbf{2 0 0 9}$ & 33591.00 & 11420.94 & 19146.87 & 2687.28 \\
\hline $\mathbf{2 0 1 0}$ & 18203.00 & 6189.02 & 10375.71 & 1456.24 \\
\hline $\mathbf{2 0 1 1}$ & 29844.94 & 9163.00 & 17011.62 & 2387.60 \\
\hline $\mathbf{2 0 1 2}$ & 71633.00 & 37804.00 & 28838.00 & 4991.00 \\
\hline $\mathbf{2 0 1 3}$ & 136923.00 & 24945.00 & 100752.00 & 11226.00 \\
\hline
\end{tabular}

(Province of Manitoba 2015g) 


\section{Appendix B}

Methodology to determine land use within the La Salle sub-watershed 
AAFC researchers in Manitoba created a Geographic Information System (GIS) database that assigned a land use to each quarter section in the La Salle River Watershed. Quarter sections used for annual crop production in the watershed were identified by the modelling team using 2001 LandSat satellite imagery. A cropping system was then assigned to each quarter section identified as annual cropland using Manitoba Agricultural Services Corporation (MASC) crop insurance data in conjunction with aerial photography and irrigation infrastructure data. Quarters that had no associated historic crop insurance data but were identified as containing annual cropland by the satellite imagery were arbitrarily assigned the most common cropping system: oilseed-spring cereals (Vanrobaeys et al. 2013). Figure B.1 was developed by the AAFC researchers and depicts the land use type for each quarter section in the La Salle River Watershed with those quarters designated as annual cropland further delineated by their cropping system.

My research focused on annual cropland and pasture land since these land uses represent a revenue source for land owners. Pasture land was assumed to be unimproved forage specifically managed for livestock grazing. No crop was harvested, but landowners were assumed to receive rental payments. For the purpose of this research, land designated as hay land was assumed to be under the perennial forage crop rotation. Also for the purpose of this research, the irrigated potato cropping system was assumed to replace irrigated vegetable production. There was insufficient data on carrots grown in Manitoba, which are the representative crop of the irrigated vegetable cropping system. Therefore, all quarters assigned to the irrigated vegetable cropping system were reclassified under the irrigated potato cropping system. It is important to note that the irrigated potato crop rotation is comprised of lower value crops than the irrigated vegetable crop rotation and therefore the opportunity cost of flooding an area under irrigated vegetable production has likely been underestimated in this study. 


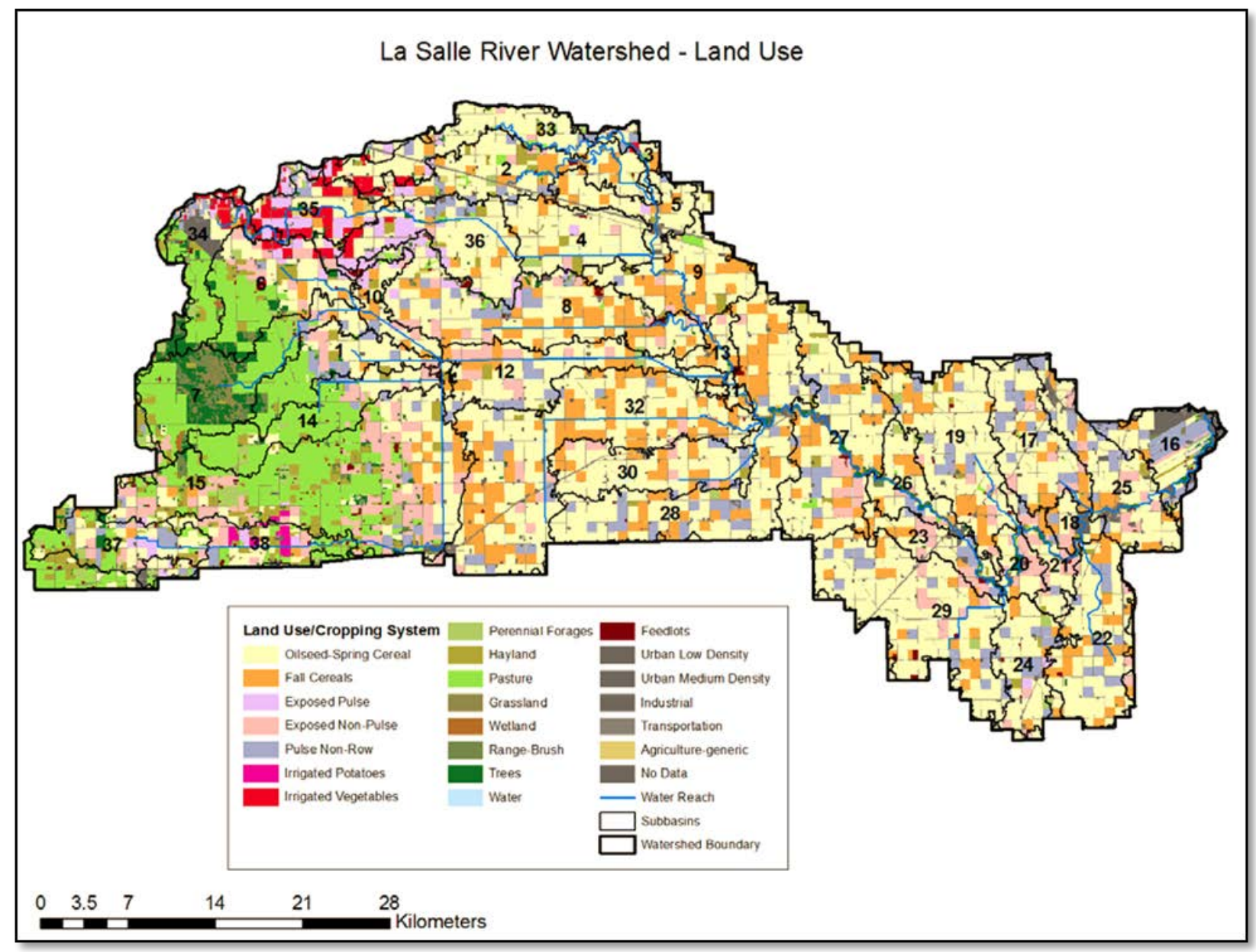

Figure B.1: Land use and cropping system per quarter section within the La Salle River Watershed (Vanrobaeys et al. 2013). 


\section{Appendix C}

Pond implementation pattern of each targeting strategy assuming discount rates of zero, three, and nine percent 


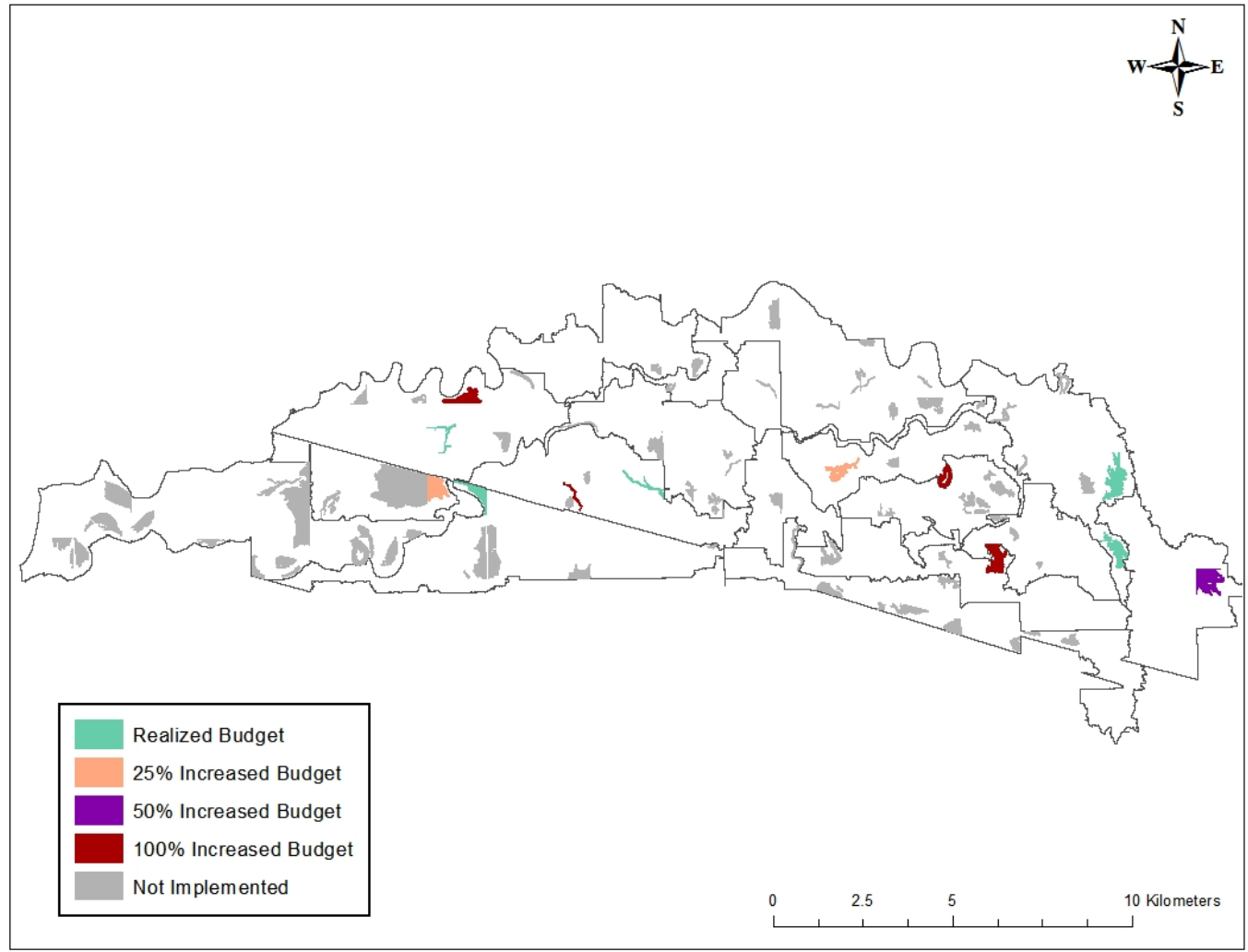

Figure C.1: Pond implementation pattern under benefit targeting using a discount rate of zero.

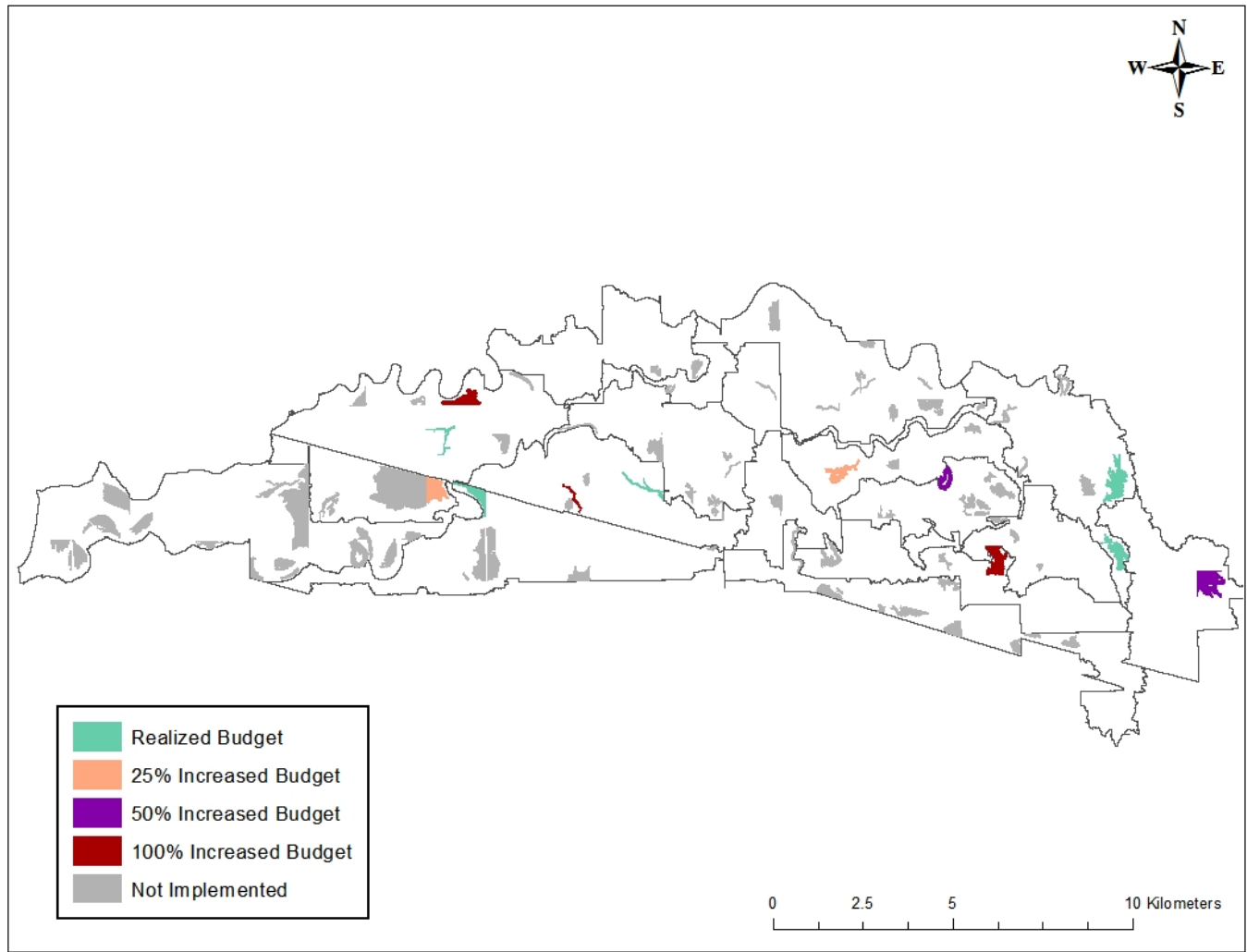

Figure C.2: Pond implementation pattern under benefit targeting using a discount rate of three percent. 


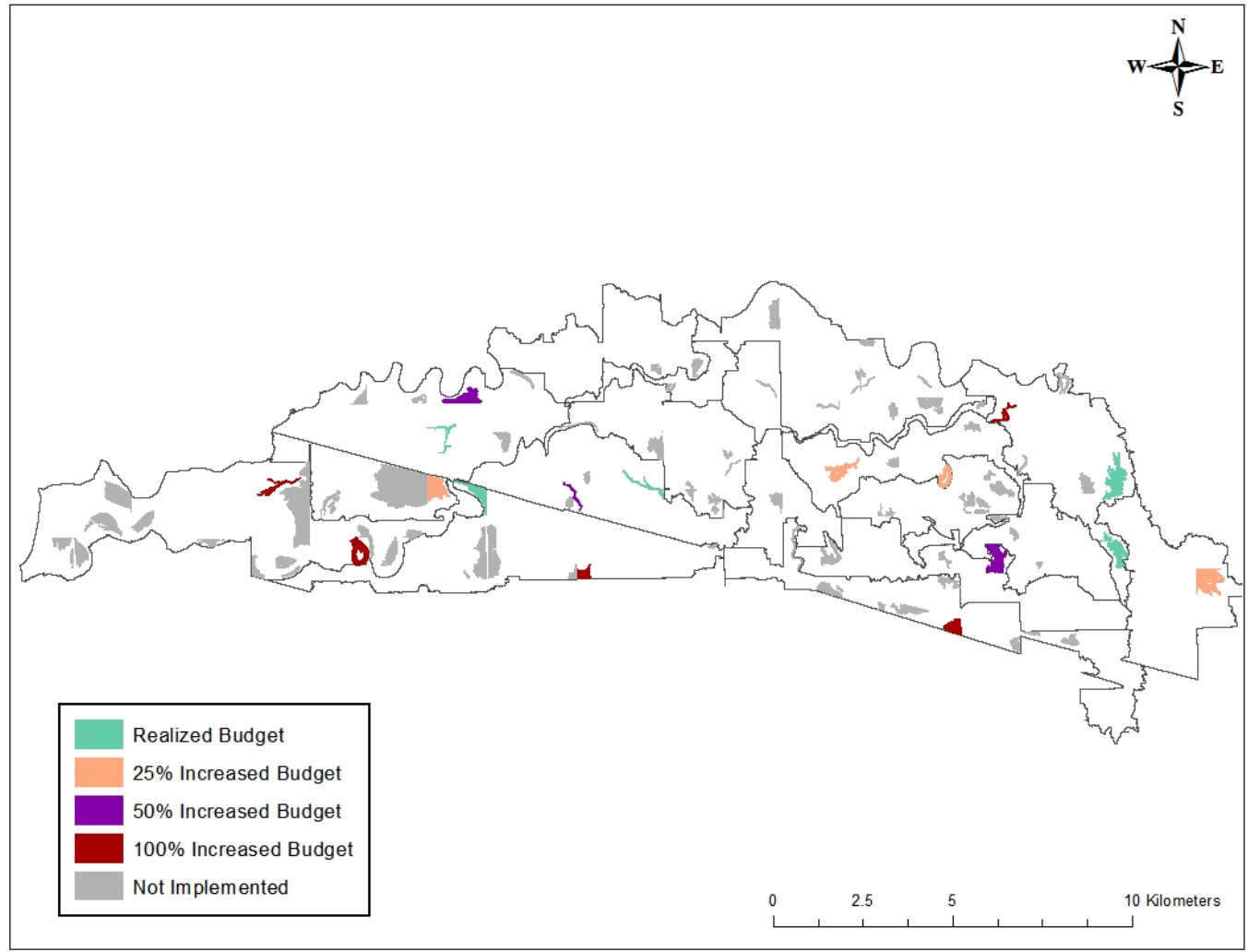

Figure C.3: Pond implementation pattern under benefit targeting using a discount rate of nine percent.

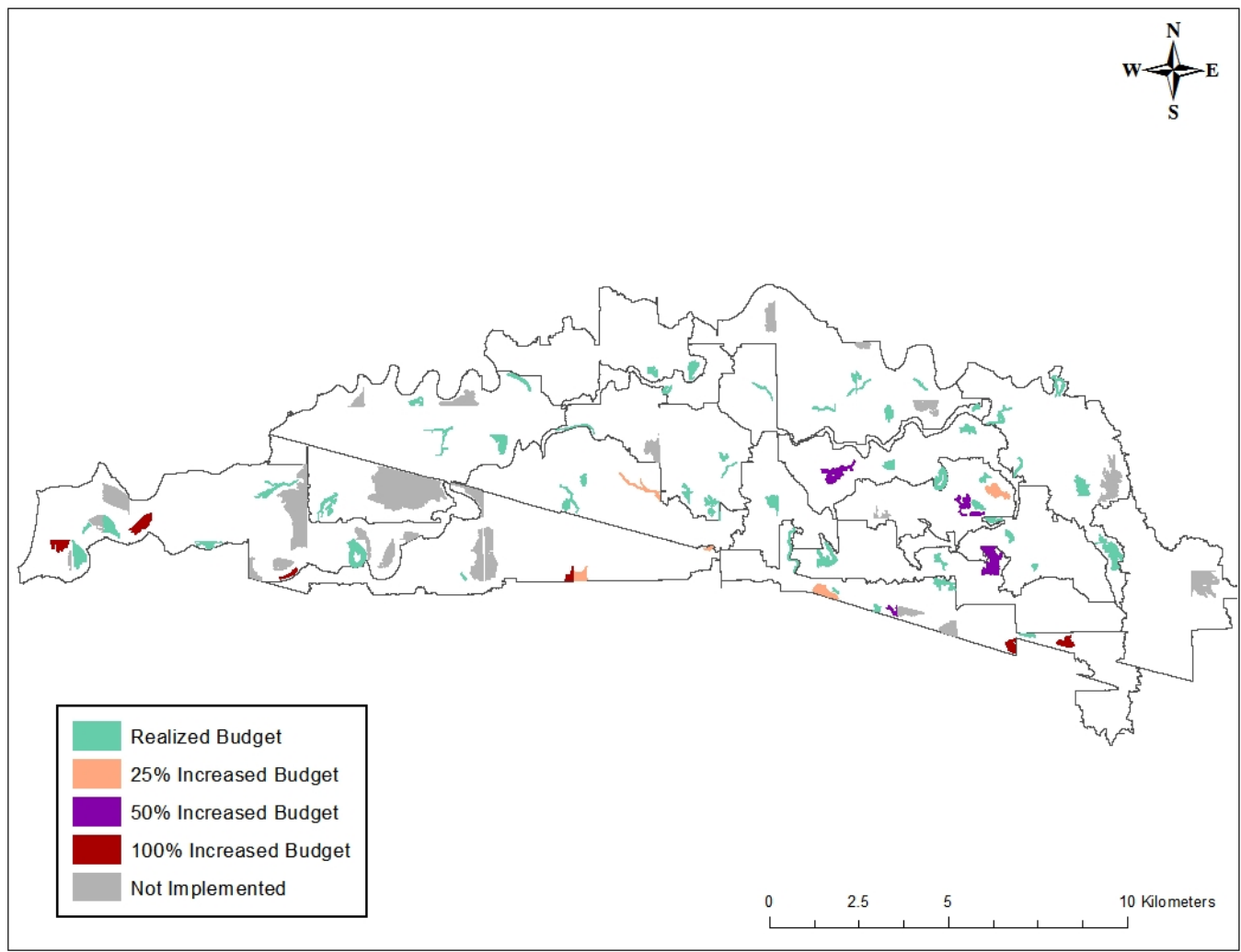

Figure C.4: Pond implementation pattern under cost targeting using a discount rate of zero. 


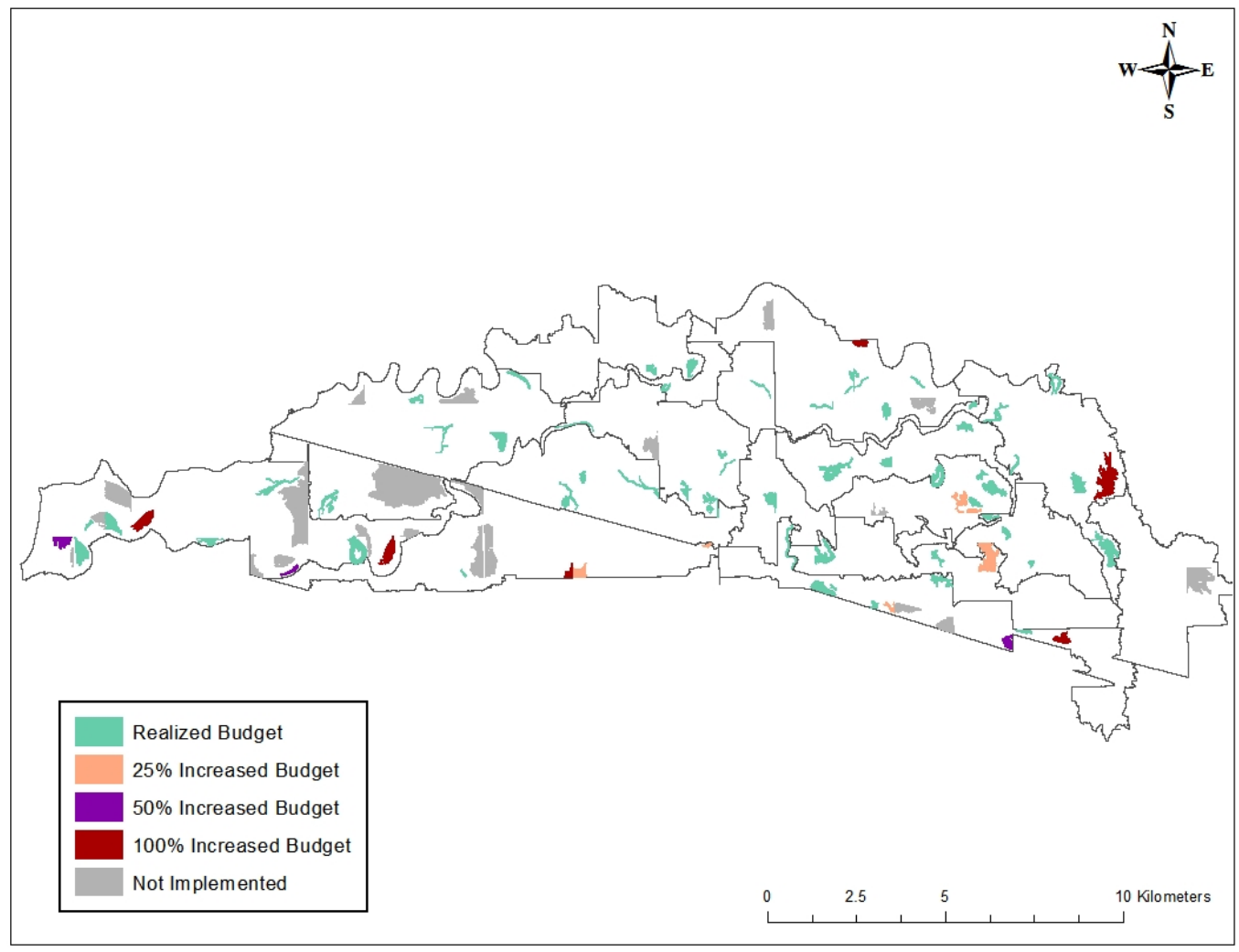

Figure C.5: Pond implementation pattern under cost targeting using a discount rate of three percent.

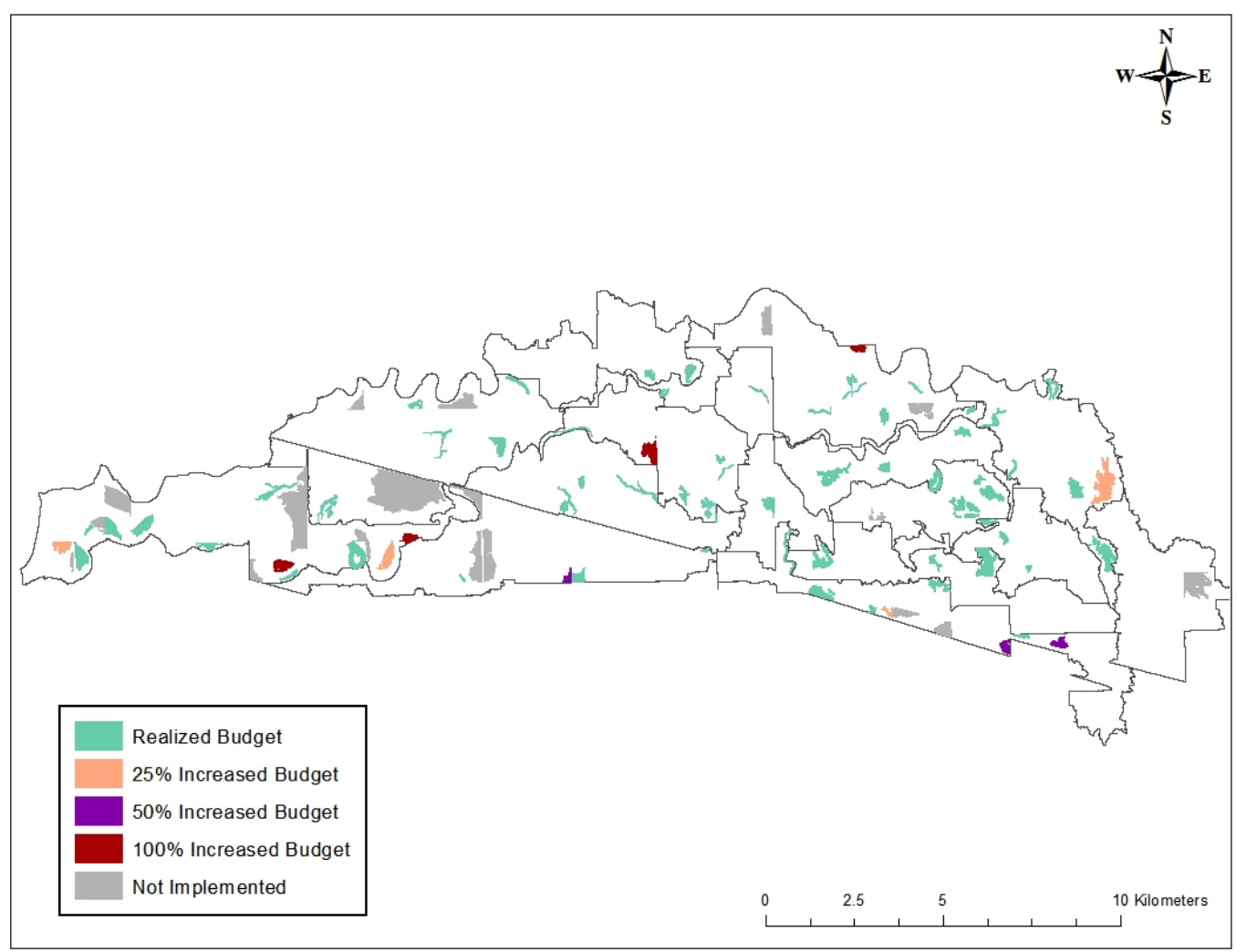

Figure C.6: Pond implementation pattern under cost targeting using a discount rate of nine percent. 


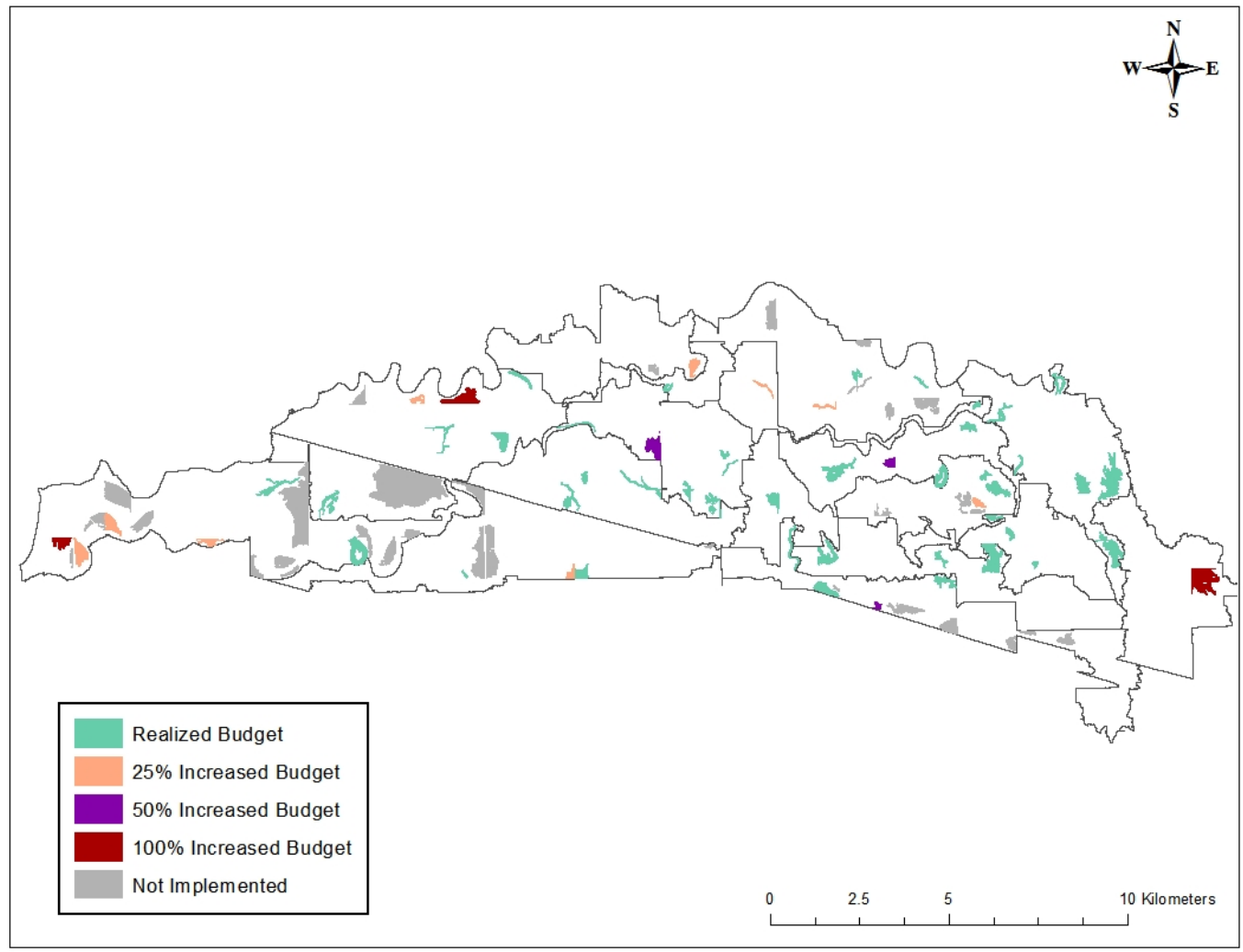

Figure C.7: Pond implementation pattern under benefit-cost targeting using a discount rate of zero.

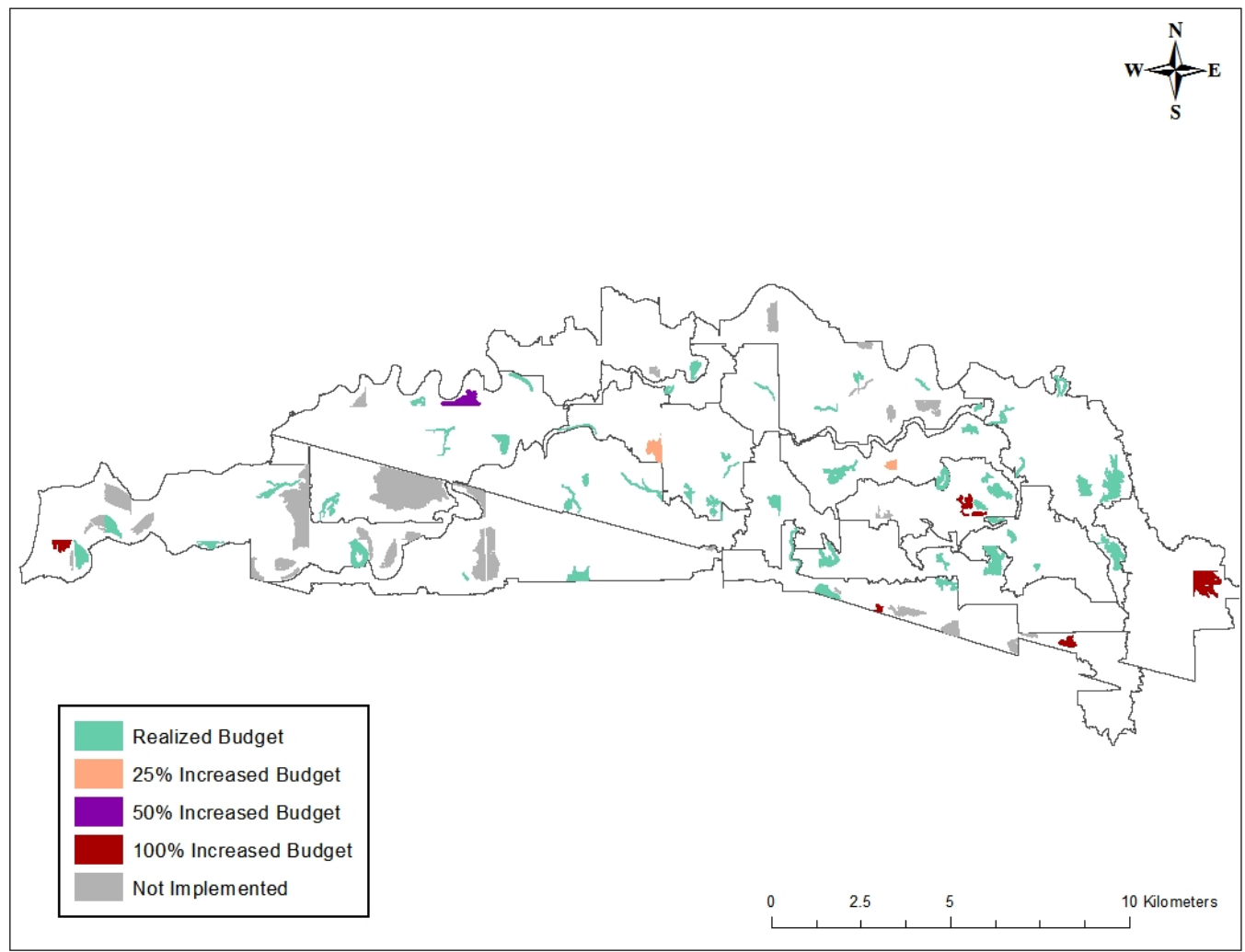

Figure C.8: Pond implementation pattern under benefit-cost targeting using a discount rate of three percent. 


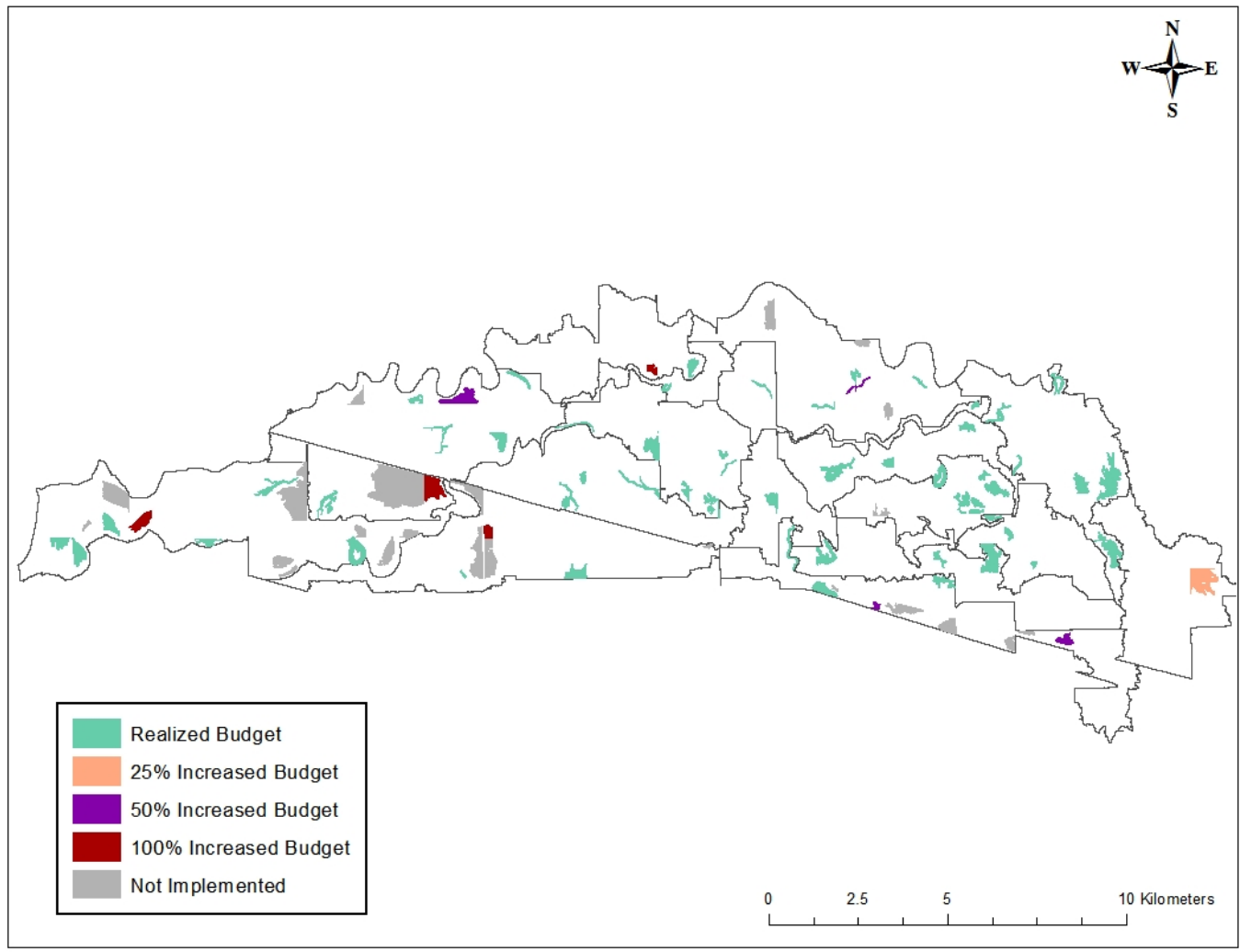

Figure C.9: Pond implementation pattern under benefit-cost targeting using a discount rate of nine percent. 


\section{Appendix D}

Analysis of the absolute value and percentage change in the number of ponds implemented, total area flooded by ponds, quantity of TP reduced, and resulting level of TP output from the La Salle sub-watershed during the study period under all targeting strategies analyzed using different budgets and discount rates 
Table D.1: Number of ponds implemented, pond area flooded, quantity of TP reduced, and resulting level of TP output from the La Salle sub-watershed during the study period under all targeting strategies analyzed using different budgets and discount rates.

\begin{tabular}{|c|c|c|c|c|}
\hline & Realized Budget & $\begin{array}{c}25 \% \text { Increased } \\
\text { Budget }\end{array}$ & $\begin{array}{c}50 \% \text { Increased } \\
\text { Budget }\end{array}$ & $\begin{array}{c}100 \% \text { Increased } \\
\text { Budget }\end{array}$ \\
\hline$r=0$ & \multicolumn{4}{|c|}{ Cost Targeting } \\
\hline $\begin{array}{l}\text { Number of } \\
\text { Ponds }\end{array}$ & 56 & 61 & 65 & 71 \\
\hline $\begin{array}{l}\text { Pond Area } \\
\text { Flooded (ha) }\end{array}$ & 248 & 281 & 328 & 365 \\
\hline $\begin{array}{l}\text { Quantity TP } \\
\text { Reduced (kg) }\end{array}$ & 8,267 & 9,910 & 11,047 & 11,757 \\
\hline $\begin{array}{l}\text { Total TP Output } \\
(\mathrm{kg})\end{array}$ & 128,539 & 126,896 & 125,759 & 125,049 \\
\hline$r=3 \%$ & & & & \\
\hline $\begin{array}{l}\text { Number of } \\
\text { Ponds }\end{array}$ & 60 & 65 & 68 & 74 \\
\hline $\begin{array}{l}\text { Pond Area } \\
\text { Flooded (ha) }\end{array}$ & 287 & 328 & 344 & 411 \\
\hline $\begin{array}{l}\text { Quantity TP } \\
\text { Reduced (kg) }\end{array}$ & 7,739 & 8,518 & 8,716 & 9,811 \\
\hline $\begin{array}{l}\text { Total TP Output } \\
\text { (kg) }\end{array}$ & 129,067 & 128,288 & 128,090 & 126,995 \\
\hline$r=6 \%$ & & & & \\
\hline $\begin{array}{l}\text { Number of } \\
\text { Ponds }\end{array}$ & 63 & 68 & 71 & 76 \\
\hline $\begin{array}{l}\text { Pond Area } \\
\text { Flooded (ha) }\end{array}$ & 316 & 350 & 372 & 431 \\
\hline $\begin{array}{l}\text { Quantity TP } \\
\text { Reduced (kg) }\end{array}$ & 7,110 & 7,433 & 7,663 & 8,579 \\
\hline $\begin{array}{l}\text { Total TP Output } \\
(\mathrm{kg})\end{array}$ & 129,696 & 129,373 & 129,143 & 128,227 \\
\hline$r=9 \%$ & & & & \\
\hline $\begin{array}{l}\text { Number of } \\
\text { Ponds }\end{array}$ & 66 & 70 & 73 & 77 \\
\hline $\begin{array}{l}\text { Pond Area } \\
\text { Flooded (ha) }\end{array}$ & 340 & 391 & 406 & 442 \\
\hline $\begin{array}{l}\text { Quantity TP } \\
\text { Reduced (kg) }\end{array}$ & 6,275 & 6,947 & 7,201 & 7,475 \\
\hline $\begin{array}{l}\text { Total TP Output } \\
(\mathrm{kg})\end{array}$ & 130,531 & 129,859 & 129,605 & 129,331 \\
\hline
\end{tabular}




\begin{tabular}{|c|c|c|c|c|}
\hline & Realized Budget & $\begin{array}{l}25 \% \text { Increased } \\
\text { Budget }\end{array}$ & $\begin{array}{l}50 \% \text { Increased } \\
\text { Budget }\end{array}$ & $\begin{array}{c}100 \% \text { Increased } \\
\text { Budget }\end{array}$ \\
\hline$r=0$ & \multicolumn{4}{|c|}{ Benefit Targeting } \\
\hline $\begin{array}{l}\text { Number of } \\
\text { Ponds }\end{array}$ & 5 & 7 & 8 & 12 \\
\hline $\begin{array}{l}\text { Pond Area } \\
\text { Flooded (ha) }\end{array}$ & 66 & 105 & 136 & 188 \\
\hline $\begin{array}{l}\text { Quantity TP } \\
\text { Reduced (kg) }\end{array}$ & 3,817 & 4,887 & 5,397 & 7,096 \\
\hline $\begin{array}{l}\text { Total TP Output } \\
(\mathrm{kg})\end{array}$ & 132,989 & 131,919 & 131,409 & 129,710 \\
\hline$r=3 \%$ & & & & \\
\hline $\begin{array}{l}\text { Number of } \\
\text { Ponds }\end{array}$ & 5 & 7 & 9 & 12 \\
\hline $\begin{array}{l}\text { Pond Area } \\
\text { Flooded (ha) }\end{array}$ & 66 & 105 & 146 & 188 \\
\hline $\begin{array}{l}\text { Quantity TP } \\
\text { Reduced (kg) }\end{array}$ & 2,943 & 3,768 & 4,549 & 5,472 \\
\hline $\begin{array}{l}\text { Total TP Output } \\
(\mathrm{kg})\end{array}$ & 133,863 & 133,038 & 132,257 & 131,334 \\
\hline$r=6 \%$ & & & & \\
\hline $\begin{array}{l}\text { Number of } \\
\text { Ponds }\end{array}$ & 5 & 7 & 10 & 15 \\
\hline $\begin{array}{l}\text { Pond Area } \\
\text { Flooded (ha) }\end{array}$ & 66 & 105 & 165 & 226 \\
\hline $\begin{array}{l}\text { Quantity TP } \\
\text { Reduced (kg) }\end{array}$ & 2,509 & 3,212 & 4,159 & 5,377 \\
\hline $\begin{array}{l}\text { Total TP Output } \\
\text { (kg) }\end{array}$ & 134,297 & 133,594 & 132,647 & 131,429 \\
\hline$r=9 \%$ & & & & \\
\hline $\begin{array}{l}\text { Number of } \\
\text { Ponds }\end{array}$ & 5 & 9 & 12 & 17 \\
\hline $\begin{array}{l}\text { Pond Area } \\
\text { Flooded (ha) }\end{array}$ & 66 & 146 & 188 & 241 \\
\hline $\begin{array}{l}\text { Quantity TP } \\
\text { Reduced (kg) }\end{array}$ & 2,165 & 3,346 & 4,024 & 5,017 \\
\hline $\begin{array}{l}\text { Total TP Output } \\
\text { (kg) }\end{array}$ & 134,641 & 133,460 & 132,782 & 131,789 \\
\hline
\end{tabular}




\begin{tabular}{|c|c|c|c|c|}
\hline & Realized Budget & $\begin{array}{l}25 \% \text { Increased } \\
\text { Budget }\end{array}$ & $\begin{array}{c}50 \% \text { Increased } \\
\text { Budget }\end{array}$ & $\begin{array}{c}100 \% \text { Increased } \\
\text { Budget }\end{array}$ \\
\hline$r=0$ & \multicolumn{4}{|c|}{ Benefit-Cost Targeting } \\
\hline $\begin{array}{l}\text { Number of } \\
\text { Ponds }\end{array}$ & 47 & 56 & 59 & 62 \\
\hline $\begin{array}{l}\text { Pond Area } \\
\text { Flooded (ha) }\end{array}$ & 274 & 324 & 344 & 401 \\
\hline $\begin{array}{l}\text { Quantity TP } \\
\text { Reduced (kg) }\end{array}$ & 10,770 & 11,502 & 11,980 & 13,078 \\
\hline $\begin{array}{l}\text { Total TP Output } \\
\text { (kg) }\end{array}$ & 126,036 & 125,304 & 124,826 & 123,728 \\
\hline$r=3 \%$ & & & & \\
\hline $\begin{array}{l}\text { Number of } \\
\text { Ponds }\end{array}$ & 56 & 58 & 59 & 64 \\
\hline $\begin{array}{l}\text { Pond Area } \\
\text { Flooded (ha) }\end{array}$ & 324 & 343 & 361 & 417 \\
\hline $\begin{array}{l}\text { Quantity TP } \\
\text { Reduced (kg) }\end{array}$ & 8,869 & 9,166 & 9,496 & 10,332 \\
\hline $\begin{array}{l}\text { Total TP Output } \\
(\mathrm{kg})\end{array}$ & 127,937 & 127,640 & 127,310 & 126,474 \\
\hline$r=6 \%$ & & & & \\
\hline $\begin{array}{l}\text { Number of } \\
\text { Ponds }\end{array}$ & 58 & 60 & 63 & 67 \\
\hline $\begin{array}{l}\text { Pond Area } \\
\text { Flooded (ha) }\end{array}$ & 343 & 359 & 410 & 447 \\
\hline $\begin{array}{l}\text { Quantity TP } \\
\text { Reduced (kg) }\end{array}$ & 7,813 & 8,015 & 8,692 & 9,207 \\
\hline $\begin{array}{l}\text { Total TP Output } \\
(\mathrm{kg})\end{array}$ & 128,993 & 128,791 & 128,114 & 127,599 \\
\hline$r=9 \%$ & & & & \\
\hline $\begin{array}{l}\text { Number of } \\
\text { Ponds }\end{array}$ & 60 & 61 & 65 & 69 \\
\hline $\begin{array}{l}\text { Pond Area } \\
\text { Flooded (ha) }\end{array}$ & 359 & 390 & 418 & 466 \\
\hline $\begin{array}{l}\text { Quantity TP } \\
\text { Reduced (kg) }\end{array}$ & 6,916 & 7,205 & 7,603 & 8,136 \\
\hline $\begin{array}{l}\text { Total TP Output } \\
(\mathrm{kg})\end{array}$ & 129,890 & 129,601 & 129,203 & 128,670 \\
\hline
\end{tabular}


Table D.2: Percentage change in number of ponds implemented, pond area flooded, and resulting quantity of TP reduced when the realized budget is increased by 25, 50, and 100 percent, respectively, under different targeting strategies and discount rates.

\begin{tabular}{|c|c|c|c|}
\hline & 25\% Budget Increase & $\begin{array}{l}50 \% \text { Budget } \\
\text { Increase }\end{array}$ & $\begin{array}{l}100 \% \text { Budget } \\
\text { Increase }\end{array}$ \\
\hline$r=0$ & \multicolumn{3}{|c|}{ Cost Targeting } \\
\hline$\%$ change in Number of Ponds & 9 & 16 & 27 \\
\hline$\%$ change in Pond Area & & & \\
\hline Flooded & 13 & 32 & 47 \\
\hline$\%$ change in Quantity TP & & & \\
\hline Reduced & 20 & 34 & 42 \\
\hline \multicolumn{4}{|l|}{$r=3 \%$} \\
\hline$\%$ change in Number of Ponds & 8 & 13 & 23 \\
\hline \multicolumn{4}{|l|}{$\%$ change in Pond Area } \\
\hline Flooded & 14 & 20 & 43 \\
\hline \multicolumn{4}{|l|}{$\%$ change in Quantity TP } \\
\hline Reduced & 10 & 13 & 27 \\
\hline \multicolumn{4}{|l|}{$r=6 \%$} \\
\hline$\%$ change in Number of Ponds & 8 & 13 & 21 \\
\hline \multicolumn{4}{|l|}{$\%$ change in Pond Area } \\
\hline Flooded & 11 & 18 & 36 \\
\hline \multicolumn{4}{|l|}{ \% change in Quantity TP } \\
\hline Reduced & 5 & 8 & 21 \\
\hline \multicolumn{4}{|l|}{$r=9 \%$} \\
\hline$\%$ change in Number of Ponds & 6 & 11 & 17 \\
\hline \multicolumn{4}{|l|}{$\%$ change in Pond Area } \\
\hline Flooded & 15 & 19 & 30 \\
\hline \multicolumn{4}{|l|}{$\%$ change in Quantity TP } \\
\hline Reduced & 11 & 15 & 19 \\
\hline$r=0$ & \multicolumn{3}{|c|}{ Benefit Targeting } \\
\hline$\%$ change in Number of Ponds & 40 & 60 & 140 \\
\hline \multicolumn{4}{|l|}{$\%$ change in Pond Area } \\
\hline Flooded & 59 & 106 & 185 \\
\hline \multicolumn{4}{|l|}{ \% change in Quantity TP } \\
\hline Reduced & 28 & 41 & 86 \\
\hline \multicolumn{4}{|l|}{$r=3 \%$} \\
\hline$\%$ change in Number of Ponds & 40 & 80 & 140 \\
\hline \multicolumn{4}{|l|}{$\%$ change in Pond Area } \\
\hline Flooded & 59 & 121 & 185 \\
\hline \multicolumn{4}{|l|}{ \% change in Quantity TP } \\
\hline Reduced & 28 & 55 & 86 \\
\hline
\end{tabular}




\begin{tabular}{|c|c|c|c|}
\hline & $25 \%$ Budget Increase & $\begin{array}{l}50 \% \text { Budget } \\
\text { Increase }\end{array}$ & $\begin{array}{l}\text { 100\% Budget } \\
\text { Increase }\end{array}$ \\
\hline \multicolumn{4}{|l|}{$r=6 \%$} \\
\hline$\%$ change in Number of Ponds & 40 & 100 & 200 \\
\hline $\begin{array}{l}\% \text { change in Pond Area } \\
\text { Flooded }\end{array}$ & 59 & 149 & 242 \\
\hline $\begin{array}{l}\% \text { change in Quantity TP } \\
\text { Reduced }\end{array}$ & 28 & 66 & 114 \\
\hline \multicolumn{4}{|l|}{$r=9 \%$} \\
\hline$\%$ change in Number of Ponds & 80 & 140 & 240 \\
\hline $\begin{array}{l}\% \text { change in Pond Area } \\
\text { Flooded }\end{array}$ & 121 & 185 & 264 \\
\hline $\begin{array}{l}\% \text { change in Quantity TP } \\
\text { Reduced }\end{array}$ & 55 & 86 & 132 \\
\hline$r=0$ & \multicolumn{3}{|c|}{ Benefit-Cost Targeting } \\
\hline$\%$ change in Number of Ponds & 19 & 26 & 32 \\
\hline $\begin{array}{l}\% \text { change in Pond Area } \\
\text { Flooded }\end{array}$ & 18 & 26 & 47 \\
\hline $\begin{array}{l}\text { \% change in Quantity TP } \\
\text { Reduced }\end{array}$ & 7 & 11 & 21 \\
\hline$r=3 \%$ & & & \\
\hline$\%$ change in Number of Ponds & 4 & 5 & 14 \\
\hline $\begin{array}{l}\% \text { change in Pond Area } \\
\text { Flooded }\end{array}$ & 6 & 11 & 29 \\
\hline $\begin{array}{l}\% \text { change in Quantity TP } \\
\text { Reduced }\end{array}$ & 3 & 7 & 16 \\
\hline$r=6 \%$ & & & \\
\hline$\%$ change in Number of Ponds & 3 & 9 & 16 \\
\hline $\begin{array}{l}\% \text { change in Pond Area } \\
\text { Flooded }\end{array}$ & 5 & 20 & 31 \\
\hline $\begin{array}{l}\% \text { change in Quantity TP } \\
\text { Reduced }\end{array}$ & 3 & 11 & 18 \\
\hline$r=9 \%$ & & & \\
\hline$\%$ change in Number of Ponds & 2 & 8 & 15 \\
\hline $\begin{array}{l}\% \text { change in Pond Area } \\
\text { Flooded }\end{array}$ & 9 & 16 & 30 \\
\hline $\begin{array}{l}\% \text { change in Quantity TP } \\
\text { Reduced }\end{array}$ & 4 & 10 & 18 \\
\hline
\end{tabular}




\section{Appendix E}

Quantity of TP runoff reduced in the La Salle sub-watershed during the study period under different targeting strategies and budget constraints 


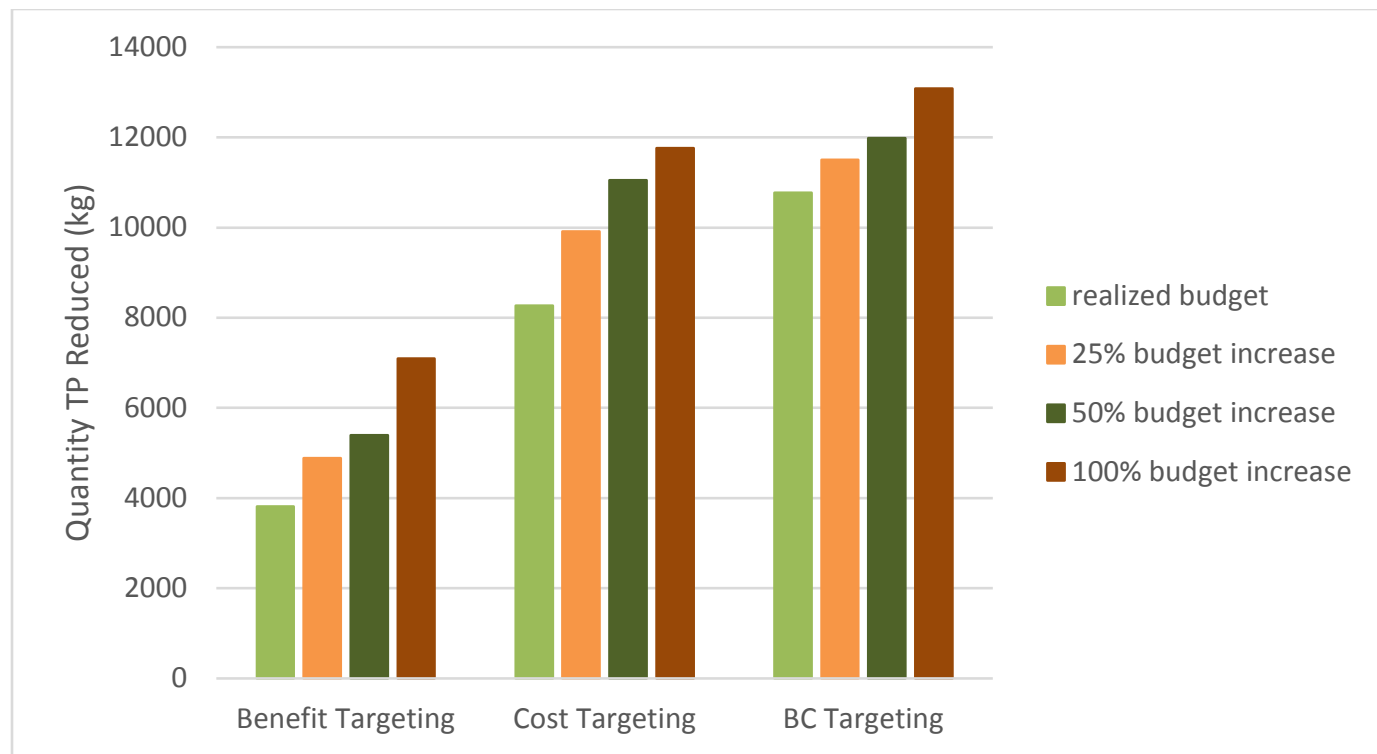

Figure E.1: Quantity of TP runoff reduced in the La Salle sub-watershed during the study period under different targeting strategies and budget constraints using a discount rate of zero.

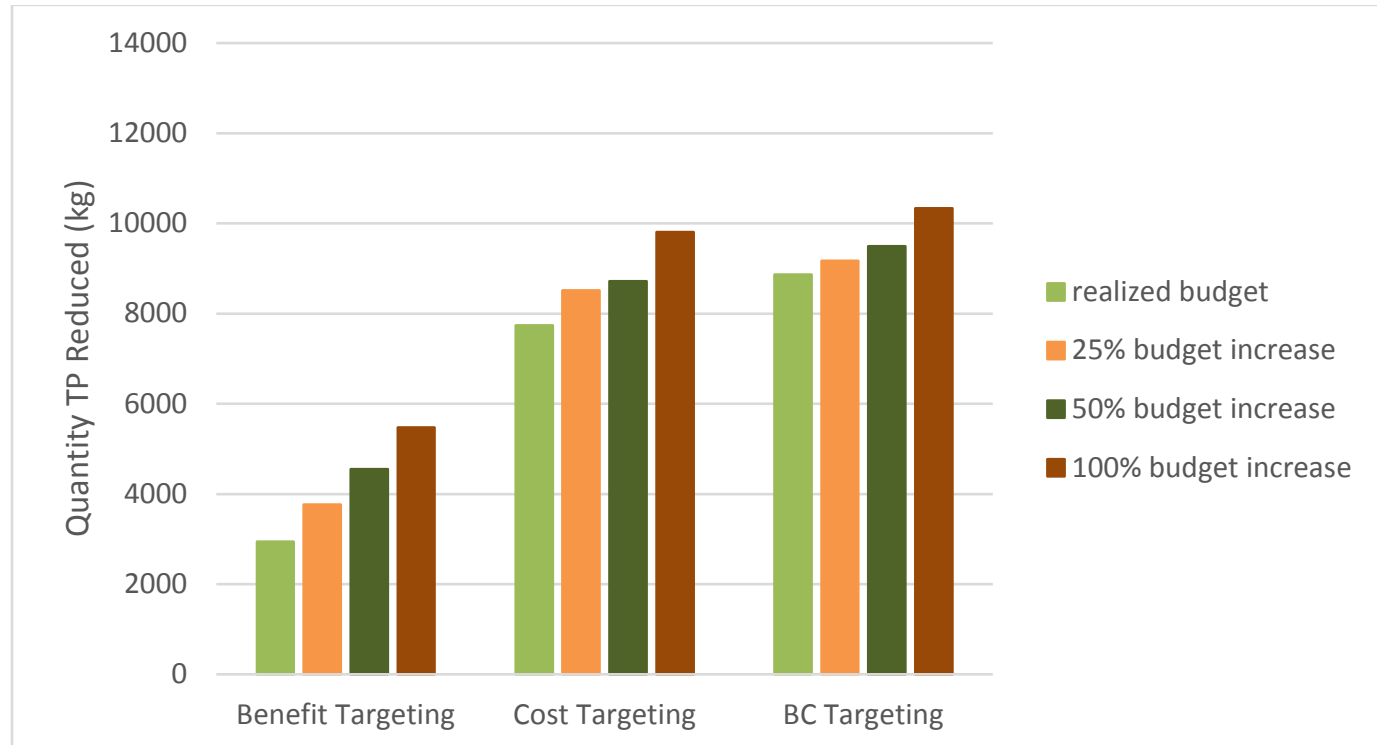

Figure E.2: Quantity of TP runoff reduced in the La Salle sub-watershed during the study period under different targeting strategies and budget constraints using a discount rate of three percent. 


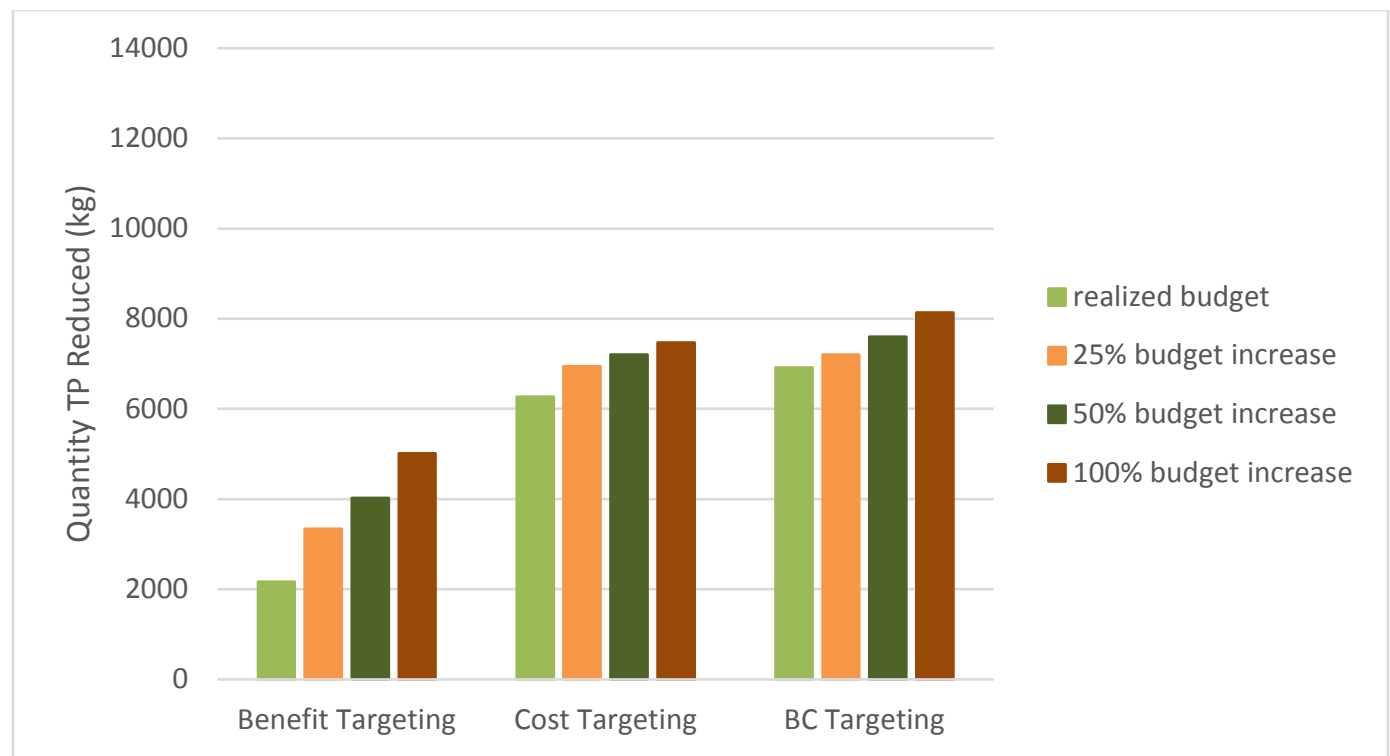

Figure E.3: Quantity of TP runoff reduced in the La Salle sub-watershed during the study period under different targeting strategies and budget constraints using a discount rate of nine percent. 


\section{Appendix F}

Average cost of TP removal in the La Salle sub-watershed during the study period under different targeting strategies and budget constraints 


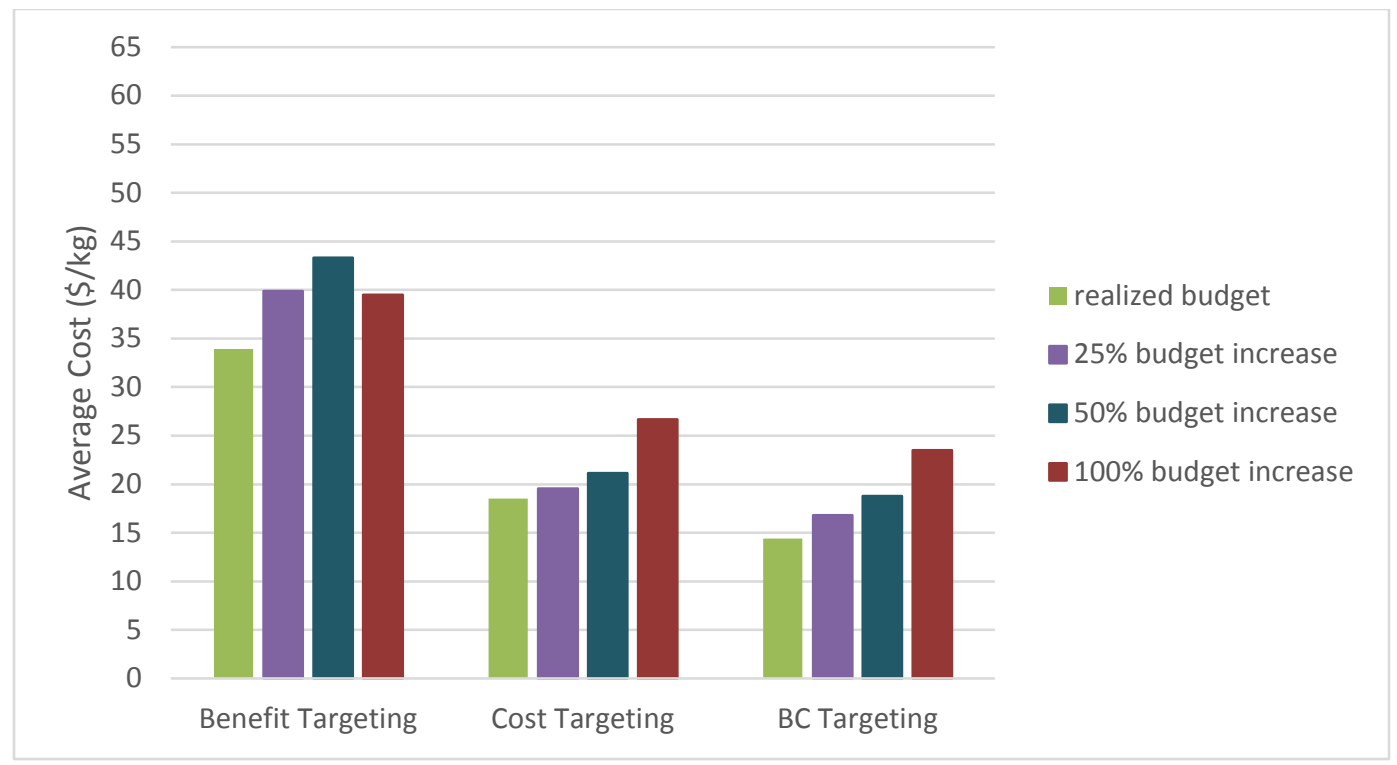

Figure F.1: Average cost of TP removal in the La Salle sub-watershed during the study period under different targeting strategies and budget constraints using a discount rate of zero.

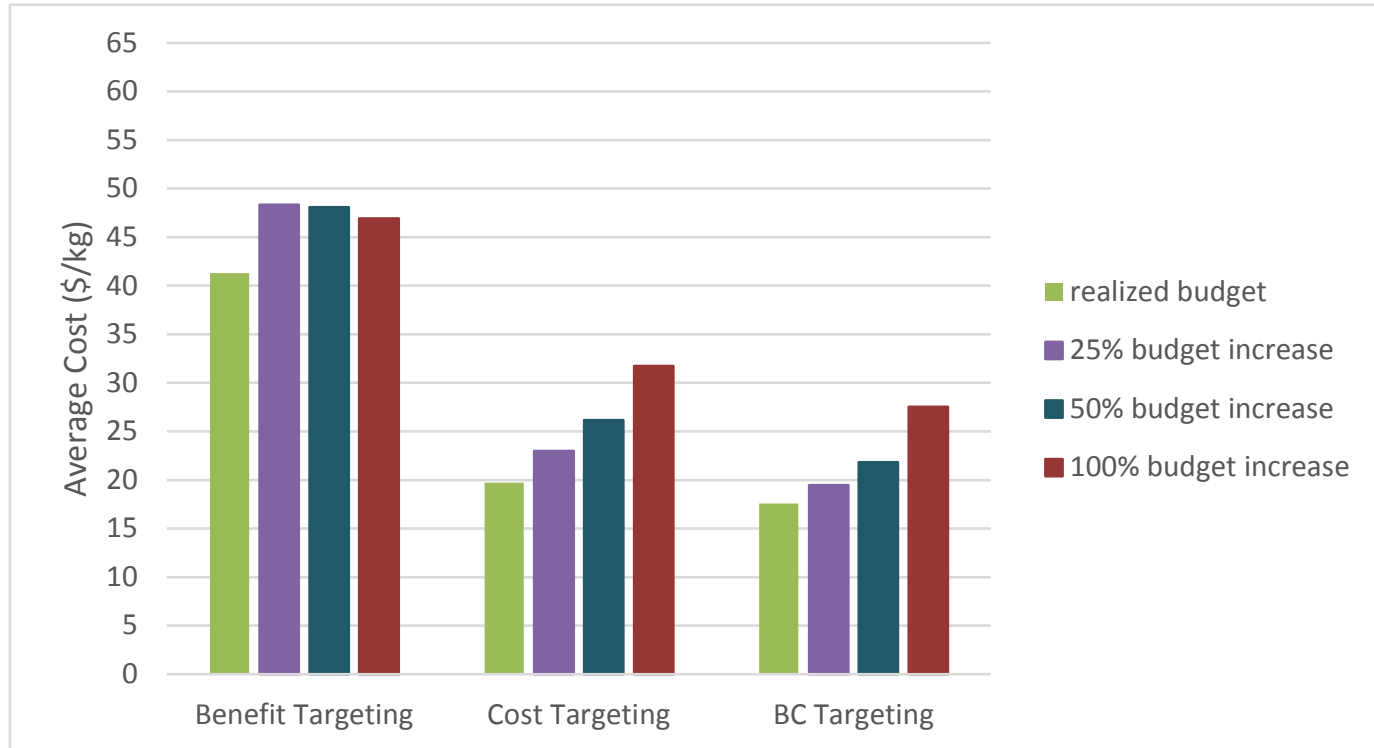

Figure F.2: Average cost of TP removal in the La Salle sub-watershed during the study period under different targeting strategies and budget constraints using a discount rate of three percent. 


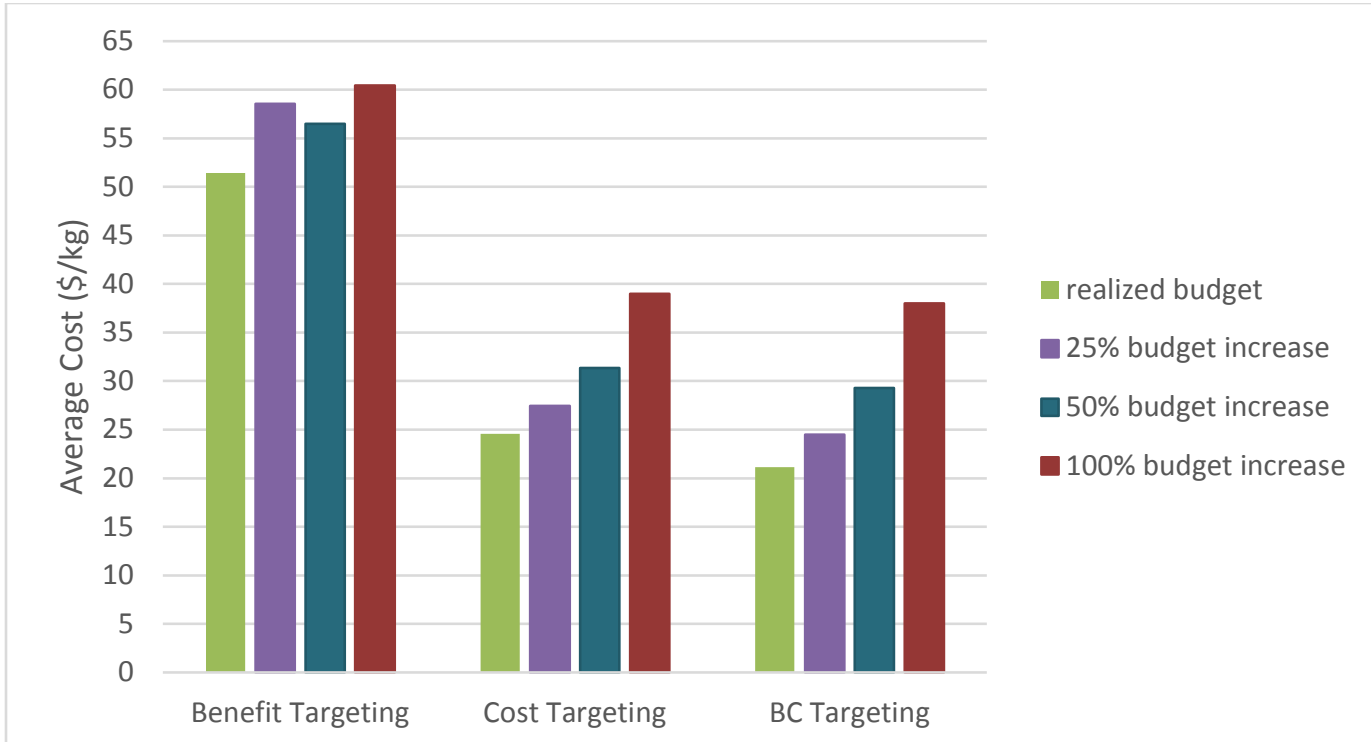

Figure F.3: Average cost of TP removal in the La Salle sub-watershed during the study period under different targeting strategies and budget constraints using a discount rate of nine percent. 


\section{Appendix G}

Pond area flooded compared to number of ponds in the La Salle sub-watershed during the study period under different targeting strategies and budget constraints 


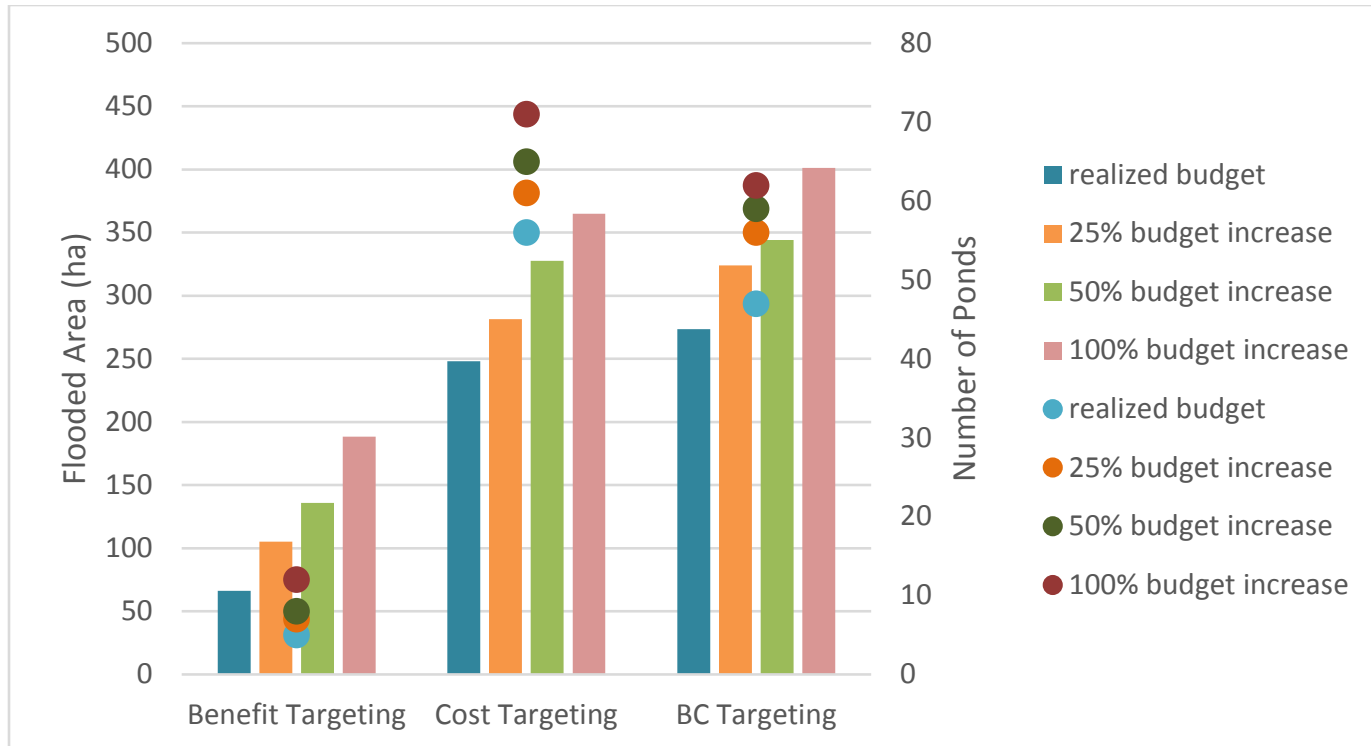

Figure G.1: Pond area flooded (bar graph) compared to number of ponds (scatter plot) in the La Salle sub-watershed during the study period under different targeting strategies and budget constraints using a discount rate of zero.

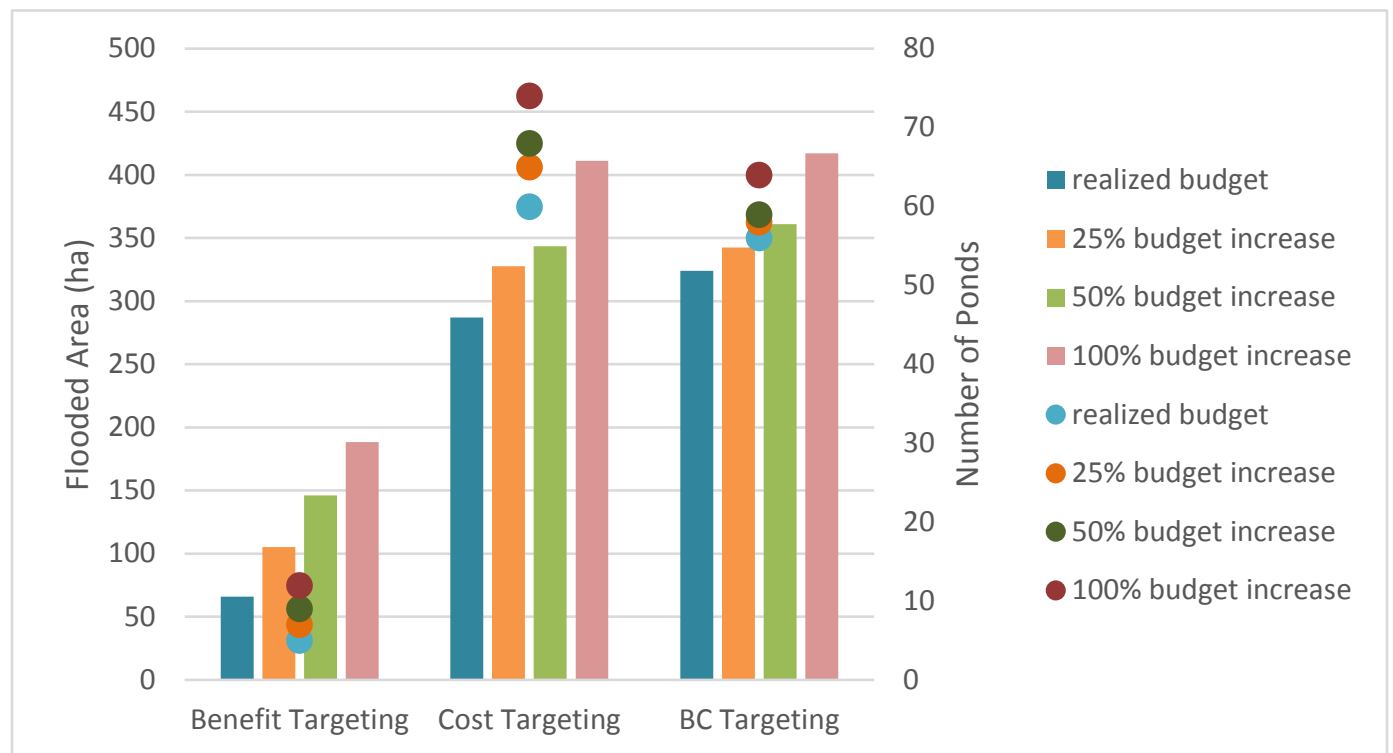

Figure G.2: Pond area flooded (bar graph) compared to number of ponds (scatter plot) in the La Salle sub-watershed during the study period under different targeting strategies and budget constraints using a discount rate of three percent. 


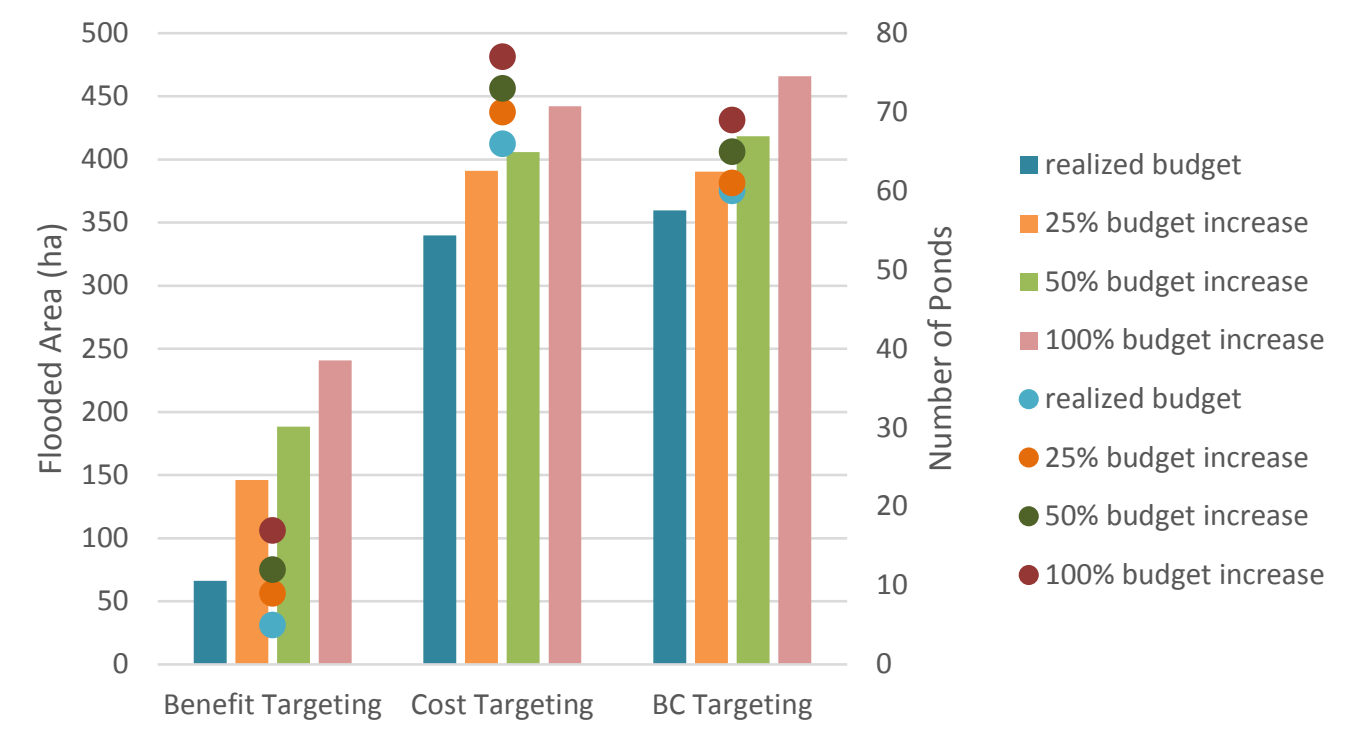

Figure G.3: Pond area flooded (bar graph) compared to number of ponds (scatter plot) in the La Salle sub-watershed during the study period under different targeting strategies and budget constraints using a discount rate of nine percent. 


\section{Appendix $\mathrm{H}$}

Quantity of TP reduced compared to level of expenditure in the La Salle subwatershed during the study period under different targeting strategies 


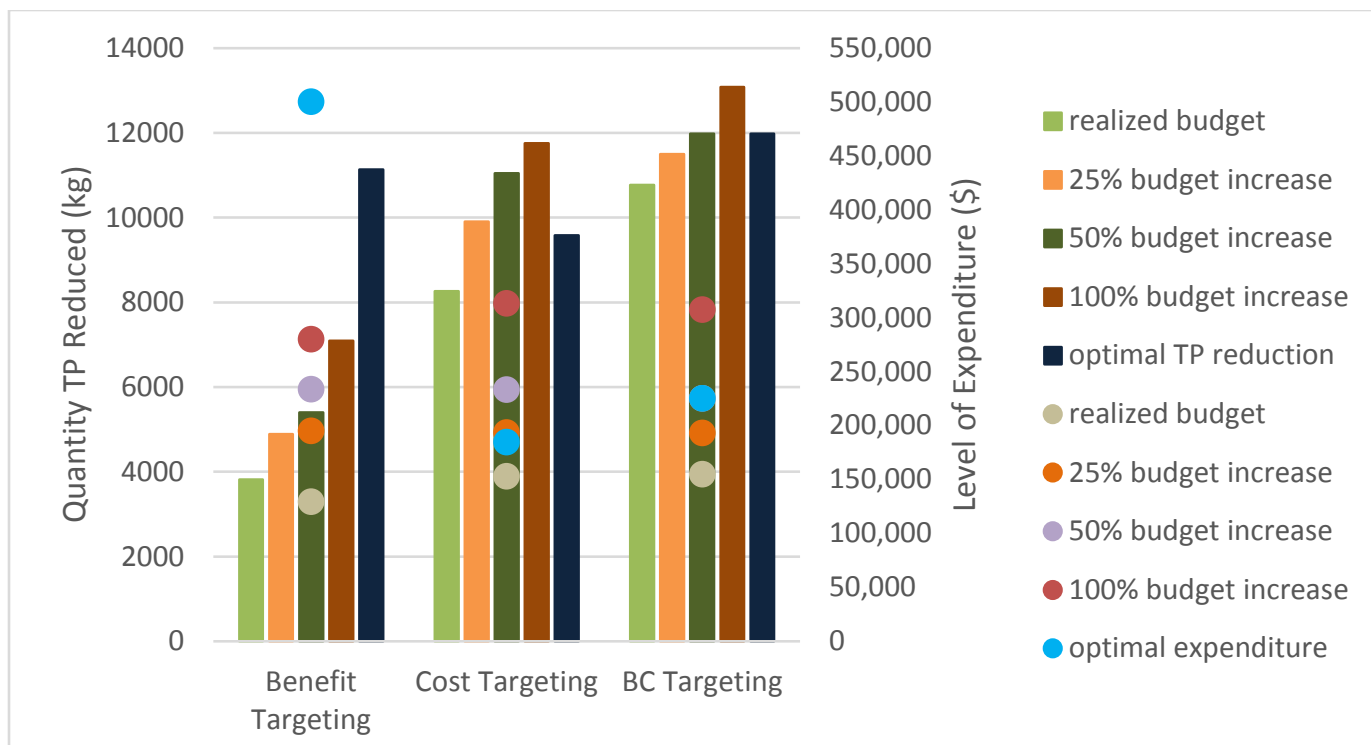

Figure H.1: Quantity of TP reduced (bar graph) compared to level of expenditure (scatter plot) in the La Salle sub-watershed during the study period under different targeting strategies using a discount rate of zero.

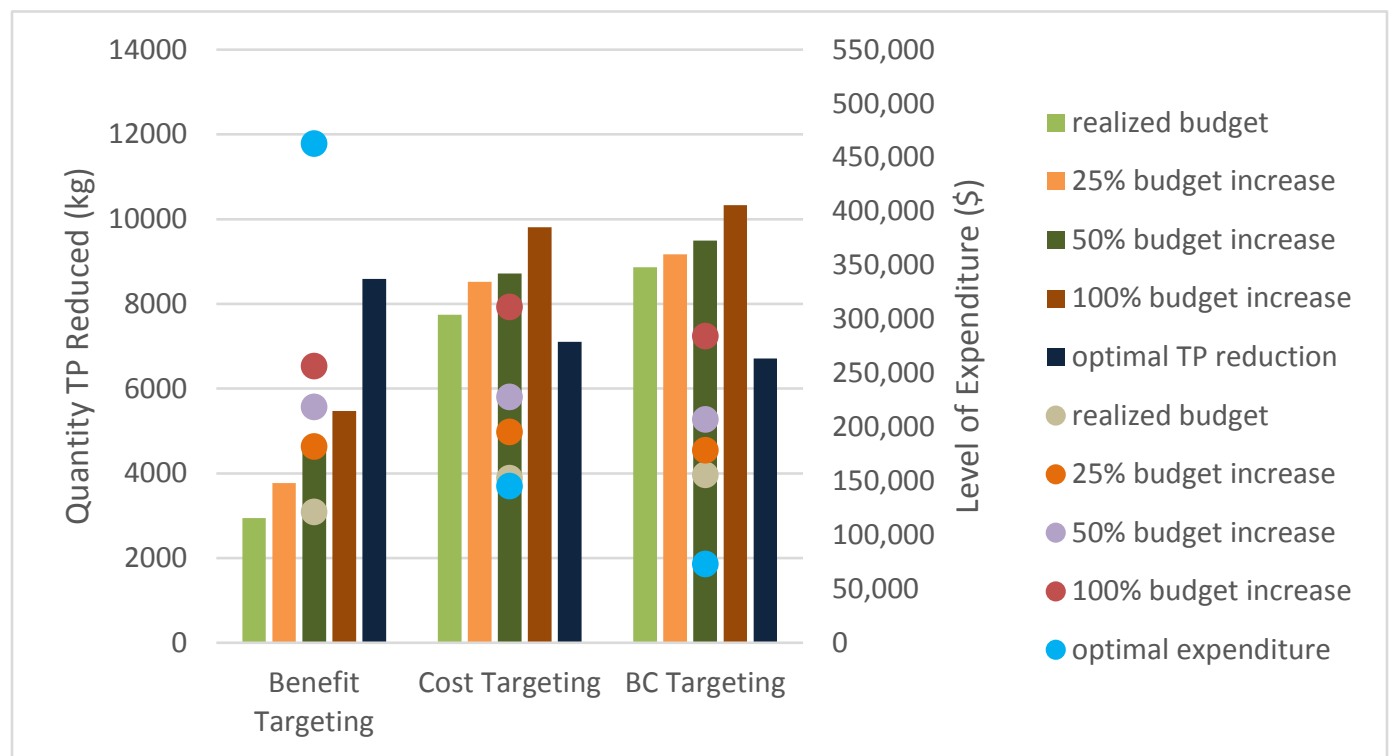

Figure H.2: Quantity of TP reduced (bar graph) compared to level of expenditure (scatter plot) in the La Salle sub-watershed during the study period under different targeting strategies using a discount rate of three percent. 


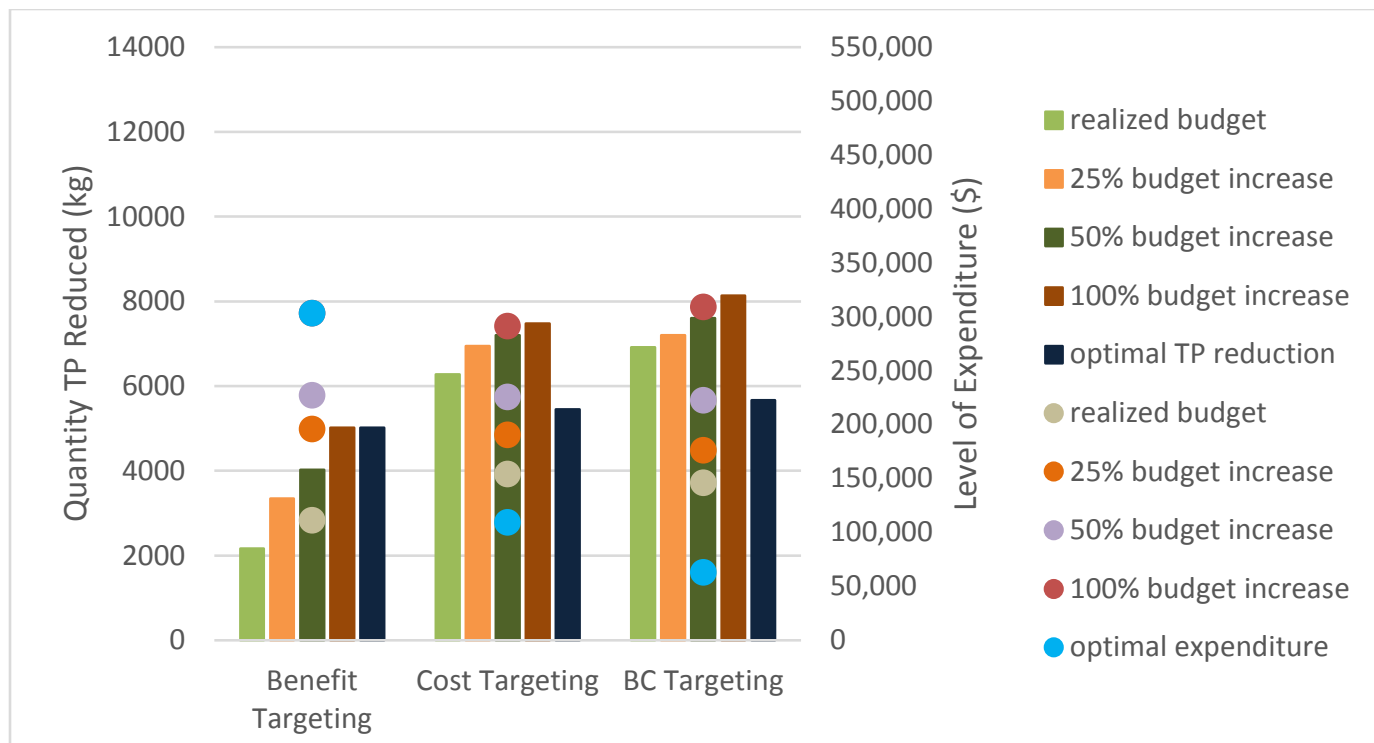

Figure H.3: Quantity of TP reduced (bar graph) compared to level of expenditure (scatter plot) in the La Salle sub-watershed during the study period under different targeting strategies using a discount rate of nine percent. 


\section{Appendix I}

Pond distributions in the La Salle sub-watershed according to benefit-cost ratio 


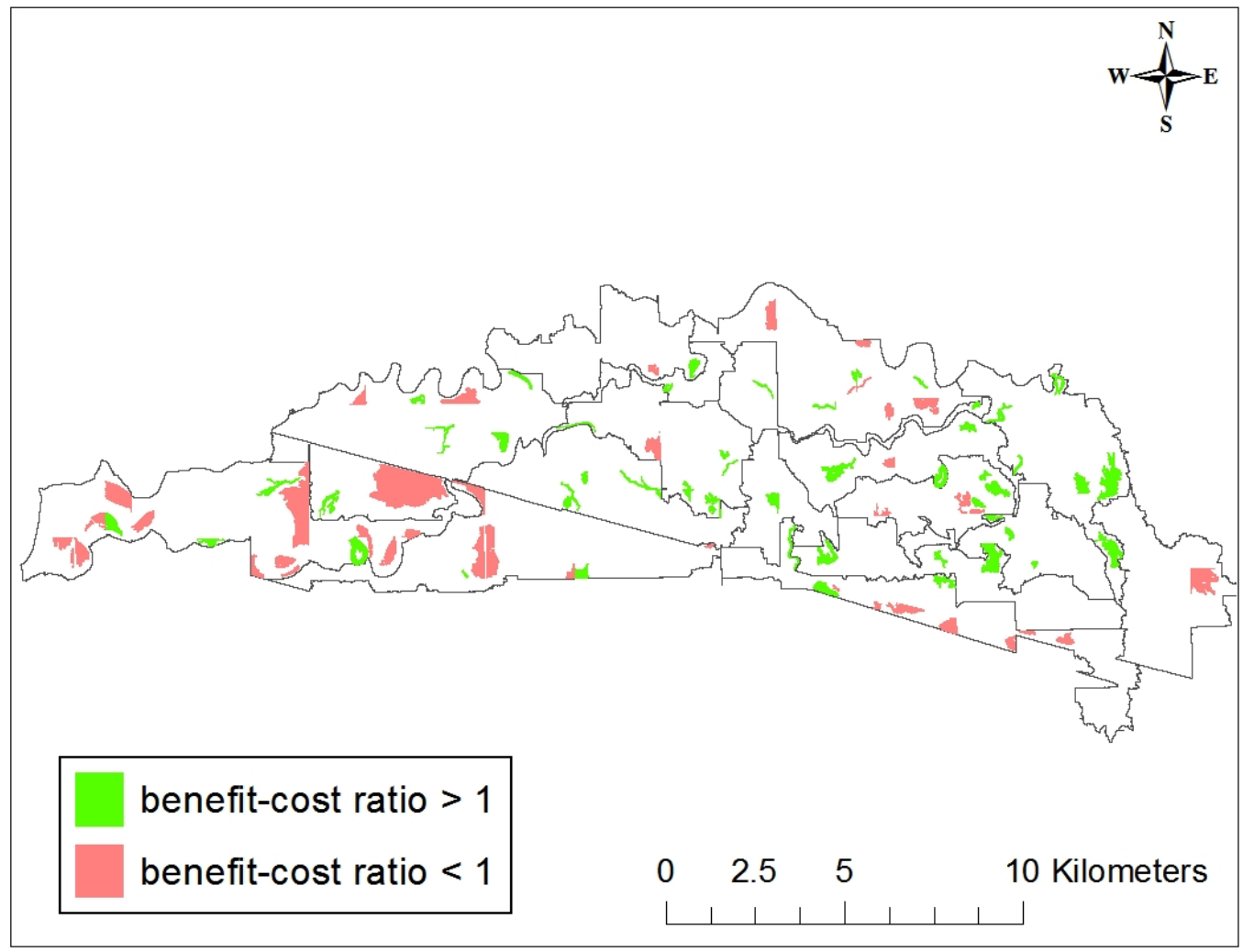

Figure I.1: Distribution of ponds in the La Salle sub-watershed according to benefit-cost ratio, assuming a discount rate of zero.

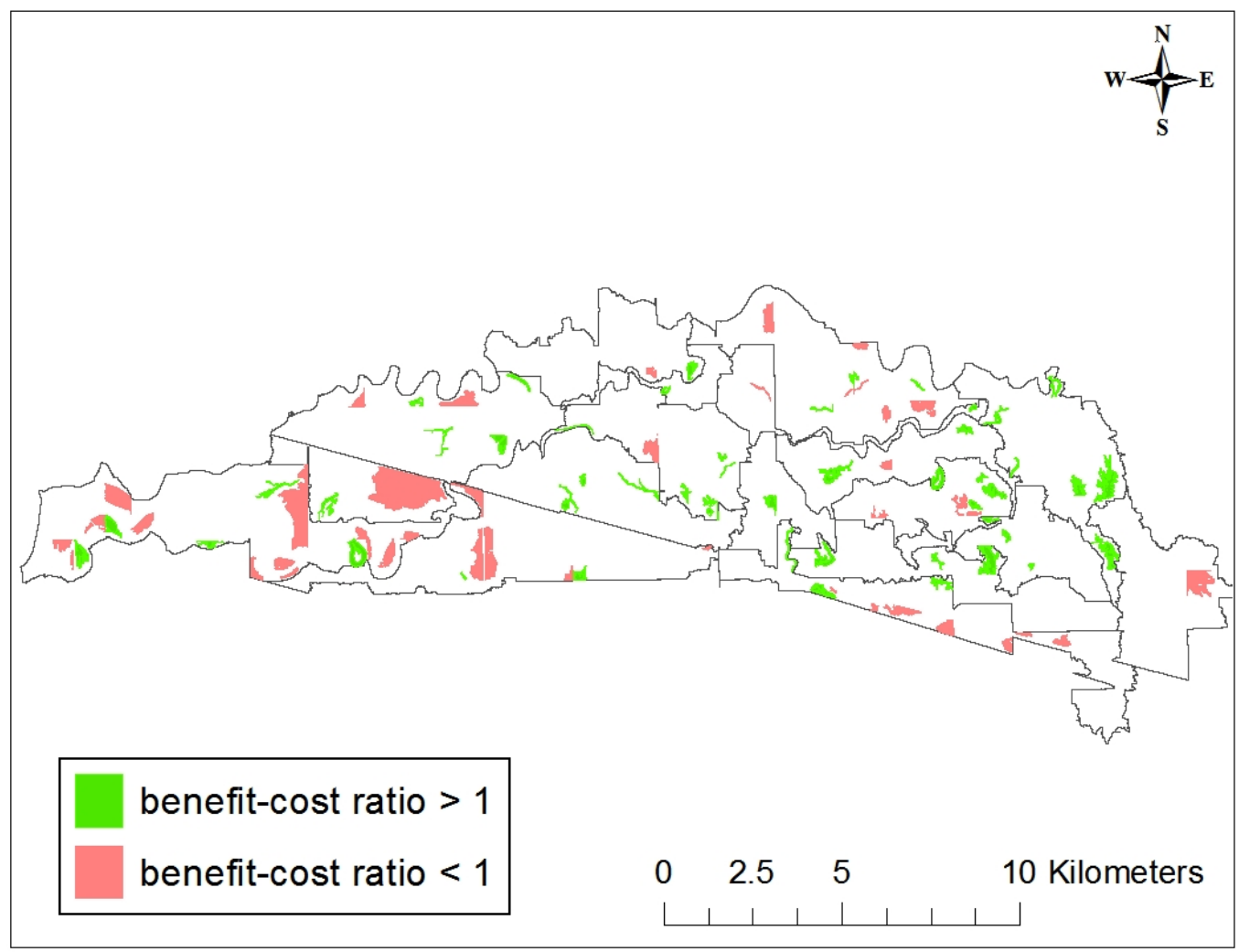

Figure I.2: Distribution of ponds in the La Salle sub-watershed according to benefit-cost ratio, assuming a discount rate of three percent. 


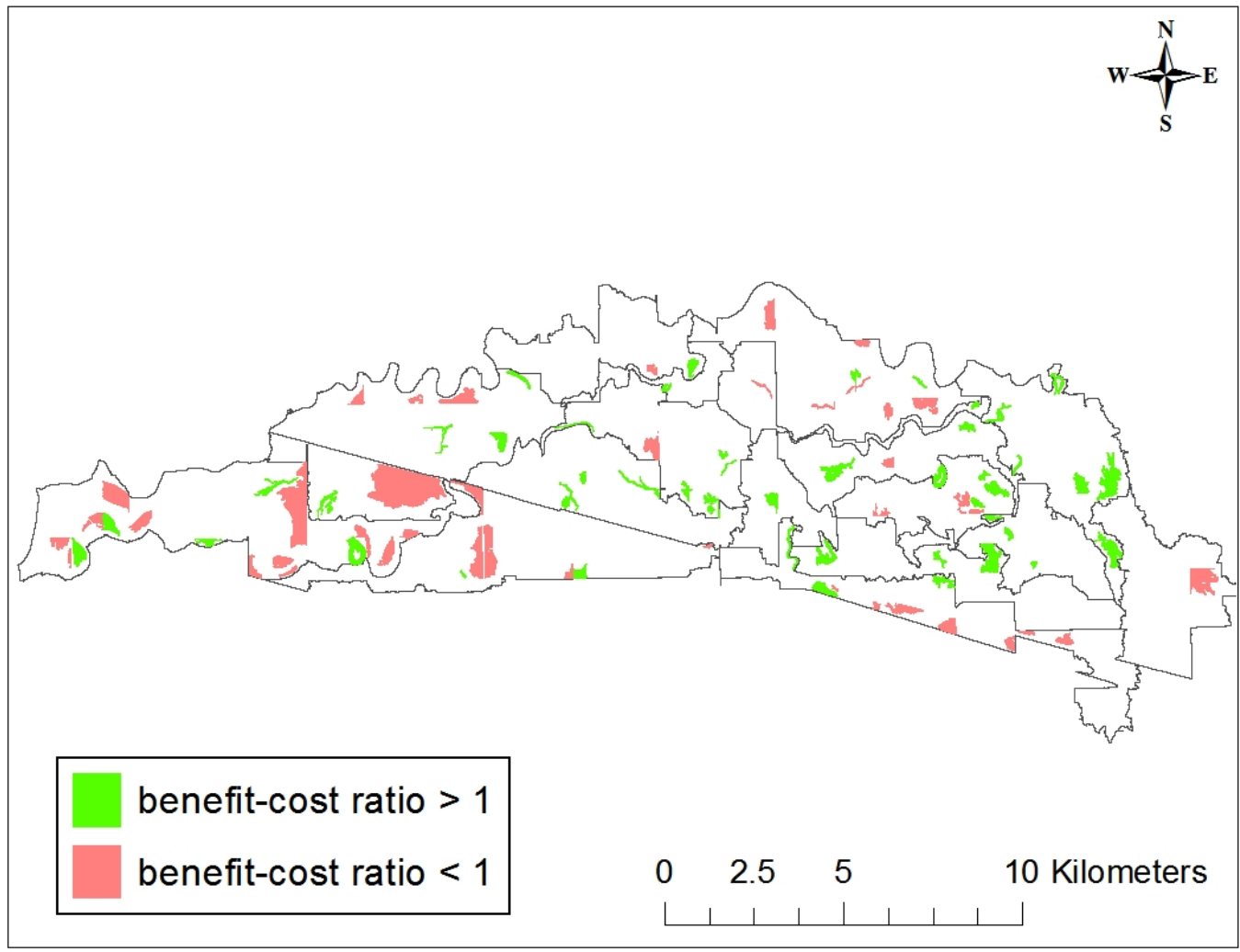

Figure I.3: Distribution of ponds in the La Salle sub-watershed according to benefit-cost ratio, assuming a discount rate of nine percent. 